


\section{DISCLAIMER}

This report was prepared as an account of work sponsored by an agency of the United States Government. Neither the United States Government nor any agency Thereof, nor any of their employees, makes any warranty, express or implied, or assumes any legal liability or responsibility for the accuracy, completeness, or usefulness of any information, apparatus, product, or process disclosed, or represents that its use would not infringe privately owned rights. Reference herein to any specific commercial product, process, or service by trade name, trademark, manufacturer, or otherwise does not necessarily constitute or imply its endorsement, recommendation, or favoring by the United States Government or any agency thereof. The views and opinions of authors expressed herein do not necessarily state or reflect those of the United States Government or any agency thereof. 


\section{DISCLAIMER}

Portions of this document may be illegible in electronic image products. Images are produced from the best available original document. 


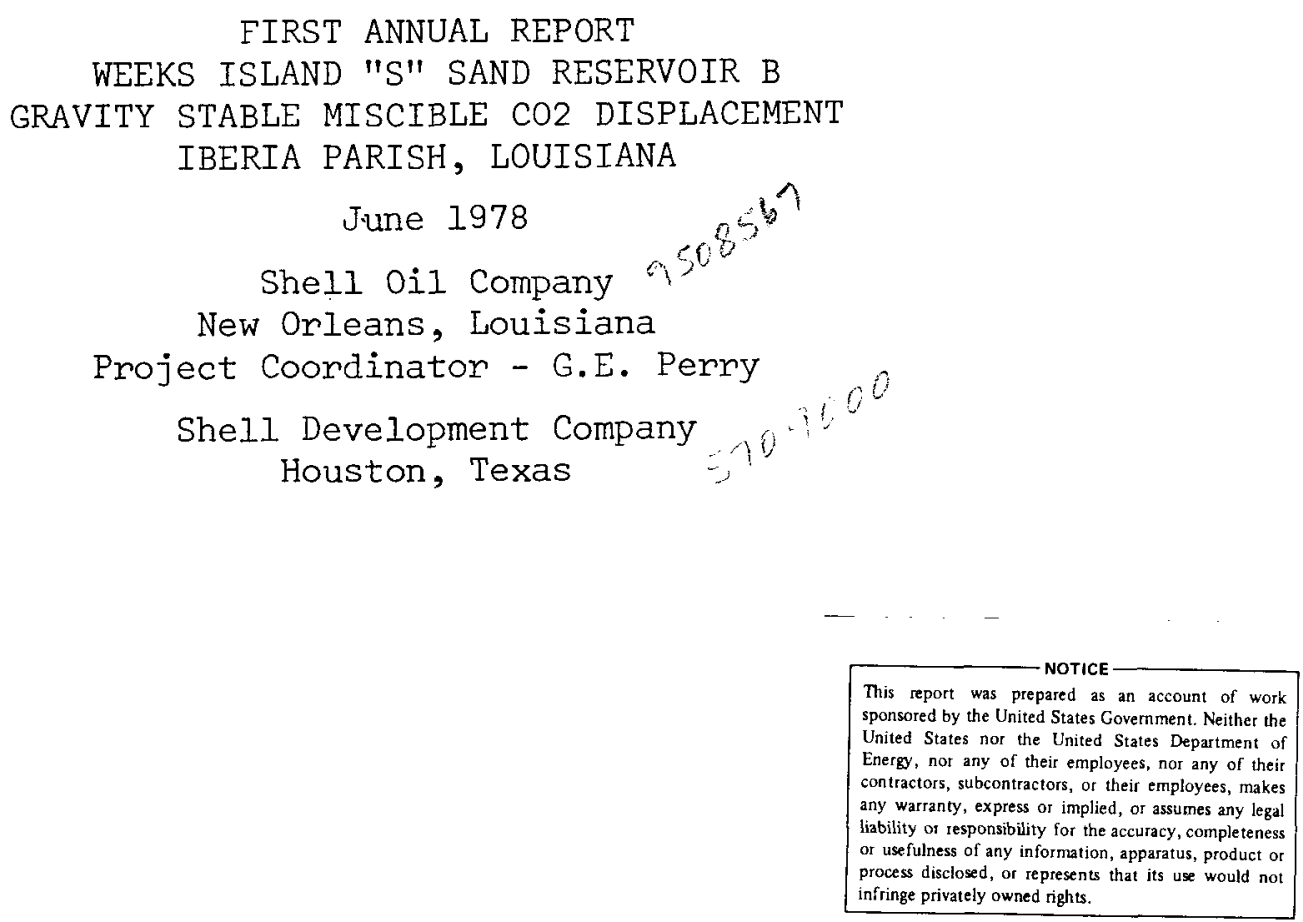

Prepared for

UNITED STATES DEPARTMENT OF ENERGY

Morgantown Energy Technology Center

Morgantown, WV

Submitted Under

Contract No. EF-77-C-05-5232

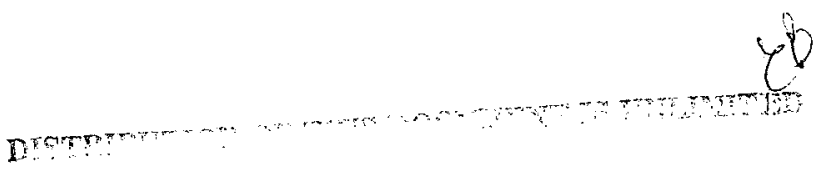


$$
\text { . }
$$ 
Purpose and Scope . . . . . . . . . . . . . . . . . . . . 1 Project Setting Weeks Island Field . . . . . . . . . . . . . . 1

"S" Reservoir B ..................... . 2

$\mathrm{CO}_{2}$ Displacement . . . . . . . . . . . . . . . . . . . 3

Phase I Objectives . . . . . . . . . . . . . . . . . 4

Phase I Results

*Miscibility . . . . . . . . . . . . . . . . . 4 Sand Pack Displacements

Phase Behavior

*Gravity Stability . . . . . . . . . . . . . . 6

*Initial Reservoir Models . . . . . . . . . . . . . 8

Petrophysical Evaluation of New Well . . . . . . . . . 8 Open Hole Log Evaluation

Core Analysis

*Residual Oil Saturation Measurements . . . . . . . . 10

Injection Preparations . . . . . . . . . . . . . . 11 $* \mathrm{CO}_{2}$ Contract

$\mathrm{CO}_{2}^{2}$ Injection Facilities

$\mathrm{CO}_{2}$ Displacement Potential . . . . . . . . . . . . 13

Remaining Oil Column . . . . . . . . . . . . . 13

Economic Feasibility . . . . . . . . . . . . . . . . . 14

Recommendations .. . . . . . . . . . . . . . . 14

\section{Figures, Tables, and Attachments}

Figure I Weeks Island Field Location Map . . . . . . . . . . 16

Figure 2 Weeks Island "S" Sand Reservoir B Structure Map . . . 17

Figure 3 Dip Cross Section $\mathrm{CO}_{2}$ Pilot "S" Sand Reservoir B. . . . 18

$\begin{array}{ll}\text { Figure } 4 & \text { Production and Injection History "S" Sand Reservoir } \\ & \text { B Oil Column. . . . . . . . . . . . . . . . . } 19\end{array}$

Figure 5 Open Hole Logs Weeks Island State Unit A No. 17 . . . 20

*Milestone Progress Report 


$$
\text { Figures, Tables, and Attachments (Cont.) }
$$

Figure 6 Correlation of Induction Log and Core Analysis Weeks

Island State Unit A No. 17 . . . . . . . . . . 21

Figure 7 Comparison of Residual Oil Measurements . . . . . . . 22

Figure 8 Mechanical Flow Diagram $\mathrm{CO}_{2}$ Injection System . . . • 23

Figure 9 Cumulative Expenditure Curve . . . . . . . . . . 24

Table 1 Calculated Oil Content Weeks Island State Unit A No. 17 core................... 25

Attachment I Phase I Research Results . . . . . . . . . . . 26

Appendix A Experimental Displacements of Weeks Island "S" Sand Oil with $\mathrm{CO}_{2}$ and Hydrocarbon Gases............ 29

Appendix B Phase Behavior Experimentation and Simulation and Gravity Stability, Weeks Island $\mathrm{CO}_{2}$ Injection Project . . . . 42

Appendix C One-Dimensional Numerical Simulator for "S" Sand Reservoir B, Weeks Island Field . . . . . . . . . . 55

Appendix D Sweep Efficiency as Influenced by Density of Injected Gas . . . . . . . . . 65

Appendix $\mathrm{E} \quad$ Residual Oil Saturation in the Interval 12,910-19,920 Feet, Weeks Island State Unit A No. 17 . . . . . . . . . . 71

Attachment 2 PVT Report "S" Sand Reservoir B Oil . . . . . . . . . 78 Attachment 3 Core Analysis Weeks Island State Unit A No. 17 . . . . 92 Attachment 4 Core Report Weeks Island State Unit A No. 17

(Description).................... . . 101 
FIRST ANNUAL REPORT

WEEKS ISLAND "S" SAND RESERVOIR B

GRAVITY STABLE MISCIBLE CO2 DISPLACEMENT

IBERIA PARISH, LOUISIANA

Shell 0il Company

P. 0. Box 60123

New Orleans, Louisiana 70160

Shell Development Company

P. 0. Box 481

Houston, Texas 77001

\section{PURPOSE AND SCOPE}

The "S" sand Reservoir $\mathrm{B} \mathrm{CO}$ pilot was designed to demonstrate the feasibility of a downward $\mathrm{CO}_{2}$ displacement in a steeply dipping, high temperature and high pressure Gulf Coast reservoir. Reservoirs of this type typically are produced by natural water drives which leave a significant residual oil volume. Other major watered out reservoirs in Weeks Island Field have an estimated tertiary potential of 26 million barrels of oil which could be recovered by a $\mathrm{CO}_{2}$ displacement.

Reservoirs of this type are not suitable for surfactant flooding as the temperatures and water salinities are too high for currently available chemical systems; while the depth, and unusually good oil mobilities preclude any additional recovery by thermal stimulation. The major reservoirs in the Weeks Island Field have high permeabilities such that if the $\mathrm{CO}_{2}$ were injected down-dip, the $\mathrm{CO}_{2}$ would tend to float to the top of the watered-out reservoirs. This is because the viscous forces are small when compared to gravity forces. The downward $\mathrm{CO}_{2}$ displacement is designed to utilize gravity forces to stabilize the displacement and increase the sweep efficiency of the injected $\mathrm{CO}_{2}$.

\section{PROJECT SETTING}

\section{WEEKS ISLAND FIELD}

The Weeks Island Field is located on and around a piercement-type salt dome, and is a member of the five-island group comprised of Jefferson Island, Avery Island, Weeks Island, Cote Blanche, and Belle Isle. These islands are topographic expressions of near-surface salt stocks. Figure 1 is a map showing the location of the Weeks Island Field. The Weeks Island salt stock rises to

Prepared for the Department of Energy under Contract EF (77-C-05-5232). 
within 35 feet of sea level and has a maximum surface expression of 135 feet above sea level. There are numerous radial and peripheral faults with vertical displacements of up to 2500 feet.

Hydrocarbon shows have been found in sands of Pleistocene to lower Miocene age, at depths from 1000 to 17,000 feet. Commercial production has been established in 37 middle to lower miocene sands, predominantly below 9500 feet. The bulk of the original in-place oil ( $87 \%$ ) was trapped in the downthrown north flank of the field where reservoir hydrocarbon column heights of up to 2600 feet have been proven. The majority of these reservoirs are driven by strong water influx from large aquifers.

"S" Sand Reservoir B

The "S" sand Reservoir B occurs in a fault block on the north flank of the dome. The reservoir is sealed against the dome by radial and peripheral faults shown on the Figure 2 structure map. The "S" Sand Reservoir B originally contained two oil columns with over 3,000,000 barrels of in-place oil overlain by a 1300-foot gas column which contained $24 \mathrm{BCF}$ of wet gas. The $\mathrm{CO}_{2}$ displacement will be undertaken in the west flank oil column which contained all but 200,000 barrels of the original in-place oil. A structure map and dip cross section of the west flank oil column is shown on Figure 3.

$\underline{\text { Reservoir History }}$

The "S" sand Reservoir B was initially produced by pressure depletion until unitization was completed in 1973 at which time pressure maintenance was initiated with freshwater injection. The freshwater injection well was Smith State Unit G2 which penetrated the reservoir below the original oil/water contact. Through February of $1978,3.14$ million barrels of water had been injected to replace the reservoir voidage of the only oil column producer Weeks Island State Unit Al6A (Al6A). Through March of 1978, Al6A has produced 2.58 million barrels of oil, including 1.80 million barrels produced since water injection was initiated. In July 1975, the producing perforations at a subsea depth of 12,822 to 12,832 collapsed. We believe this was due to the arrival of a substantial quantity of water at the producing perforations. In a subsequent workover, a pulsed neutron log indicated a probable gas/oil contact at a subsea depth of $12,760^{\prime}$ and a substantial gas saturation to a subsea depth of $12,776^{\circ}$. Weeks Island State Unit Al6A was then recompleted to a subsea depth between 12,777 to $12,787^{\prime}$, and the substantial gas saturation above the perforations was confirmed by increased gas production from the new completion. The gas/oil ratio was reduced by increasing the water injection to a range in excess of the oil withdrawals. Water appeared in the production of the new perforations in July of 1976. Injection was then reduced to allow gas cap expansion to drive the oil that was above the perforations downward to the producing interval. Gas broke through to the 
producing perforations in August of 1977. Flow from the well was restricted in an effort to reduce the gas production and the well died. Since that date, the well has been gas lifted against a choke to keep the well producing at a controlled rate.

The production and injection history of the "S" Reservoir B oil column is plotted on Figure 4. The increasing GOR and water cut is evidence of the thin oil column now trapped in the vicinity of the existing producing perforations in Weeks Island State Unit Al6A.

Since reservoir unitization in 1973, a gravity stable cycling of the "S" Reservoir B gas cap has been conducted on the eastern end of the reservoir. Dense wet gas has been produced from perforations at the oil/water contact in Myles 25 and the less dense processed gas has been returned to the formation through Myles 22. Although the dry gas has remained gravity segregated above the wet gas, Myles 25 is producing an increasing quantity of dry gas and a deeper cycling producer is planned in the western end of the gas cap. Cycling operations should not interfere with $\mathrm{CO}_{2}$ displacement of the watered out oil column.

$$
\mathrm{CO}_{2} \text { DISPLACEMENT }
$$

The project will displace approximately 900 acre-feet of watered-out reservoir in the 120-foot displacement interval shown on the Figure 3 cross section. The process will involve injecting approximately 460,000 reservoir barrels of a $\mathrm{CO}_{2}$-methane mixture into Weeks Island State Unit $\mathrm{Al6A}$. The $\mathrm{CO}_{2}^{-}$ methane slug will be injected through perforations just above the gas/oil contact at $-12,760$ feet subsea and will be displaced downdip to new producing perforations in Weeks Island State Unit Al7.

Injection of the $\mathrm{CO}_{2}$-methane mixture is expected to commence in July of 1978 at which time the present oil producer, Weeks Island State Unit Al6A, will be converted to injection service. The $\mathrm{CO}_{2}$ slug design will require the injection of 130 tons per day of $\mathrm{CO}_{2}$ for thirteen months. Since the reservoir is sealed by faults, the downward displacement of the $\mathrm{CO}_{2}$-methane slug during the thirteen-month injection period will be accomplished by gas lifting 1200 to 1500 barrels of water per day from the present downdip water injector, Smith State Unit $\mathrm{G}$ No. 2. After $\mathrm{CO}_{2}$ injection has ceased, the continued downward displacement of the injected $\mathrm{CO}_{2}$ and the remaining oil column into the wateredout oil column can be accomplished by two methods. The constant reservoir pressure method would require the injection of approximately 1.5 BCF of gas into the gas cap while producing water from the downdip well, Smith State Unit $G$ No. 2. The second method simply entails gas cap expansion and would be accomplished by producing water from Smith State Unit.G No. 2 causing a 400 psi reduction in reservoir pressure. The amount of supplemental gas finally injected will be determined by the availability of field gas. The present gas cycling injector, Myles No. 22, will be used as the supplemental gas injection well. 
A 3 year project 1 ife is foreseen with a 1200 to 1500 reservoir barrel per day displacement rate. We estimate that tertiary oil production due to $\mathrm{CO}_{2}$ injection would commence in the third year of the project. Cased-hole thermal ${ }^{2}$ decay logs and/or compensated neutron logs will be used in Weeks Island State Unit $\mathrm{A}-17$ to monitor the advancing $\mathrm{CO}_{2}$, prior to the arrival of the oil bank at the downdip completion.

\section{PHASE I OBJECTIVES}

The objectives of Phase I were to determine the likelihood of project success and to prepare for the initiation of the $\mathrm{CO}_{2}$ displacement. To determine the likelihood of success, laboratory measurements were scheduled to determine the miscibility of the crude oil and $\mathrm{CO}_{2}$ at reservoir conditions, while measurements of crude oil density and viscosity and $\mathrm{CO}_{2}$ plant gas mixture density were planned for use in calculations of the displacement stability.

A new well was also scheduled to measure the reservoir parameters through the use of logs and cores while work on the initial reservoir mathematical model was undertaken. This model is to be then expanded to include the new reservoir parameters determined from the new well and the displacement processes defined by the laboratory measurements.

The preparation for $\mathrm{CO}_{2}$ injection required a contract for an adequate $\mathrm{CO}_{2}$ supply and the construction of facilities to provide for $\mathrm{CO}_{2}$ injection and water disposal. The final stage of preparation is the conversion of the oil producer, Weeks Island State Unit Al6A, to $\mathrm{CO}_{2}$ injection and the conversion of the water injector, Smith State Unit G2, to a water producer.

\section{PHASE I RESULTS}

\section{Miscibility}

PVT measurements, sand pack displacements with $\mathrm{CO}_{2}$ and the phase behavior measurements have been made on the $S$ sand Reservoir $B$ oil at reservoir conditions of pressure and temperature. PVT measurements show that at reservoir conditions pure $\mathrm{CO}_{2}$ is more dense than oil while vertical sand pack displacements with $\mathrm{CO}_{2}$ indicates substantial oil can be recovered. However, the phase behavior measurements indicate that displacement will be initially two-phase and miscibility, if achieved, will have to be generated. Nevertheless, oil recovery should be good as a result of the hydrocarbon vaporization which occurs when $\mathrm{CO}_{2}$ contacts crude oil at these reservoir conditions.

\section{Sand Pack Displacements}

Several high pressure, high temperature, vertical sand pack displacements with the Weeks Island $S$ sand crude have been conducted to study the 
downward displacement of oil by $\mathrm{CO}_{2}$ injection. To investigate the effect of methane dilution on the process, various mixtures of plant gas and $\mathrm{CO}_{2}$ were used as displacing fluids in the vertical sand packs. Experimental results indicate miscibility was not obtained in the short sand pack displacements but a high recovery, two-phase displacement was achieved.

The Shell Development report which describes the method, equipment and results of the sand pack displacements is attached as Appendix A. The Shell Development report compares the results of $\mathrm{CO}_{2}$ displacements with varying plant gas dilution, with a completely miscible propane displacement of a Weeks Island crude and a completely immiscible natural gas displacement of the $S$ sand reservoir. B crude oil. The sand pack results are shown as plots of effluent light transmittance versus pore volumes injected (and produced). The light transmittance is a qualitative measure of the displacing fluid content in the oil. A smooth transition of light transmittance at the breakthrough of the displacing fluid indicates a continuously increasing content of the displacing fluid in the oil which we would expect with the blended front of a miscible displacement, while sharp rapid changes in light transmittance indicate a segregated flow which would occur with an immiscible displacement. Figure 2 of Appendix A illustrates the response of a fully miscible propane flood. This response is a benchmark of miscibility characterized by the smooth transition from zero to full light transmittance over a producing interval of several percent of a pore volume. The transition occurs with gas breakthrough at approximately one pore volume of production. Figure A7 of Appendix A illustrates the rapid change of light transmittance at gas breakthrough for an immiscible natural gas displacement.

All of the $\mathrm{CO}_{2}$ displacements recovered significantly more oil than the natural gas displacement, which recovered approximately 89 percent of a pore volume at gas breakthrough. With the exception of the displacement conducted with pure $\mathrm{CO}_{2}$ at the rate of 1.2 feet per day, all the displacements with $\mathrm{CO}_{2}$ exhibited the rapid transition of the light transmittance of an immiscible displacement. The transition that occurred with the pure $\mathrm{CO}_{2}$ displacement at the rate of 1.2 feet per day can be interpreted as mixing which could occur with an unstable displacement in a small tube. In a small diameter tube the bypassed oil tends to diffuse and disperse into the displacing fluid.

\section{Phase Behavior}

One of the distinguishing features of the Weeks Island gravity stable $\mathrm{CO}_{2}$ displacement is the fact that the flood will be conducted on a gas saturated crude. It is this saturated condition that results in the formation of two phases on the initial contact with $\mathrm{CO}_{2}$. Shell Development had a single contact phase experiment performed on recombined " $S$ " sand Reservoir B crude in a mixture of 95 percent $\mathrm{CO}_{2}$ and 5 percent plant gas. Shell Development's report on this phase behavior is attached as part of Appendix B. 
Figure 1 in Appendix $B$ is a diagram of a single contact phase behavior described by this experiment in which the volume of the gaseous and liquid phases were measured at various pressures and molecular percent of the $\mathrm{CO}_{2} / \mathrm{plant}$ gas mixture. Section A-A' on Figure B-l is a compositional path which would be followed for additions of $\mathrm{CO}_{2}$ and plant gas to the reservoir fluid at a constant pressure equal to the bubble point pressure of the oil. Section $B-B^{\prime}$ shows a compositional path taken for additions of the $\mathrm{CO}_{2} /$ plant gas mixture at a reservoir pressure which is above the bubble point and below the pseudocritical pressure. Section C-C' shows a path for displacement pressure greater than pseudocritical pressure.

In Figure 2 of Appendix $B$ the volume percent of the second phase is plotted versus the mole percent of the $\mathrm{CO}_{2} / \mathrm{plant}$ gas mixture for the above three pressures. The term second phase is used ${ }^{2}$ since the character of the phase depends upon whether the two phase region is entered through a dew point or through a bubble point. If the two phase region is entered through a dew point, the second phase is a liquid. If the two phase region is entered through a bubble point, the second phase is a vapor.

It is planned that the $\mathrm{S}$ sand Reservoir $\mathrm{B} \mathrm{CO}_{2}$ displacement will be conducted at the present reservoir pressure which is also the bubble point pressure for this gas saturated crude. Therefore, the first contact phase behavior should follow along Line $A-A^{\prime}$ on Figures $B-1$ and $B-2$. The first addition of the $\mathrm{CO}_{2} / \mathrm{plant}$ gas mixture results in the formation of a liquid and vapor phase. With continued additions of $\mathrm{CO}_{2}$ and plant gas, the volume of the second or vapor phase grows until at a high concentration of $\mathrm{CO}_{2}$ and plant gas essentially all the liquid has been extracted into the vapor phase. If the downward displacement is gravity stable, we expect a two phase displacement with the liquid phase being displaced by the vapor phase. The expected production characteristic would rapidly change from liquid to vapor at the passing of the vapor phase front. A similar type of producing characteristic was observed from our short tube sand pack displacements.

\section{Gravity Stability}

The physical properties of the S Sand Reservoir B oil have been measured for the conditions of $225^{\circ} \mathrm{F}$ and $5100 \mathrm{psi}$. Neglecting interphase mass transfer, these measurements are reported in the attached PVT analysis indicate that a downward displacement with pure $\mathrm{CO}_{2}$ would be inherently unstable because the oil with the density of .669 grams per milliliter would be displaced by $\mathrm{CO}_{2}$ with a higher density of .689 grams per milliliter. In order to obtain gravity stability, the original pilot design called for a reduction of the density of the displacing fluid which would be accomplished by the dilution of the $\mathrm{CO}_{2}$ with natural gas. Calculations of the gravity stability resulting from a 5 percent natural gas dilution of the $\mathrm{CO}_{2}$ are reported in Appendix B. The calculations indicate the process will be stable with either an immiscible displacement or a miscible displacement. 
The Dumore analysis for estimating stable and critical velocities for a gravity dominated miscible displacement assumed linear blending for the densities and $1 / 4$ power blending for the viscosities of the blended fluids.

$$
\begin{aligned}
& \rho_{B}=f_{1} \rho_{1}+f_{2} \rho_{2} \\
& \mu_{B}=\frac{\mu_{1} \mu_{2}}{\left[f_{1} \mu_{2}^{1 / 4}+\left(1-f_{1}\right) \mu_{1}^{1 / 4}\right]^{4}}
\end{aligned}
$$

Where:

$\rho=$ density

$\mu=v i s \operatorname{cosity}$

$f=$ fraction of fluid

Subletter B refers to the blended fluid

Subnumbers refer to fluid 1 or 2

Since we expect the process to start and possibly remain as àn immiscible displacement, the stability calculations reported in Appendix $B$ include the calculated critical rate for an immiscible displacement after repeated contacts between the oil and the $\mathrm{CO}_{2} / \mathrm{plant}$ gas mixture. The densities and viscosities used in this calculation were obtained from a equilibrium K-value type fluid properties computer program which has been used to model a sequence of multicontact equilibrium experiments. The results of these calculations are illustrated on Figure 7 of Appendix B. The calculations indicate the initial contact of $\mathrm{CO}_{2}$ with the oil would increase the gravity stability of the oil/ $/ \mathrm{CO}_{2}$ interface.

Since the design darcy velocity of the displacement is in the order of 0.04 feet per day, which is less than a tenth of the calculated critical immiscible displacement velocities and less than $1 / 4$ of the calculated stable velocities for a completely miscible displacement, we believe it will be possible to achieve a gravity stable displacement with a 5 percent plant gas dilution of the $\mathrm{CO}_{2}$. Darcy velocity has been defined as a flow rate divided by the cross sectional area $\mathrm{q} / \mathrm{A}$. 


\section{Initial Reservoir Models}

An initial one-dimensional mathematical model of the $S$ sand Reservoir $B$ has been constructed. The simulation results of this model are reported in Appendix $C$ of the Shell Development Phase I report. This initial model used the reservoir parameters and fluid properties as they were originally conceived from the $S$ sand Reservoir A data. This model will now be altered to accept the recent put data and the $\log$ and core data obtained from the new well, Weeks Island State Unit Al7.

Although this model does not yet contain the new data now being gathered, it is capable of matching reservoir pressure and fluid contact behavior and the model can now be expanded. Because the gas cap is several times larger than the oil column, the pressure match is sensitive to gas cap size and rather insensitive to oil column size and PVT properties. However, the pressure match does indicate the reservoir is sealed from significant fluid flows from other sources. Moreover, this preliminary model indicates the original gas/oil contact was a significant distance above the level indicated by the 1975 logs and performance of Weeks Island Al6A.

A preliminary analysis of the sweep efficiency at gas breakthrough as a function of density differences between the displaced and displacing phases is attached as Appendix $D$. Although the calculation does not include the varying density differences between the oil and gas, which will occur with repeated contacts of the fluids, this work does indicate it is reasonable to expect a a good sweep. If it becomes apparent in future work or early production that the displacement will have a nonuniform contact, the final producing perforations may be lowered to increase the swept volume of the pilot.

Additional S Reservoir B models will be constructed using Shell's existing simulators. It may be necessary to modify the fluid property calculations in these simulators to account for the observed compositional behavior of the reservoir fluids. It may also be necessary to perform additional phase behavior measurements that will investigate the envisioned repeated contacts that will occur between the displacing gaseous $\mathrm{CO}_{2}$ phase and the liquid oil phase.

\section{Petrophysical Evaluation of New Well}

A new well, Weeks Island State Unit Al7, has been drilled at the location shown in Figure 3. This well, which was drilled to evaluate the reservoir parameters, will be used to monitor the advancing displacement and will ultimately serve as the producing well for the pilot. The well has been drilled and the evaluation is essentially complete. The open hole logs indicate water has invaded all of the sand at subsea depths lower than the perforations in the offset producer Al6A, as shown on Figure 3. 
A special polymer mud was used in the " $S$ " sand drilling and coring operations to minimize a possible reduction in the residual oil saturation. This low water loss mud contained no surface active agents. Mud particle size was also adjusted for optimum pore bridging to minimize viscous stripping due to spurt loss.

Open Hole Evaluation

Calculations from conventional open hole logs indicate the invading water has left a remaining hydrocarbon saturation of between 26.5 and 33 percent. (It is important to note that we are talking about residual hydrocarbon and not residual oil saturation. This will be explained later in the text.) The hydrocarbon saturation above the flushed zone is greater than 90 percent. The open hole resistivity and porosity logs across the "S" sand interval are shown in Figure 5. Petrophysical parameters used in the water saturation calculations are shown in Table 3 of Appendix E. The tapered resistivity indicated on the induction $\log$ is the result of a varying water salinity that occurred as the injected freshwater mixed with the original formation water. The original formation water has been estimated from field experience to have contained approximately 190,000 parts per million disolved solids. A remaining hydrocarbon saturation was calculated in two intervals; the first between 12,917 feet and 12,919 feet and a second interval between 12,960 feet and 12,970 feet. Although these two intervals had respective resistivities of 3 ohm meters and 1 ohm meter, most of this resistivity difference can be attributed to the varying water salinity. The water salinity was obtained by perforating and swabbing formation water from the intervals at the rate of 10 barrels per hour. Titrations of the recovered water measured 10,825 parts per million chlorine in the water recovered from the upper interval and 35,500 parts per million chlorine in the water which was recovered from the lower test interval. No hydrocarbons were obtained during the swab tests which indicates the remaining hydrocarbons were immoble.

\section{Core Analysis}

During the drilling operations, 77 feet of coring was attempted with 71 feet of recovery. The core analysis obtained to date is included in Attachment 3. (Core analysis should be complete within another month.) The initial analysis on 58 feet of this core indicates an average unstressed porosity of 27.1 percent and an average unstressed air permeability of 3.5 darcies. Subsequent stressed data indicate the porosity should be reduced by 1.1 percent to relate to subsurface conditions. All of the core material was obtained using an oriented conventional core barrel. No pressure core barrel is presently available that can core a 5000 psi reservoir. Measured oil saturations from this core should therefore be less than or equal to the in situ saturations since it is possible that blowdown losses did occur. Figure 6 is a plot which 
compares the $\log$ response with the porosity, permeability and calculated barrels per acre/foot obtained from core analysis. Twenty-five core plugs oriented perpendicular to the dip, parallel to the dip and parallel to the strike were cut from the oriented core at eight depths between 12,937 feet and 12,976 feet. No preferential direction of permeability was found by these measurements as indicated in the attached core analysis.

\section{$\underline{\text { Residual Oil Saturation Measurements }}$}

Several independent methods were used to calculate the residual oil saturation in the interval between 12,910 feet and 12,920 feet. Our best estimate of the remaining oil saturation in this interval is between 22 .percent and 24 percent. We feel these numbers to be representative of the entire flushed zone interval.

Figure 7 summarizes the residual oil saturations as determined by the various methods. Other measurement techniques, such as Nuclear Magnetism Logging, tracer tests and pressure core barrels were investigated but were not feasible due to either pressure or temperature constraints.

Residual Oil Saturation From Log-Inject-Log

A description of the procedure and calculations used to determine residual oil saturation by this method are included in Appendix $E$ of the Shell Development Phase I report. The summary of the results of the individual stationary readings are included in Table 1 of Appendix $E$. The average residual oil saturation determined by this method is $.221+.025$. Since these measurements were made in the subsurface under very controlle $\bar{d}$ conditions, we feel this is the more accurate of the various methods used to determine the residual oil saturation.

Residual Oil Saturation From Core Analysis

The average value of residual oil saturation from core analysis from the log-inject-log interval is $.23+.042$ (see Table 2 of Appendix $E$ ). The value of residual oil saturation obtaine $\bar{d}$ from conventional core analysis corrected to in situ conditions is generally assumed to be less than or equal to the residual oil saturation at in situ conditions. This is normally assumed since viscous stripping due to spurt losses from the drilling mud can remove immobile oil. In addition, expansion of the gas during the pressure reduction as the core is brought out of the ground can expel oil which is immobile at reservoir conditions. However, we feel these effects were greatly minimized or totally removed in the case of the Weeks Island core and hence the residual oil from the conventional core could closely approximate in situ conditions. Great care was used in the design of the mud system to minimize fluid loss as well as spurt loss. As seen 
in the core analysis, the permeability of the rock is extremely high. In highly permeable homogeneous rock with a high water saturation, residual oil saturation measurements in conventional or rubber sleeve cores can approach that of in situ conditions. We believe this occurs because it is possible that gas can be expelled from a highly permeable rock at a differential pressure too low to mobilize trapped oil.

Determination of Residual Oil From Open Hole Log Suite

The residual oil saturation as determined from open hole logs in the log-inject-log interval is $.243+.054$. It has been earlier stated that the residual hydrocarbon saturation in this interval is .33. The open and cased hole log data indicate a free gas saturation of six to ten percent. The hydrocarbon saturation is therefore a summation of the residual oil as well as the free gas saturation. A detailed discussion of the analysis is contained in Appendix E. The reservoir pressure has dropped below the bubble point causing gas to come out of solution and the pressure was subsequently never increased above the bubble point. With a residual gas saturation the total residual hydrocarbon saturation can be higher than the residual oil saturation which would have occurred if the pressure had not dropped below the bubble point. However, the residual oil saturation to water displacement will generally be lower with the presence of a residual gas saturation than it would be in the absence of a residual gas saturation.

Residual Oil Saturation From Counter Current Imbibition Data

The average residual oil saturation as determined from CCI data in the log-inject-log interval is .293. Values determined from this method are believed to be a good estimate of the expected residual hydrocarbon saturation assuming the rock is 100 percent water wet. In the case of Weeks Island Reservoir B, this number should be equal to or less than the total hydrocarbon saturation calculated from the open hole logs.

\section{Injection Preparations}

$\underline{\mathrm{CO}_{2} \text { Contract }}$

An evaluation of several methods of supply and transportation of approximately 50,000 tons of carbon dioxide at the 130 ton/day injection rate indicated it is most feasible to purchase liquid carbon dioxide from a commercial vendor with transport by 20 ton capacity trucks. The alternatives of barge and rail delivery were indicated to be more expensive than trucking.

Four potential suppliers were requested to submit a proposal to supply the liquid carbon dioxide. Liquid Carbonic Corporation was selected as 
low bidder. Under the terms of the Contract, the supplier furnishes transportation of the carbon dioxide along with storage vessels and transfer pumps which have been set on Shell-furnished foundations at the injection site.

The quality of liquid carbon dioxide should meet "food grade" standards, i.e., $99.9 \%$ carbon dioxide. The quantity of carbon dioxide delivered by truck shall be determined by difference in weight of the truck before and after filling, the empty and full weights are to be recorded on weight tickets to be furnished with each shipment.

Liquid Carbonic Corporation agreed to the Government's General Provisions (Long) and the contract was accepted by the Department of Energy in a letter dated October 28, 1977.

\section{C02 Injection Facilities}

A $\mathrm{CO}_{2}$ injection facility consisting of storage equipment, charge pumps, a Union Tx-150 injection pump and natural gas blending equipment has been constructed at the site. Figure 8 is a mechanical flow diagram of the injection facility which has a pumping capacity of $26+\mathrm{gpm}$ of liquid $\mathrm{CO}_{2}$. The storage system consists of five-50 ton capacity tanks. These tanks are piped in parallel; however, each tank can be shut off from the others for service work. The unloading pumps are Smith Precision gear-type pumps which can unload a 20 ton truck in 40 minutes. The designed injection rate of 130 tons a day will require the delivery of between six and seven truckloads of $\mathrm{CO}_{2}$ per day.

Liquid $\mathrm{CO}_{2}$ will be transferred from the storage tanks to the injection pump via the $\mathrm{CO}_{2}$ charge pumps, which are also Smith Precision gear-type pumps. The charge pumps will raise the suction pressure to the injection pump so cavitation will not occur in the injection pump. Any difference in capacity between the charge pump and the injection pump will be handled by a pressure control valve which limits the charge pressure at the injection pump to $400 \mathrm{psi}$. The control scheme allows for varying the amount of $\mathrm{CO}_{2}$ that is injected through the opening of a flow control bypass which diverts $\mathrm{CO}_{2}{ }^{2}$ from the injection pump back to the storage tanks. The injection system is designed for a 5000 psi operating pressure. We anticipate a maximum pressure of 3500 psi during startup and restart operations and a normal injection pressure of approximately 2000 psi. Higher pressures are anticipated during startup operations because the tubing of the injection well could be filled with natural gas which is less dense than $\mathrm{CO}_{2}$.

The mixing of the natural gas and $\mathrm{CO}_{2}$ will be controlled through the ratio controller which senses the flow rate through meter runs on both the $\mathrm{CO}_{2}$ and gas lines. These controls are somewhat simple, Shell having decided that ${ }^{2}$ 
the complications for temperature compensation on the $\mathrm{CO}_{2}$ could cause more problems than the possible benefit. Temperature compensation could correct the flow of natural gas by approximately 8 percent. However, the instrumentation involved would increase the complexity by a factor of 2 . It is planned to calibrate the flow system by analyzing samples of the injected fluid for $\mathrm{CO}_{2}$ at established laboratories in the New Iberia area. Shell has installed a densitometer to read the density of the natural gas- $\mathrm{CO}_{2}$ mixture, but use of the densitometer is for monitoring purposes only. Until Shell determines the practicality of this densitometer, it will not be used for control purposes.

The other unusual feature of the $\mathrm{CO}_{2}$ injection facilities is that all high-pressure reliefs are rupture discs, because dry ice will form when $\mathrm{CO}_{2}$ expands from high pressure. The dry ice could not only plug the relief opening, but could also erode the seats of relief valves.

$\mathrm{CO}_{2}$ Displacement Potential

The 900 acre feet of the "S" Sand Reservoir B we propose to displace with $\mathrm{CO}_{2}$ should contain a minimum of 258,000 barrels of water drive residual oil. A Dean Stark analysis of the residual oil and 58 core plugs corrected for oil density and rock compressibility found an average stock tank oil content of 287 barrels per acre foot of rock as shown on Table 1 . The residual content was confirmed by our log-inject-log analysis at four stations in the interval from 12,911 to 12,917 feet in Weeks Island Al7. A comparision of the residual oil content from the core analysis and the log-inject-log measurements are discussed in the residual oil measurement section of this report.

Laboratory measurements indicate it will be possible to recover a substantial portion of the 258,000 barrels of residual oil even if true miscibility is not achieved. Although we believe it reasonable to expect a substantial recovery of residual oil, our experiments are not quantitative. The $S$ Reservoir B models Shell is planning to construct will be used to define our estimated recovery during the next phase of the project.

\section{Remaining Oil Column}

We estimate that on June 1,1978 the remaining oil column in the $S$ Reservoir B was approximately 24 feet thick and contained approximately 145,000 barrels of oil recoverable by continued supplemental operations. However, the production of this column would require cycling of the cap gas which is now being produced with the oil.

This estimate of presently recoverable oil is based on a January 1 , 1978 gas/oil contact at a subsea depth of $-12,760^{\prime}$ and the water/oil contact at a subsea depth of $-12,786^{\prime}$. The estimate also assumes the last five feet of 
oil column could not be economically produced. Although it is impossible to define the gas/oil contact in the new well, Weeks Island State Unit A 17, the logs definitely indicate that water had invaded the oil column to a subsea depth of $-12,786^{\prime}$. We estimate the gas/oil contact on January 1,1978 should be at the estimated position of July of 1975, because during this time interval the reservoir volume of the produced oil and water is only 5,000 barrels less than the $1,404,000$ barrels of water injected.

Further work is planned on the definition of the present oil column size and nonproducible volume of this oil column. This work could include coning models which would incorporate the end point relative permeabilities we will obtain from the core taken from Weeks Island State Unit Al7.

\section{Economic Feasibility}

The process to be tested in the " $\mathrm{S}$ " Sand Reservoir B gravity stable $\mathrm{CO}_{2}$ displacement will utilize 862 MMCF of $\mathrm{CO}_{2}$ to displace 900 acre-feet of watered out sand which contains 258,000 barrels of oil. The project will inject $3.34 \mathrm{MCF}$ of $\mathrm{CO}_{2}$ per barrel of residual oil. Field test results will help determine the potential economics of this tertiary recovery process.

\section{Recommendations}

Shell Oil Company recommends that injection of $\mathrm{CO}_{2}$ diluted with 5 percent plant gas be initiated in the "S" Reservoir $B$. The water drive residual oil saturation available to the process has been defined to be at least 287 barrels per acre foot. Although experiments indicate the proposed displacement will be initially immiscible and may remain immiscible, these experiments indicate it may be possible to recover a substantial portion of the residual oil saturation.

An accurate forecast of the actual recovery will require additional $S$ Reservoir B mathematical models. Shell proposes to construct these models with the use of Shell's existing simulators. It may be necessary to modify the fluid property calculations to account for the observed compositional behavior of the fluids at reservoir conditions. It may also be necessary to make other physical measurements of the fluid properties and flow characteristics to properly set up these models.

$\mathrm{CO}_{2}$ injection facilities have been constructed and a contract has been obtained for an adequate supply of $\mathrm{CO}_{2} \cdot \mathrm{CO}_{2}$ injection can commence upon recompletion of the present oil producer to $\mathrm{a}^{2} \mathrm{CO}_{2}$ injection well. Work has started on the conversion of the present water injector to a water producer. 
Shell proposes the following changes in the Phase II operations:

1. The water production rate should be maintained at 1200 barrels per day during the injection phase. The 1200 barrels of daily water production will match the reservoir volume of the 130 ton/day $\mathrm{CO}_{2}$ injection rate expanded by the addition of 5 percent plant gas.

2. Well Al7 should be logged frequently with thermal decay and/or compensated neutron logs during the initial six months of injection to determine if the $\mathrm{CO}_{2}$ displacement is proceeding as planned.

3. The present log-inject-log perforations in Weeks Island State Unit A17, which are located 48 feet below the $\mathrm{CO}_{2}$ injection interval, should be left open, and an effort be made to monitor the mobile fluid passing these perforations as the displacement progresses. 


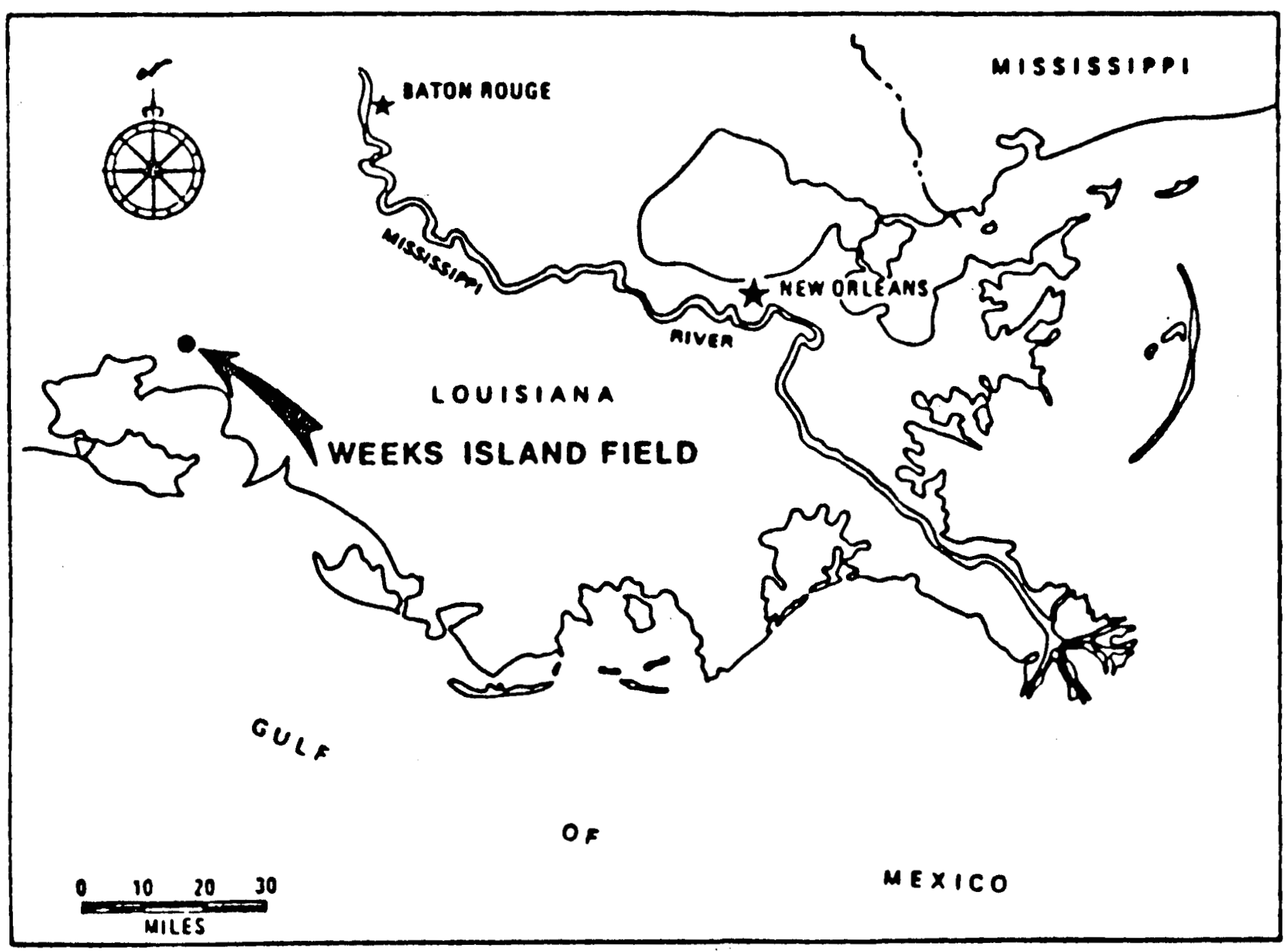

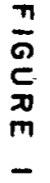

LOCATTON MAP 


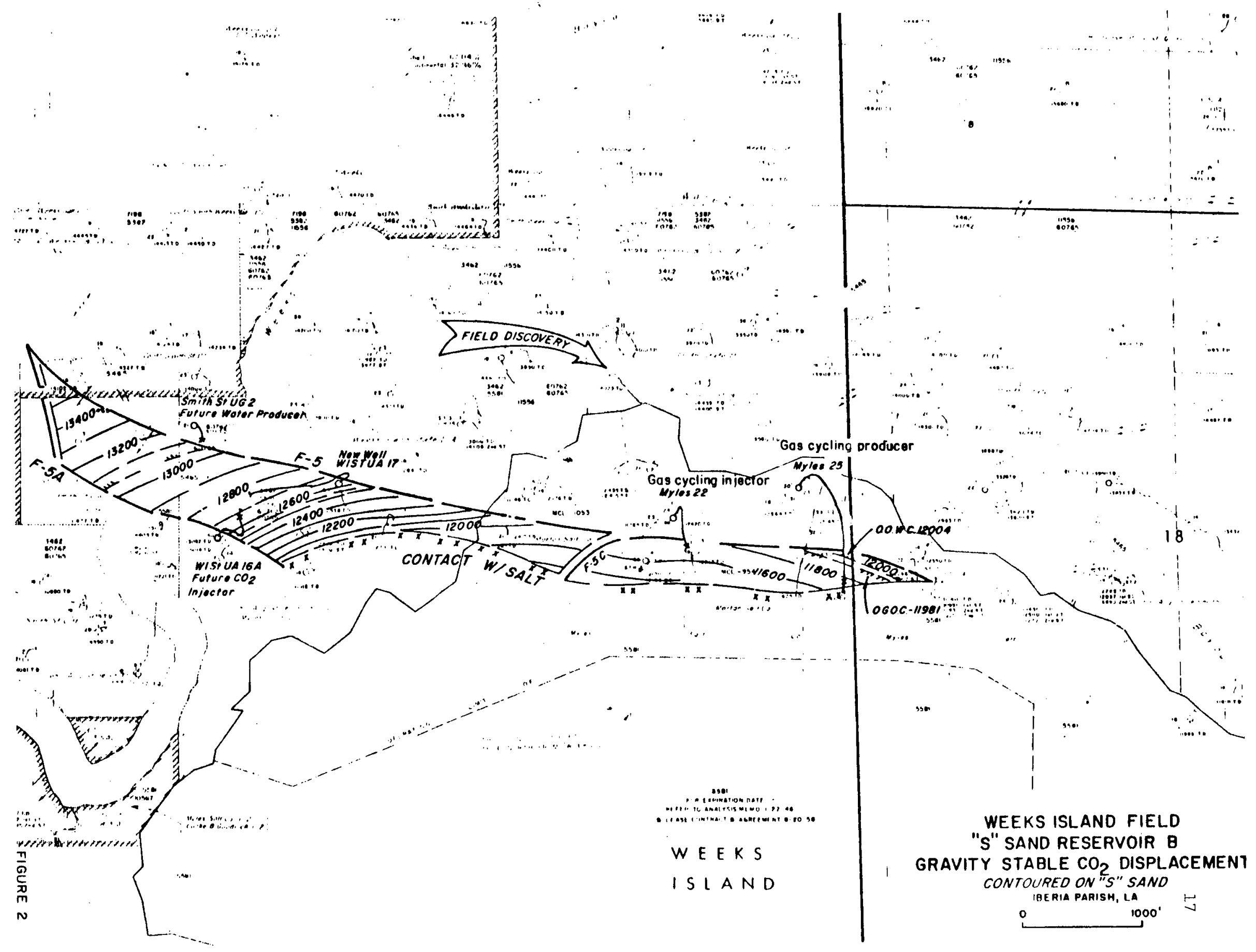




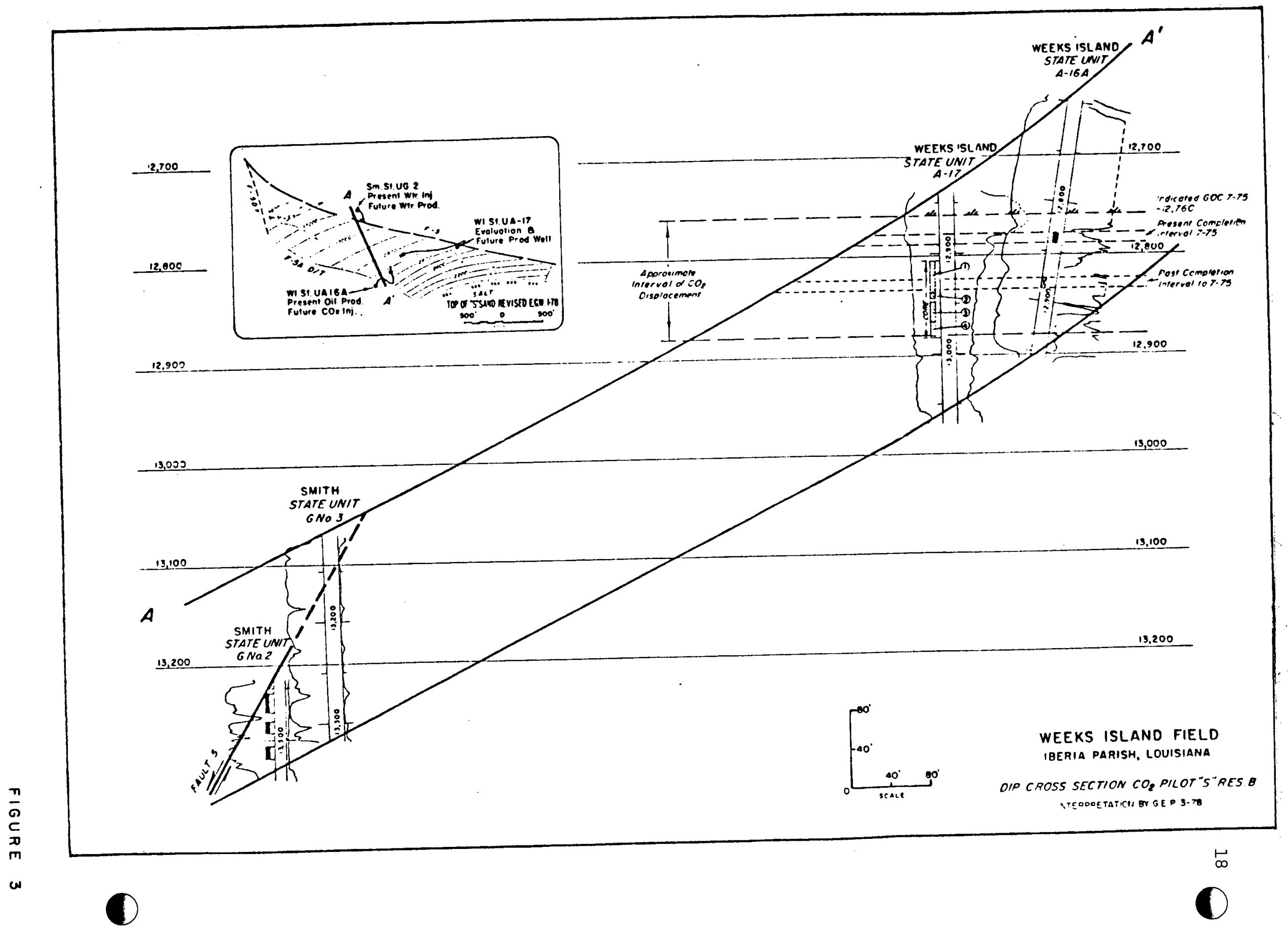




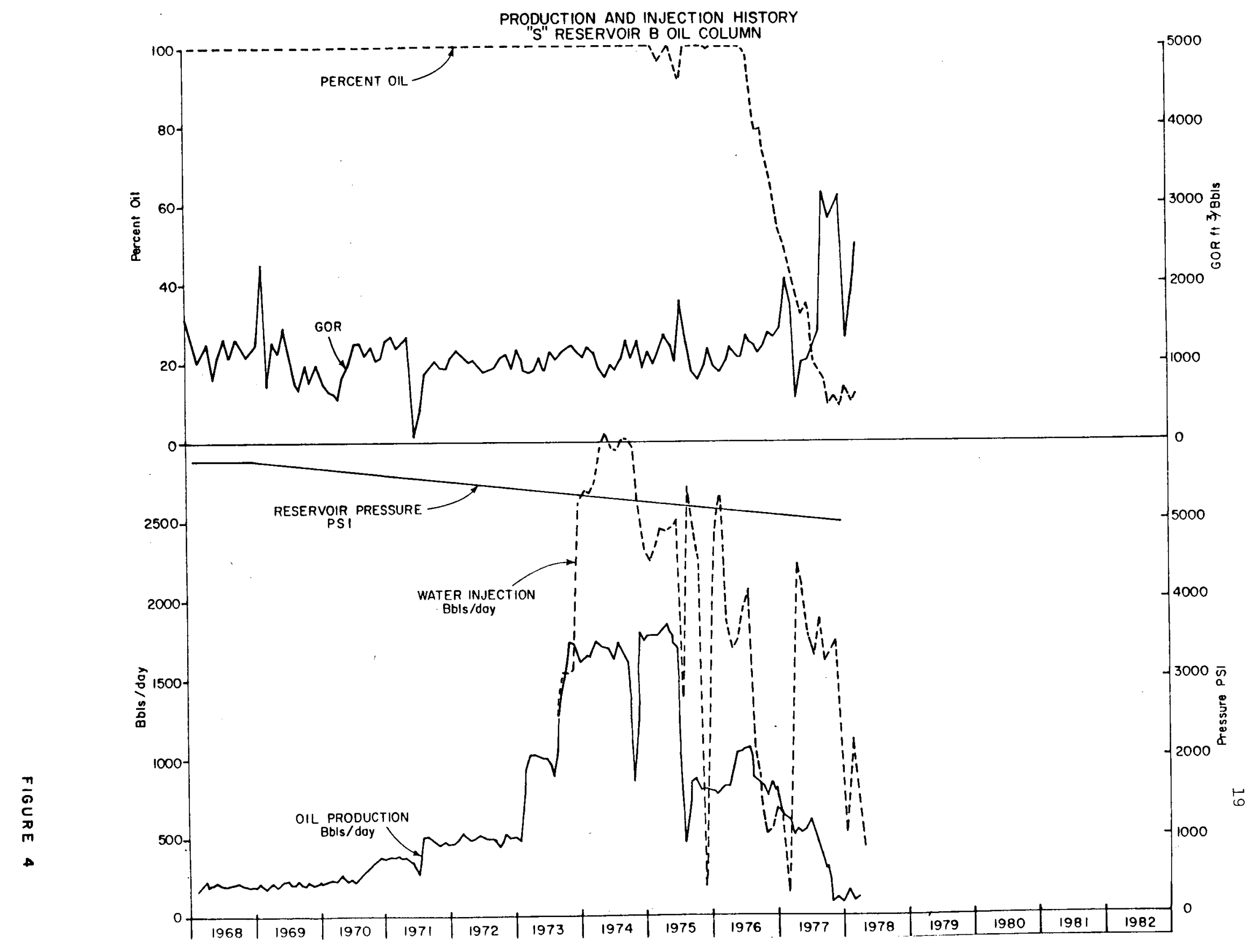




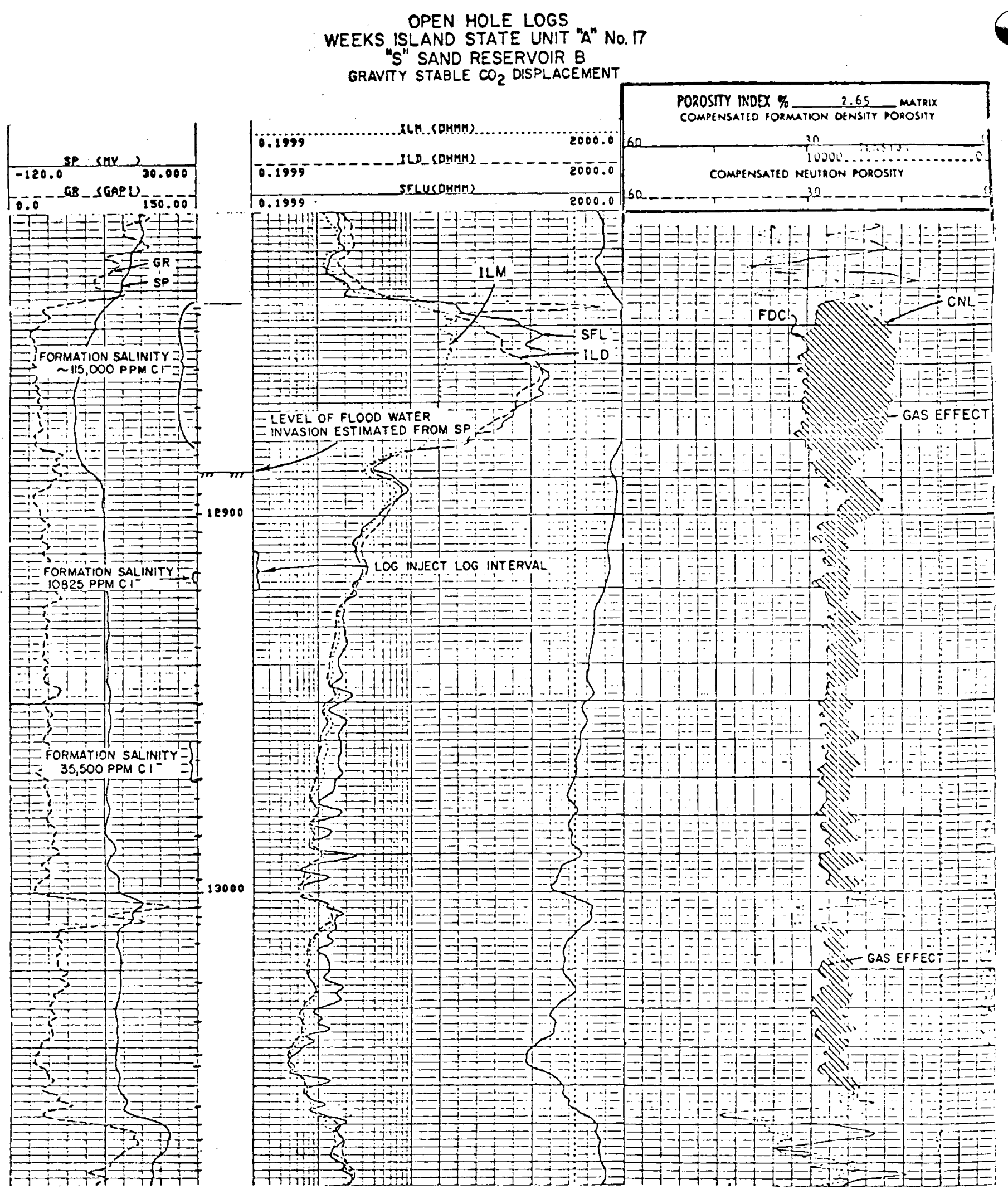

FIGURE 5 
CORRELATION OF INOUCTION LOG AND CORE ANALYSIS WEEXS ISLANO STATE UNIT A-I

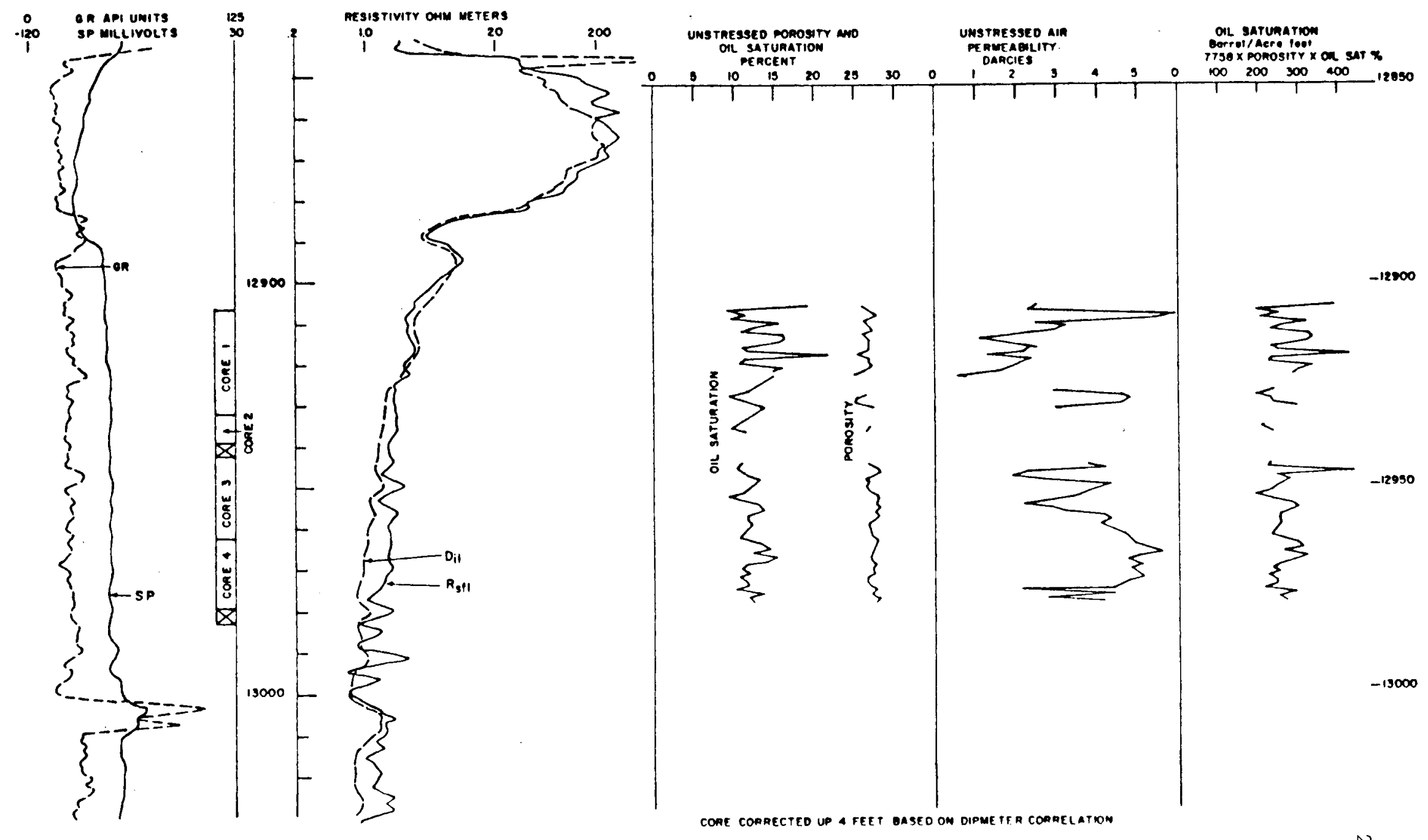


RESIDUAL OIL MEASUREMENTS

WEEKS ISLAND ST U A17

"S" SAND RESERVOIR B

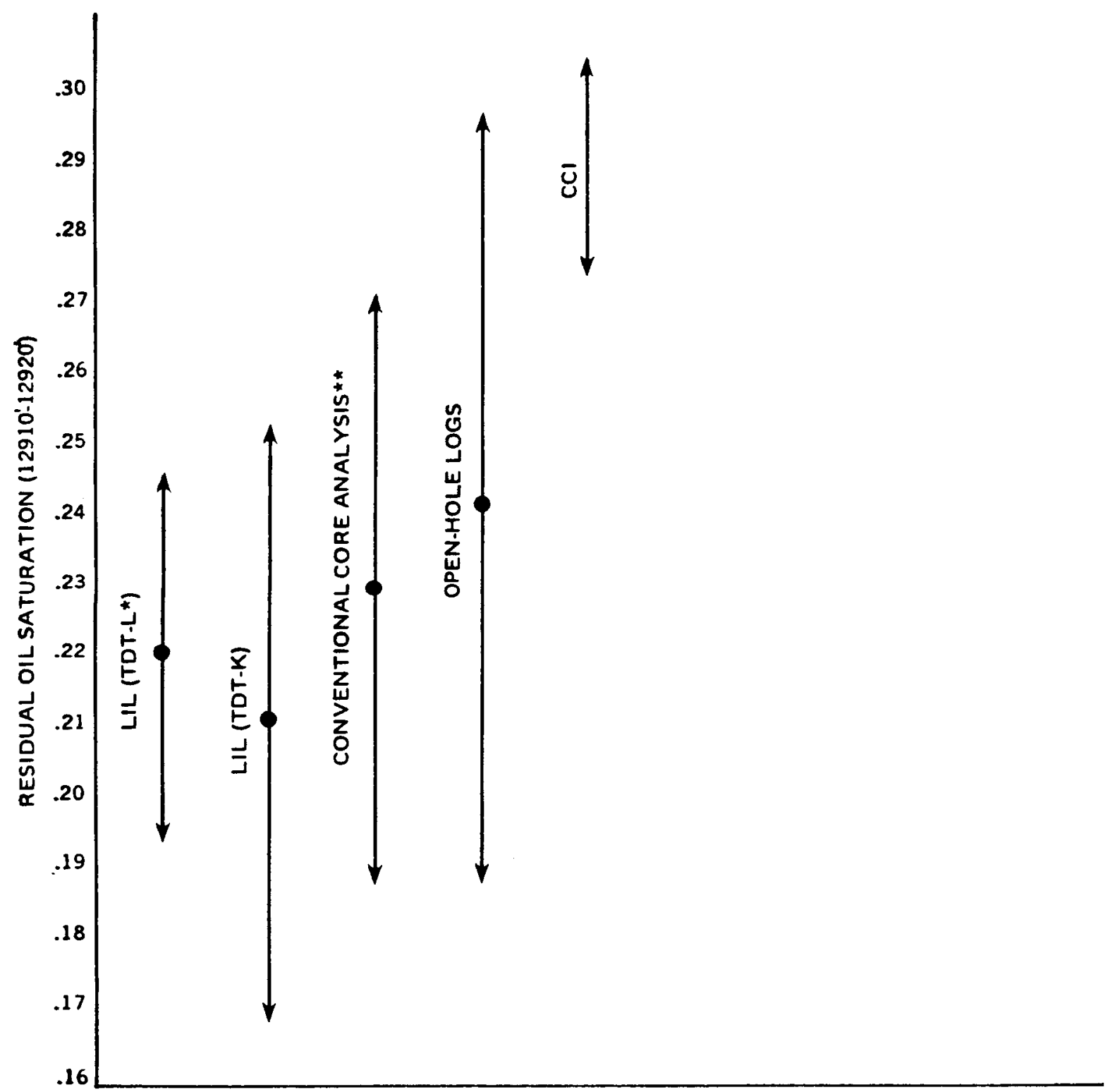

METHOD OF DETERMINATION

- This is a modified TDT-K with TDT-G electronics(source-detector spacing $60 \mathrm{~cm}$.) Readings are taken while stationary.

* * Saturation of core plug at 12918 is omitted. The saturation of this plug was over 2.5 standard deviations from the average. 


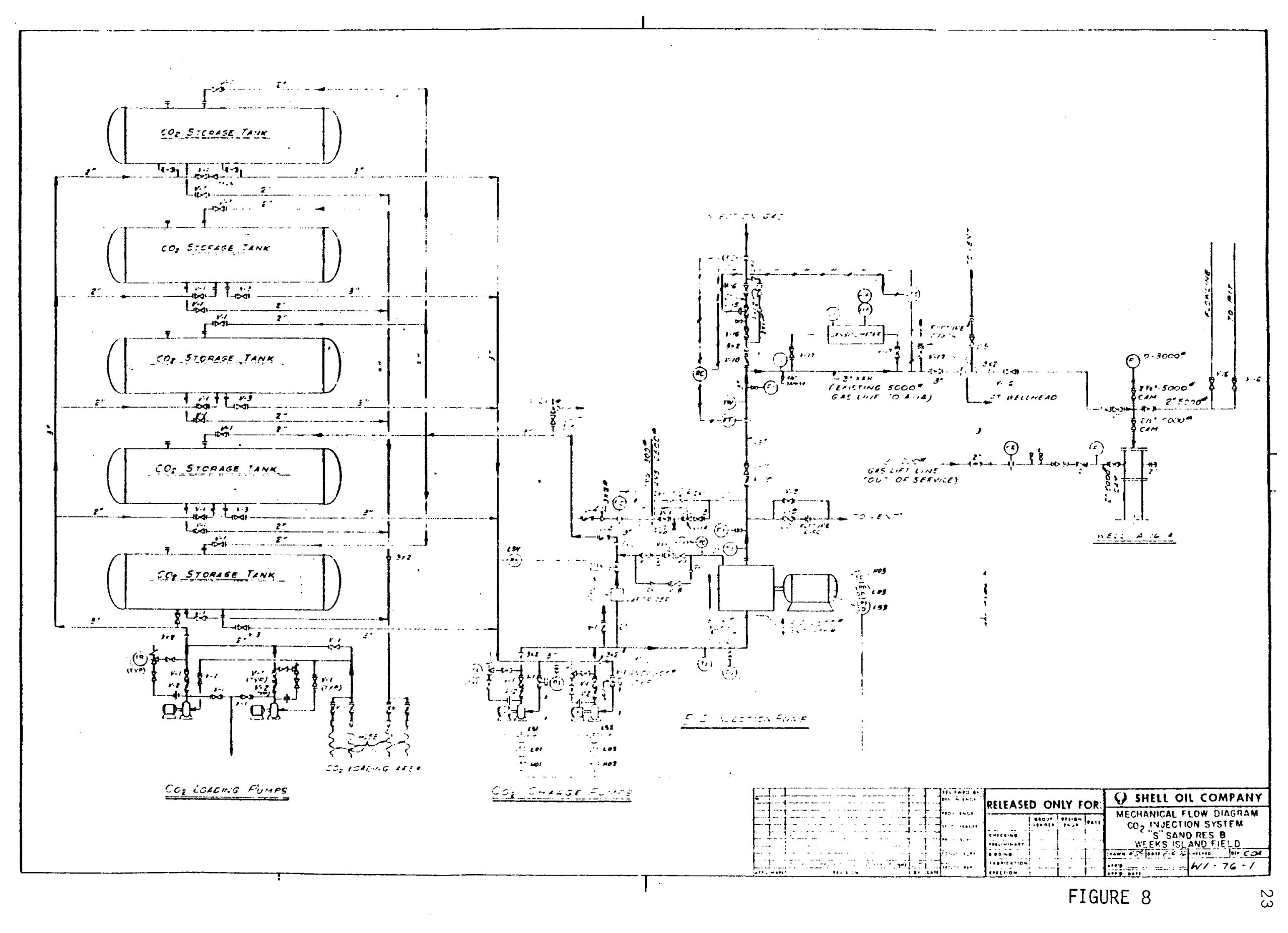




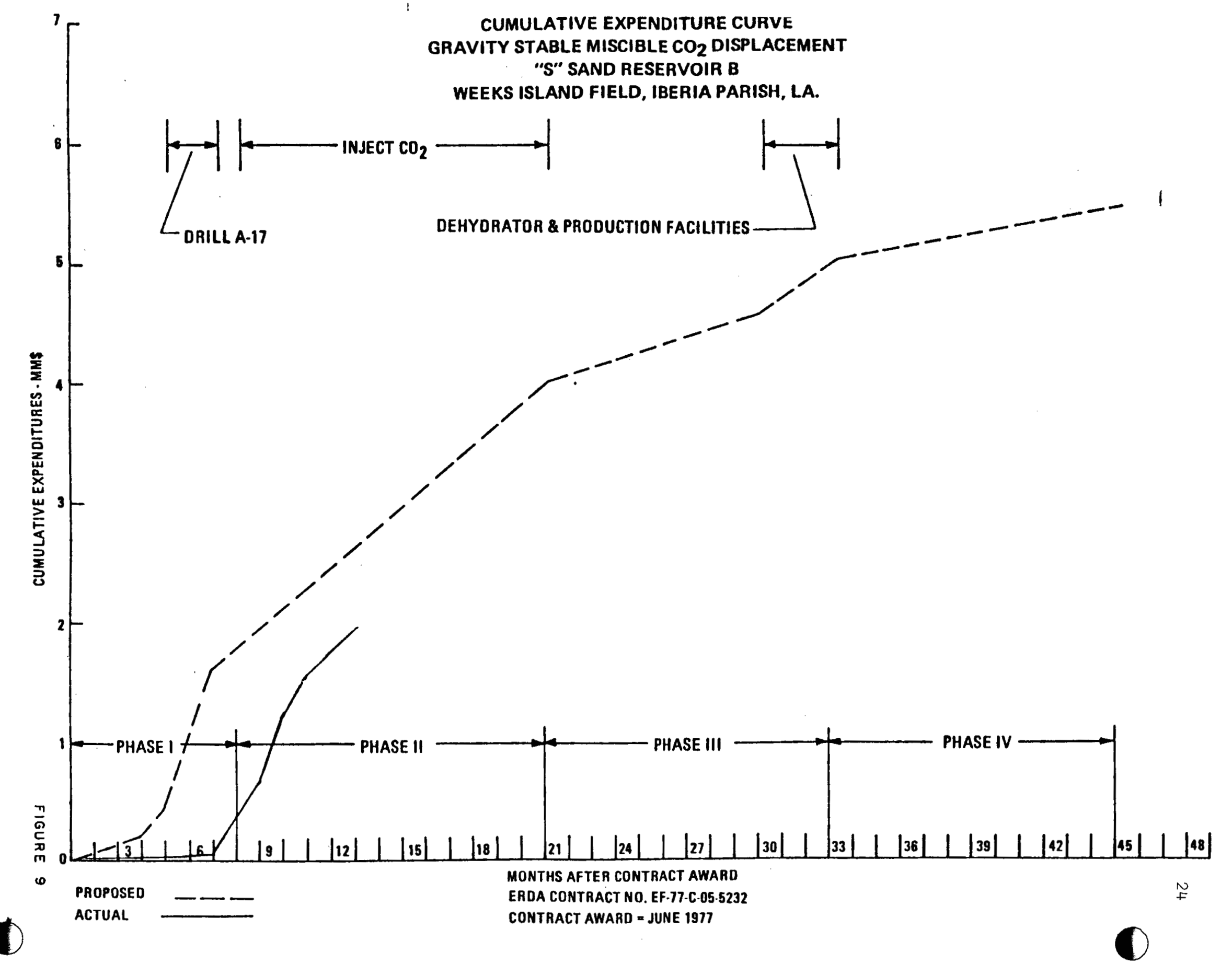




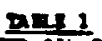

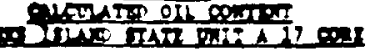

\begin{tabular}{|c|c|c|c|c|c|c|c|c|}
\hline S10 & inter & $\begin{array}{c}\text { Nereal } \\
\text { N-3eh }\end{array}$ & $\begin{array}{c}\text { A } \\
\text { Dotresed } \\
\text { rercest } \\
\text { Poroust } \\
\end{array}$ & 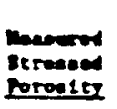 & $\begin{array}{l}5 \\
\text { Poroeits (1) } \\
\text { Corrected } \\
\text { Por strees } \\
\end{array}$ & $\begin{array}{l}\text { ad seturatsen } \\
\text { Percent } \\
\text { sefre } 2\end{array}$ & $\begin{array}{l}\text { In Plece (2) } \\
\text { stoct Tank } \\
\text { of Setroficp }\end{array}$ & $\begin{array}{l}\text { Dlo. of (j) } \\
\text { stoct fort orl } \\
\text { Per Acre Pe. }\end{array}$ \\
\hline 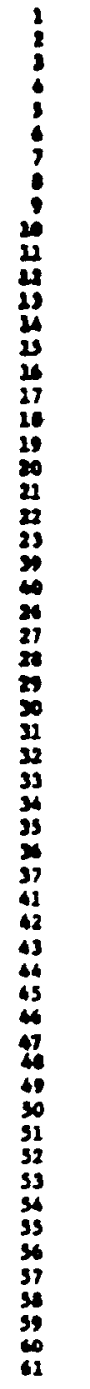 & 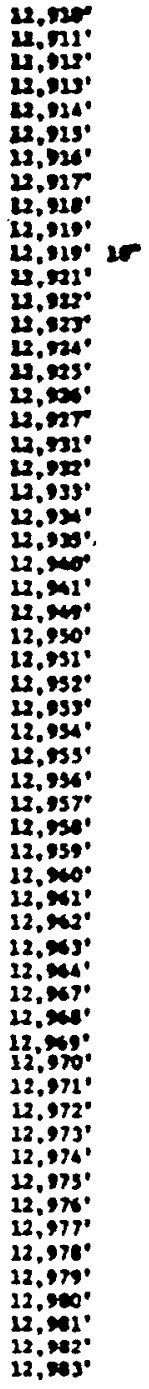 & 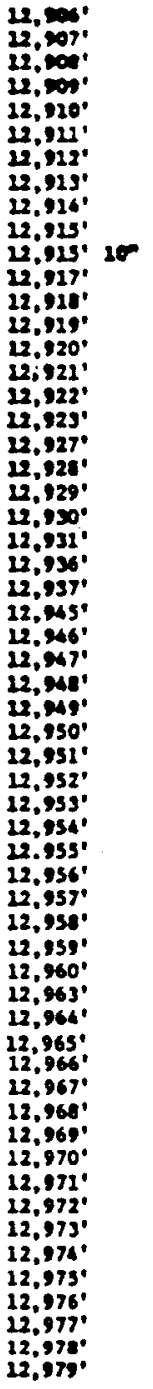 & 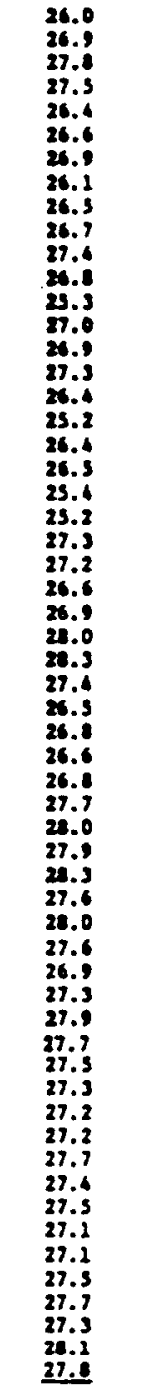 & 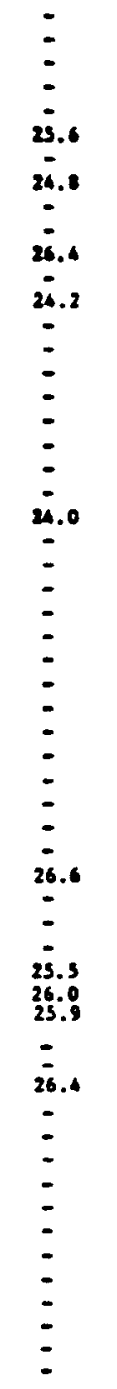 & $\begin{array}{l}26.9 \\
25.8 \\
26.7 \\
26.4 \\
25.3 \\
25.6 \\
25.8 \\
26.8 \\
25.4 \\
25.6 \\
26.4 \\
23.7 \\
26.2 \\
25.9 \\
25.8 \\
26.2 \\
25.3 \\
24.3 \\
25.3 \\
25.4 \\
24.4 \\
26.0 \\
26.2 \\
26.1 \\
25.5 \\
23.5 \\
26.9 \\
27.1 \\
26.3 \\
25.4 \\
25.7 \\
25.6 \\
25.9 \\
26.6 \\
26.9 \\
26.8 \\
26.6 \\
26.5 \\
26.9 \\
26.9 \\
25.5 \\
26.0 \\
25.9 \\
26.6 \\
26.4 \\
26.4 \\
26.1 \\
26.1 \\
26.1 \\
26.3 \\
26.4 \\
26.0 \\
26.0 \\
26.4 \\
26.6 \\
26.5 \\
26.9 \\
26.7\end{array}$ & 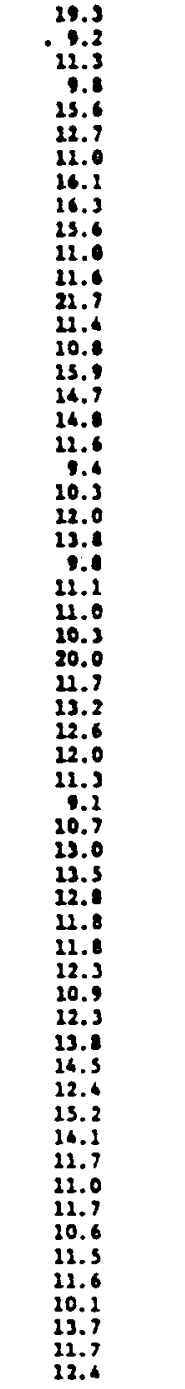 & 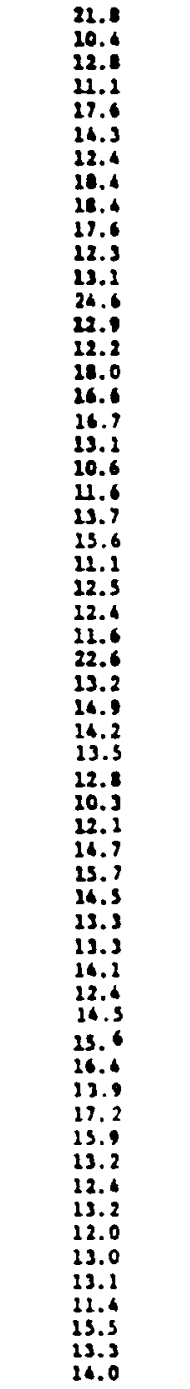 & 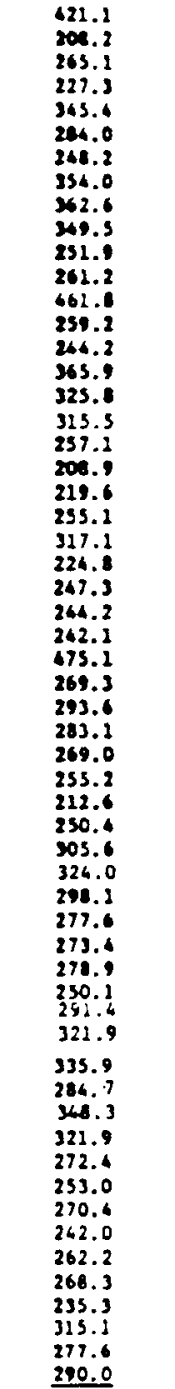 \\
\hline Arerees & & & 27.1 & & & & & 287.6 \\
\hline
\end{tabular}

(1) Deanted or (.95s) (Onetreseed Poroest)

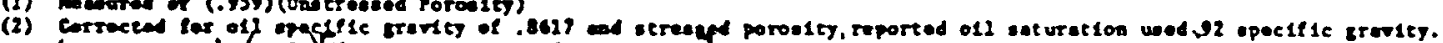

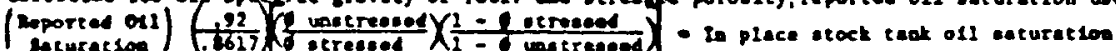

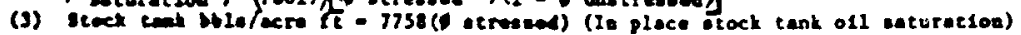


ATTACHMENT 1

TECHNICAL INFORMATION RECORD BRC-123

Project 31-81894

Weeks Island $\mathrm{CO}_{2} \mathrm{Pilot}$ Project

PHASE I REPORT - RESEARCH RESULTS

GRAVITY STABLE MISCIBLE $\mathrm{CO}_{2}$ DISPLACEMENT

"S" SAND RESERVOIR B, WEEKS ISLAND FIELD

By

J. R. Johnston

J. D. Baron

M. B. Moranville

J. D. Robinson

D. R. Montague 


\section{PHASE I REPORT - RESEARCH RESULTS \\ GRAVITY STABLE MISCIBLE $\mathrm{CO}_{2}$ DISPLACEMENT \\ "S" SAND RESERVOIR B, WEEKS ISLAND FIELD}

The purpose of this report is to document research results conducted in support of the Weeks Island $\mathrm{CO}_{2}$ field test, to recommend a composition of the injected fluid, and to present the estimates of residual oil saturation based on petrophysical data from Well SU A-17. The details of experimental and computational work are reported in five appendices. Appendix A presents the sandpack (slim tube) displacements of $\mathrm{SRB}$ crude with $\mathrm{CO}_{2}$ plus mixtures of $\mathrm{CO}_{2}$ and plant gas at temperature and pressure conditions expected to prevail in the reservoir. Appendix $B$ shows the results of single contact phase behavior experiments using $\mathrm{SRB}$ crude and $\mathrm{CO}_{2} \mathrm{PG}\left(95 \% \mathrm{v} \mathrm{CO}_{2}\right.$ and $5 \% \mathrm{v}$ plant gas). Also presented are the results of a computer simulation study that includes compositional effects. This model has been used to calculate and match the experimental data. In Appendix B, we report the results of an analysis of the gravity stability of the process displacement based on experimental data and compositional calculation techniques. Appendix $C$ describes the results of a reservoir simulation study concerning a preliminary history match of reservoir performance. Appendix $D$ shows an additional numerical simulation conducted to qualitatively assess the importance of gravity stability to areal sweep for the SRB. Appendix E contains the estimates of residual oil saturation derived from a log-inject-log technique and conventional logs in SU A-17.

Results and Recommendation

$\mathrm{CO}_{2}$ injection is not a miscible process at the SRB reservoir conditions but a $\mathrm{CO}_{2}$-crude oil vaporization process. By vaporization, we mean that the $\mathrm{CO}_{2}$ strips and replaces hydrocarbon components from the crude. The "stripping" is enhanced with repeated contacts with fresh $\mathrm{CO}_{2}$. Displacement by gravitational forces is the other mechanism which is important to the performance of the project.

Slim tube, sandpack displacements of SRB crude by mixtures of $\mathrm{CO}_{2}$ and zero to ten percent by volume of plant gas resulted in efficient and stable displacements and these results were better than displacements using no $\mathrm{CO}_{2}$. These experiments would indicate that $\mathrm{CO}_{2}$ diluted with five to ten percent of ${ }^{2}$ plant gas (primarily methane) would result in a "miscible-like" displacement process. It also appears that based on slim tube experiments alone, undiluted $\mathrm{CO}_{2}$ might be the most efficient material for the SRB field test. We must be cautious, however, in interpretation of these results. The slim tube experiments are secondary and not tertiary displacements primarily designed as a screening tool to determine "miscible-like" performance, and as such they are not correctly scaled for duplication of reservoir performance.

Under SRB reservoir conditions, $\mathrm{CO}_{2}$ not diluted with light hydrocarbons is more dense than the reservoir oil. Fortunately, process mechanisms can work to the benefit of displacement stability. Upon mixing SRB oil and $\mathrm{CO}_{2}$, two phases are formed. The $\mathrm{CO}_{2}$ rich vapor phase is less dense than the liquid phase. Based on a zero dimensional analysis and the phase behavior study results, the vertical displacement by $\mathrm{CO}_{2} \mathrm{PG}$ or $\mathrm{CO}_{2}$ alore should be gravity stable at the expected flood 
conditions. These results must be tempered, however, by the known effect of the difference in densities between the displaced and the displacing fluids on volumetric sweep efficiency. Based on simulation results, sweep efficiency increases monotonically with density difference.

After weighing the competing benefits of better displacement efficiency expected from a 100 percent $\mathrm{CO}_{2}$ displacement and the benefits of better volumetric sweep from a less dense gas mixture, a mixture of five percent by volume of plant gas and 95 percent $\mathrm{CO}_{2}$ is the recommended injection system for this field test. This dilution should allow gravity forces to augment the vaporization process and should result in an optimum tradeoff between the process efficiency and the sweep efficiency.

A log-inject-log test in SU A-17 from 12910-12920 ft found the residual oil saturation in this interval to be $20-22 \%$. The open and cased hole log data indicate a free gas saturation of 6 to $10 \%$ is also present in this interval. The open hole $\log$ data are consistent with the value of $\mathrm{S}_{\text {or }}$ found in the log-inject-log test.

\section{References}

1. Holm, L. W. and Josendal, V. A. (1974), Mechanisms of Oil Displacement by Carbon Dioxide, Journal of Pet. Technology, December, p. 1427-38.

2. Dumore, J. M. (1964), Stability Considerations in Downward Miscible Displacments, SPEJ, pp 356-362, December.

3. Chuoke, R, L., Van Meurs, P., Vander Poel, C. (1959), The Instability of Slow, Immiscible, Viscous Liquid-Liquid Displacements in Permeability Media, Petro. Trans., AIME, v 216, pp 188-194.

4. (1976), Technical Proposal Gravity Stable Miscible $\mathrm{CO}_{2}$ Displacement "S" Sand Reservoir B Weeks Island Field, Iberia Parish, Louisiana, Southern E\&P Region, New Orleans, January.

5. Robinson, J. D. (1974), Neutron Decay Time in the Subsurface: Theory, Experiment, and an Application to Residual Oil Determination, SPE 5119, October.

6. Robinson, J. D. (1974), United States Patent No. 3,852,593, Pulsed Neutron Capture Logging for Determining Residual Oil, December 3.

7. Schlumberger Limited, Report (1976-77), Departure Curves for the Thermal Decay Time Log and Log Interpretation Charts. 


\begin{abstract}
APPENDIX A
Experimental Displacements of Weeks Island "S" Sand

Oil with $\mathrm{CO}_{2}$ and Hydrocarbon Gases
\end{abstract}

Introduction

Several high pressure, high temperature sandpack displacements of Weeks Island "S" sand crude have been conducted to study the vertical displacement of oil by $\mathrm{CO}_{2}$ injection as an enhanced oil recovery process for this reservoir. The purpose of these experiments is to provide the evidence necessary to decide on an injection composition. Based on our experimental results shown in this appendix and Appendix $\mathrm{B}, \mathrm{CO}_{2}$ injection is not a miscible process at the expected reservoir conditions but a $\mathrm{CO}_{2}$-crude oil vaporization process. The properties of the injected gas or mixture of gases are important to process performance.

At "S" Sand Reservoir B (SRB) conditions of about $225^{\circ} \mathrm{F}$, about $5100 \mathrm{psi}$ and saturated crude, $\mathrm{CO}_{2}$ is more dense than the reservoir oil (about $0.686 \mathrm{~g} / \mathrm{cc}$ versus about $0.667 \mathrm{~g} / \mathrm{cc}$ ). If these densities persist during a downward vertical displacement of SRB crude by $\mathrm{CO}_{2}$, instability and low oil recovery would occur. However, based on the experimental phase behavior results which are reported in Appendix $\mathrm{B}$, properties of the individual phases which occur after mixing $\mathrm{CO}_{2}$ and crude define the stability. Slim tube sandpack experiments show that the $\mathrm{CO}_{2}$ displacements are stable and result in good oil recovery.

To investigate the importance of the density of the injected gas, mixtures of plant gas and $\mathrm{CO}_{2}$ were used as displacing fluids in vertical sandpacks. Additional vertical displacements in sandpacks with $\mathrm{CO}_{2}$ and $\mathrm{CO}_{2}$-plant gas mixtures have been conducted to show the sensitivity of rate and reservoir pressure to process performance. These results are compared to a miscible (propane) displacement and to displacements of crudes from two other fields by $\mathrm{CO}_{2}$ injection to illustrate the mechanisms involved in the sandpack floods.

Experimental Procedure

The sandpacks were fabricated using $5 / 16$ inch stainless tubing five feet long, firmly packed with 170-200 mesh Ottawa sand. The pore volume was about $25 \mathrm{cc}$ ( $34 \%$ porosity) and the pack permeability was on the order of 10 darcies. Separator liquid and gas samples from the "S" sand Reservoir "B" in well A-16-A were recombined at a GOR of 1073 SCF/STB. This yielded a mixture with a bubble point of 5060 psig at $225^{\circ} \mathrm{F}$. The measured viscosity at the same conditions was $0.334 \mathrm{cp}$ and the density was $0.6669 \mathrm{~g} / \mathrm{cc}$. The composition of the 5060 psig bubble point crude is shown in Table A-1.

The miscibility studies were conducted in a five-foot vertical sandpack at $5180 \mathrm{psig}$ and $225^{\circ} \mathrm{F}$. For one of these runs, this mixture was flashed to 4675 psig and a run was performed at 4800 psig. 
In a typical displacement the evacuated sandpack was filled with a solvent at the run pressure. The recombined fluid was then introduced into the top of the pack as the solvent was removed from the bottom to a receiver filled with mercury. The mercury was withdrawn from the receiver at a constant rate by a RUSKA pump. The system pressure was maintained by a large high pressure gas source which displaced mercury into the bottom of the source vessel containing the recombined fluid. After the sandpack was completely filled with recombined reservoir fluid, the displacing gas mixture was introduced into the top of the sandpack. The sandpack effluent passed through a visual cell for direct observation of the displacement. The same procedure was used to displace the recombined reservoir fluid with displacing gas. See Figure A-1 for a schematic diagram of the experimental procedures.

As the fluids were withdrawn from the sandpack, a light passing through the windowed cell allowed both visual observation and measurement of transmitted light intensity by means of photo resistor in a bridge circuit connected to a strip-type chart recorder. We have found that the amount of light transmitted through the effluent of the displacement can be a qualitative measure of miscibility achieved during sandpack displacements. The amount of oil recovered after any laboratory displacement would be a most important evaluation parameter; however, because of experimental uncertainties in fluid volumes during high pressure gas displacements, the gas breakthrough time and shape of the light transmittance response proved to be the best gauge of performance for these experiments. The time of gas breakthrough in terms of pore volumes injected is not accurate enough to distinguish between breakthrough times within several percent PV.

\section{Results of Sandpack Displacements}

Sandpack flood results are shown as plots of light transmittance (through the sandpack effluent) versus pore volumes injected (and produced) as read from the strip-type chart recordings of each experiment. To show the type of response one can expect when a miscible displacement results, Figure A-2 presents the response from a fully miscible propane - Weeks Island crude flood. This response is then a benchmark of miscibility characterized by a several percent PV transition interval of zero to full transmittance and gas breakthrough (start of increase in light transmittance) at near 1.0 PV.

Three sandpack displacements of SRB crude with $\mathrm{CO}_{2}$ plus zero, five and ten percent $C_{1}$ * are shown in Figures $A-3, A-4$ and $A-5$. All three experiments were conducted at a frontal advance rate of about $1.2 \mathrm{ft} /$ day. The $5 \%$ and $10 \% \mathrm{C}_{1}-\mathrm{CO}_{2}$ displacements are qualitatively indistinguishable. Both indicate

*

All references to $C_{1}$ dilutions are actually plant gas dilutions which is about $97-98 \% \mathrm{C}_{1}$. 
a $94 \pm \%$ PV breakthrough and a very steep transition interval of light transmittance. Both floods were effective in oil recovery but the shape of transmittance curve may be too steep in comparison with the propane displacement which was genuinely miscible. Using $100 \% \mathrm{CO}_{2}$ as shown in Figure $\mathrm{A}-3$, resulted in an improved recovery from the standpoint of gas breakthrough time and character of transmittance curve.

Figure A-6 shows the results of pure $\mathrm{CO}_{2}$ in downward displacements at a slow rate $\left(0.6 \mathrm{ft} /\right.$ day) Compare this flood with ${ }^{2}$ Figure $\mathrm{A}-3$, a $100 \% \mathrm{CO}$ displacement at $1.2 \mathrm{ft} /$ day. The slow rate flood probably comes as close to a miscible displacement with $\mathrm{CO}_{2}$ as we may have observed at these conditions. Note the long transmittance transition intervals particularly in Figure A-6. Floods at both rates show that even though $\mathrm{CO}_{2}$ is more dense than the crude oil, a gravity stability is achieved. This phenomena is probably the result of the $\mathrm{CO}_{2}$ going in solution with the crude causing the lightest hydrocarbon components to ${ }^{2}$ be liberated as a gas. The oil density is increased with the $\mathrm{CO}_{2}$ in solution and the displacing gas phase is lightened (less dense) with liberation of light hydrocarbons from the liquid phase. See reference 1 for a discussion of these mechanisms.

Figure A-7 shows the results of a sandpack displacement using plant gas. The high recovery at breakthrough $(0.89 \pm \%$ PV) indicates that there is probably a considerable amount of gravity drainage in a sandpack vertical flood. This would also account for some of the favorable recoveries of breakthrough in the other runs. This is probably one of the factors in the more favorable results in the $0.6 \mathrm{ft} /$ day, $100 \% \mathrm{CO}_{2}$ versus the $1.2 \mathrm{ft} /$ day, $100 \% \mathrm{CO}_{2}$ (Figure A-3) displacements.

In a previously unreported set of vertical displacement experiments performed in 1966 at this laboratory on a West Texas crude, $\mathrm{CO}_{2}$ was used as the displacing fluid. In the first run, breakthrough was observed at $0.87 \mathrm{PV}$ with injection at a displacement rate of $22 \mathrm{ft} /$ day. Since this appeared to be early for breakthrough, the densities of both fluids were determined. The density of the $\mathrm{CO}_{2} \mathrm{Q} 2050 \mathrm{psig}$ and $106^{\circ} \mathrm{F}$ was $0.7501 \mathrm{~g} / \mathrm{cc}$ and the density of the recombined sample was $0.6339 \mathrm{~g} / \mathrm{cc}$. Hence, it was decided that with this apparent gravity instability, the $\mathrm{CO}_{2}$ should be injected at the bottom of the pack. The injection rate was reduced to $8 \mathrm{ft} /$ day to further improve the displacement stability. Results were very poor; breakthrough occurred at $0.49 \mathrm{PV}$. The downward displacement was repeated at $6 \mathrm{ft} /$ day and the breakthrough occurred at 0.95 PV.

These results seem consistent with our conceptual understanding of the process mechanisms and phase behavior experimental data. We believe that in spite of the seemingly unfavorable density contrast between the reservoir crude and $\mathrm{CO}_{2}$, gravity stability is achieved by the exchange of $\mathrm{CO}_{2}$ for light hydrocarbons in the crude and dilution of $\mathrm{CO}_{2}$ by light hydrocarbons in the gaseous driving fluid. Further, we suspect that the unsuccessful displacement from the bottom of the sandpack failed for the same reasons of $\mathrm{CO}_{2}$ light hydrocarbon exchange. When $\mathrm{CO}_{2}$ was injected into the bottom of the sandpack, the light 
hydrocarbon gas which was liberated, probably percolated upward creating flow paths which the $\mathrm{CO}_{2}$ preferred to follow. This resulted in poor sweep of the sandpack and poor oil recovery.

Summary

These experimental results show that $\mathrm{CO}_{2}$ alone or mixtures of $\mathrm{CO}_{2}$ and plant gas are more efficient than plant gas in displacing oil. The increased recovery efficiency performance is due to the extraction of some hydrocarbon fractions of the crude oil in the $\mathrm{CO}_{2}$. Pure $\mathrm{CO}_{2}$ establishes gravity stability in a vertical displacement even though $\mathrm{CO}_{2}$ is more dense than SRB oil at reservoir conditions. Although miscibility will not be fully developed under expected reservoir conditions, pure $\mathrm{CO}_{2}$ and $\mathrm{CO}_{2}$ diluted with up to $10 \%$ plant gas will approach miscible-like displacement performance, with perhaps $100 \% \mathrm{CO}_{2}$ achieving this condition more closely than mixtures diluted with plant gas.

One must remember that slim tube, sandpack, displacements such as these cannot be readily scaled for field application. The results are qualitative and are good for screening injection systems. Other tools are necessary to apply the results of the screen. 
Table A-1

Analysis of Fluid

Component

Carbon Dioxide

Nitrogen

Methane

Ethane

Propane

i-Butane

n-Butane

i-Pentane

$\mathrm{n}$-Pentane

Hexanes

Heptanes Plus
Mol $\%$

5.66

3.91

46.69

5.76

1.82

0.60

2.09

0.30

0.50

0.79

31.88

Properties of Heptanes Plus:

Sp. Gr.

Mol. Wt.
0.8712

240

Density of Recombined fluid at $5180 \mathrm{psig}$ and $225^{\circ} \mathrm{F}=0.6669 \mathrm{~g} / \mathrm{cc}$ Viscosity of Recombined Fluid at $5180 \mathrm{psig}$ and $225^{\circ} \mathrm{F}=0.334 \mathrm{cp}$ F.V.F. $=1.563$ bbls saturated crude per barrel S.T. oil at 14.69 psia and $60^{\circ} \mathrm{F}$ 


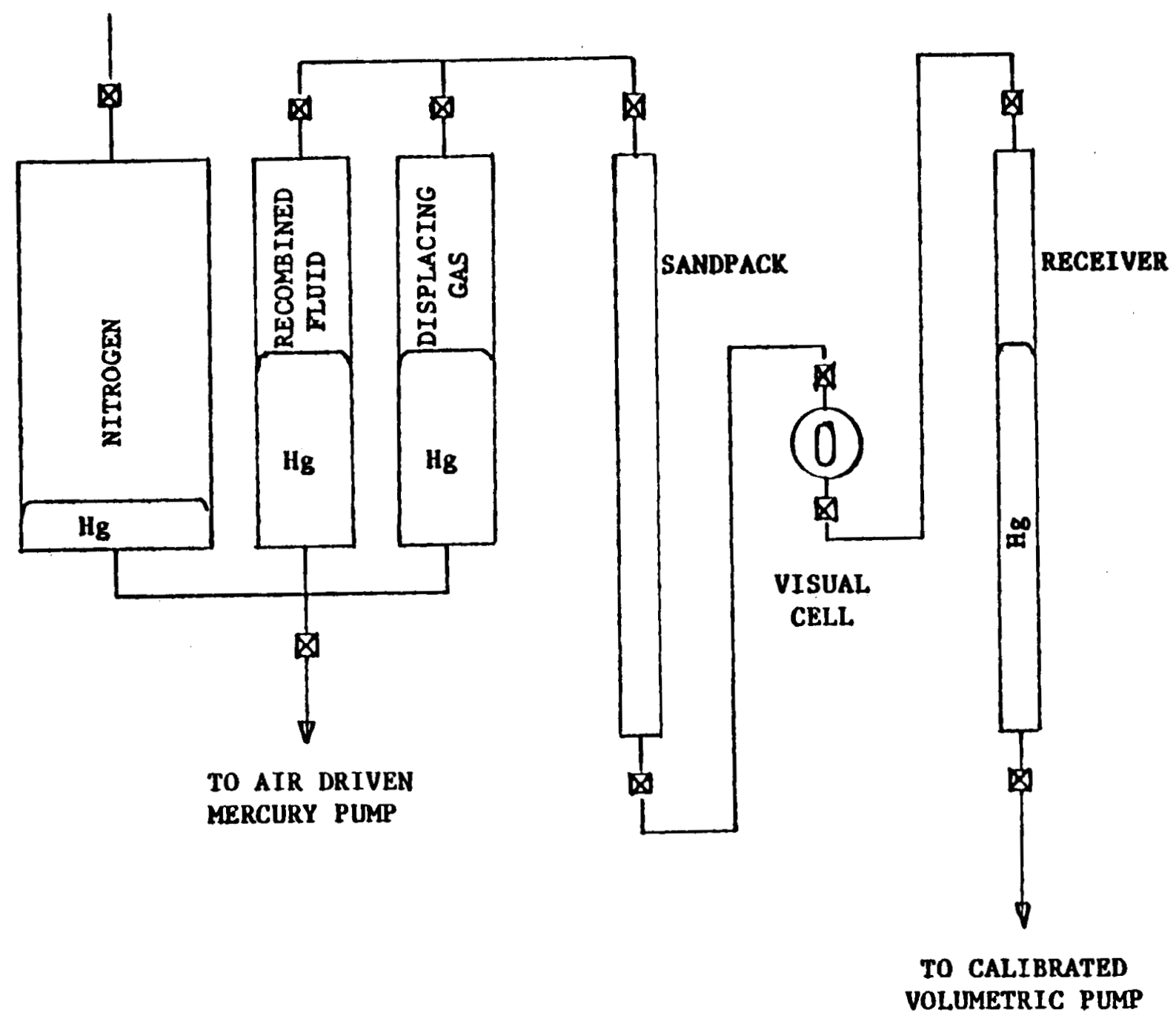

$\frac{\pi}{0}$
$\mathbf{C}$
D
$m$
$\underline{P}$

Fig. A-1 - Schematic diagram of apparatus. 


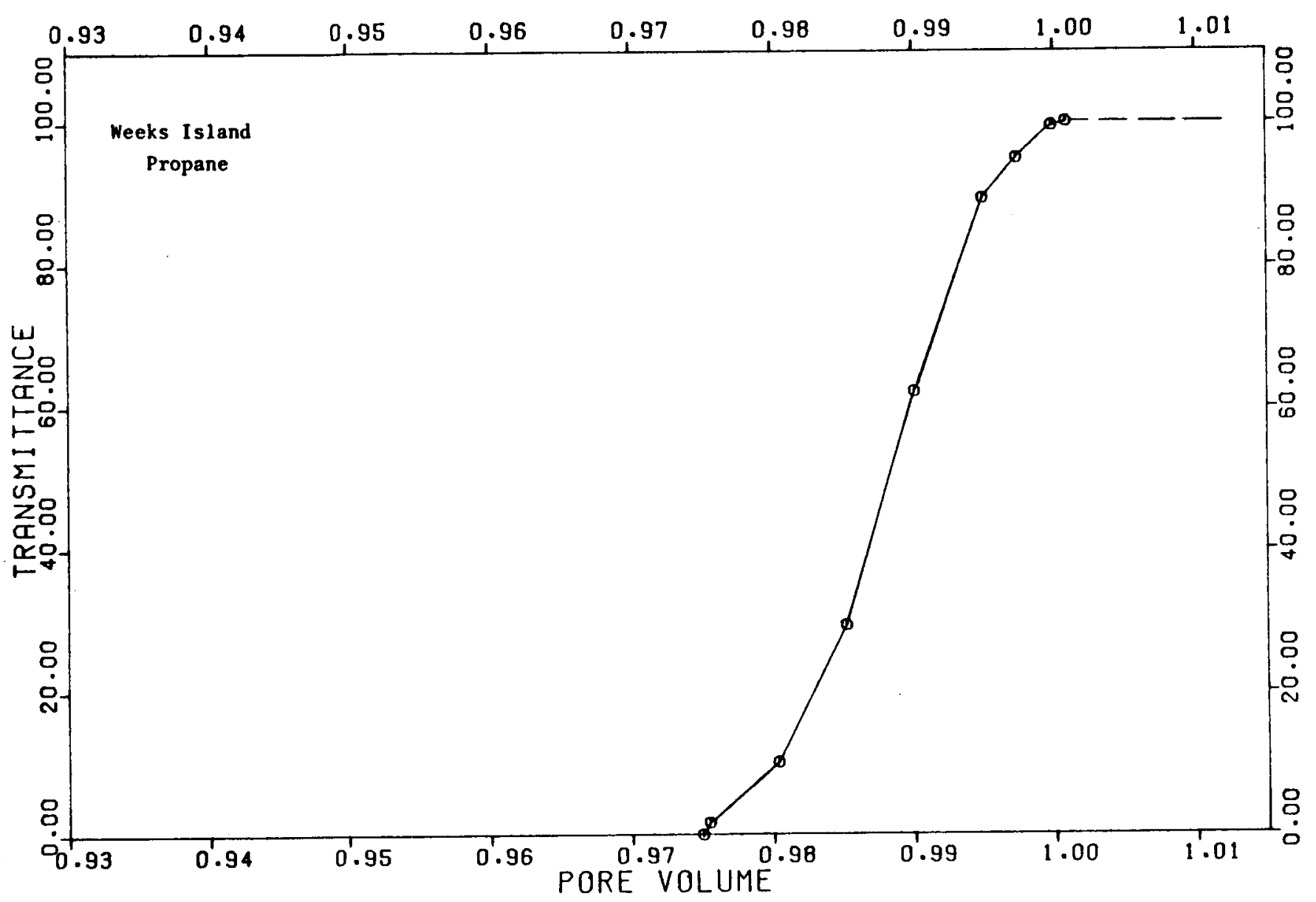

Fig. A-2 - Sandpack displacemnt - light transmittance vs pore volumes injected - Weeks Island crude with propane. 


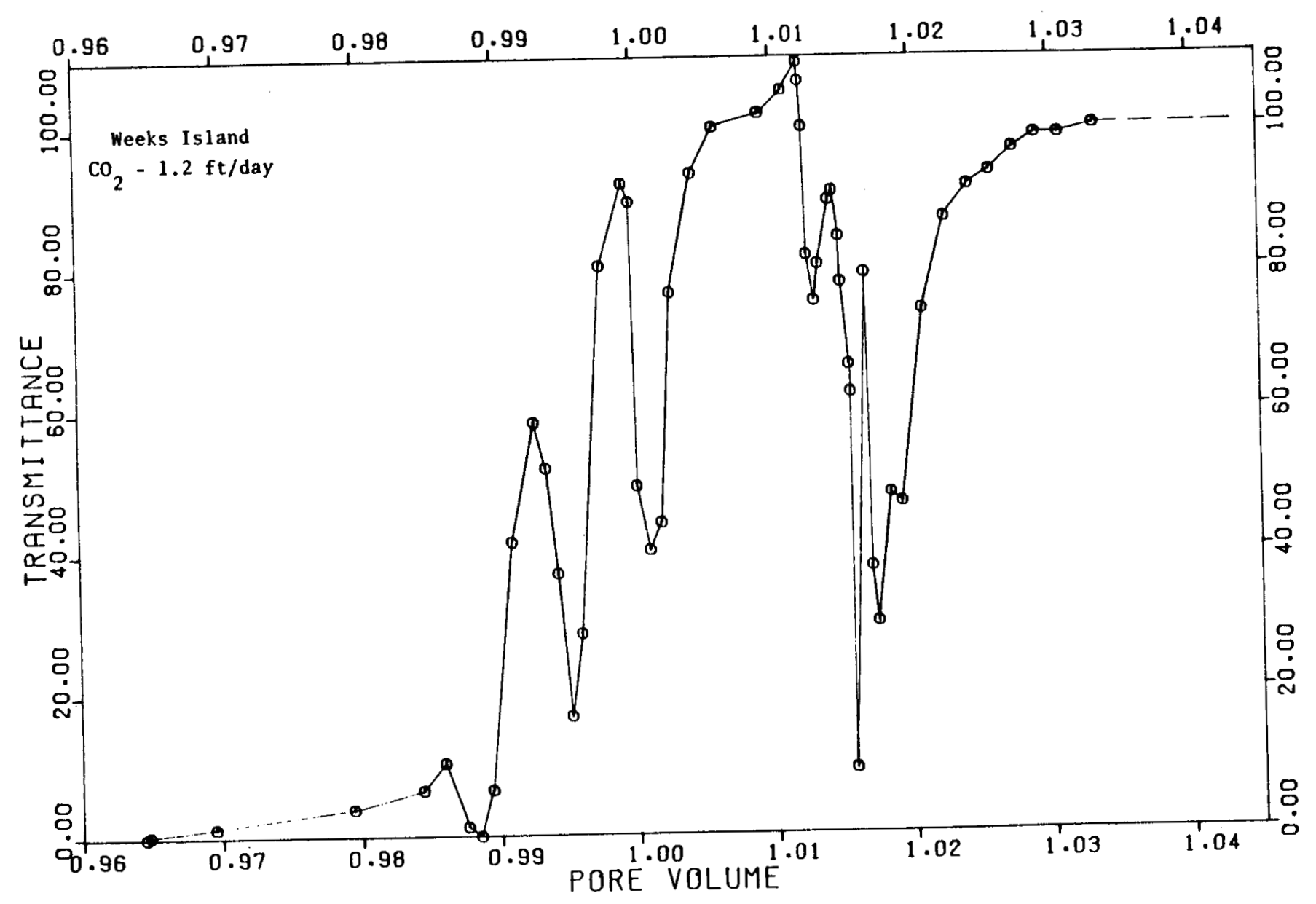

Fig. A-3 - Sandpack displacement - 1ight transmittance vs pore volumes injected - SRB crude with $\mathrm{CO}_{2}$ at about $1.2 \mathrm{ft} / \mathrm{day}$. 


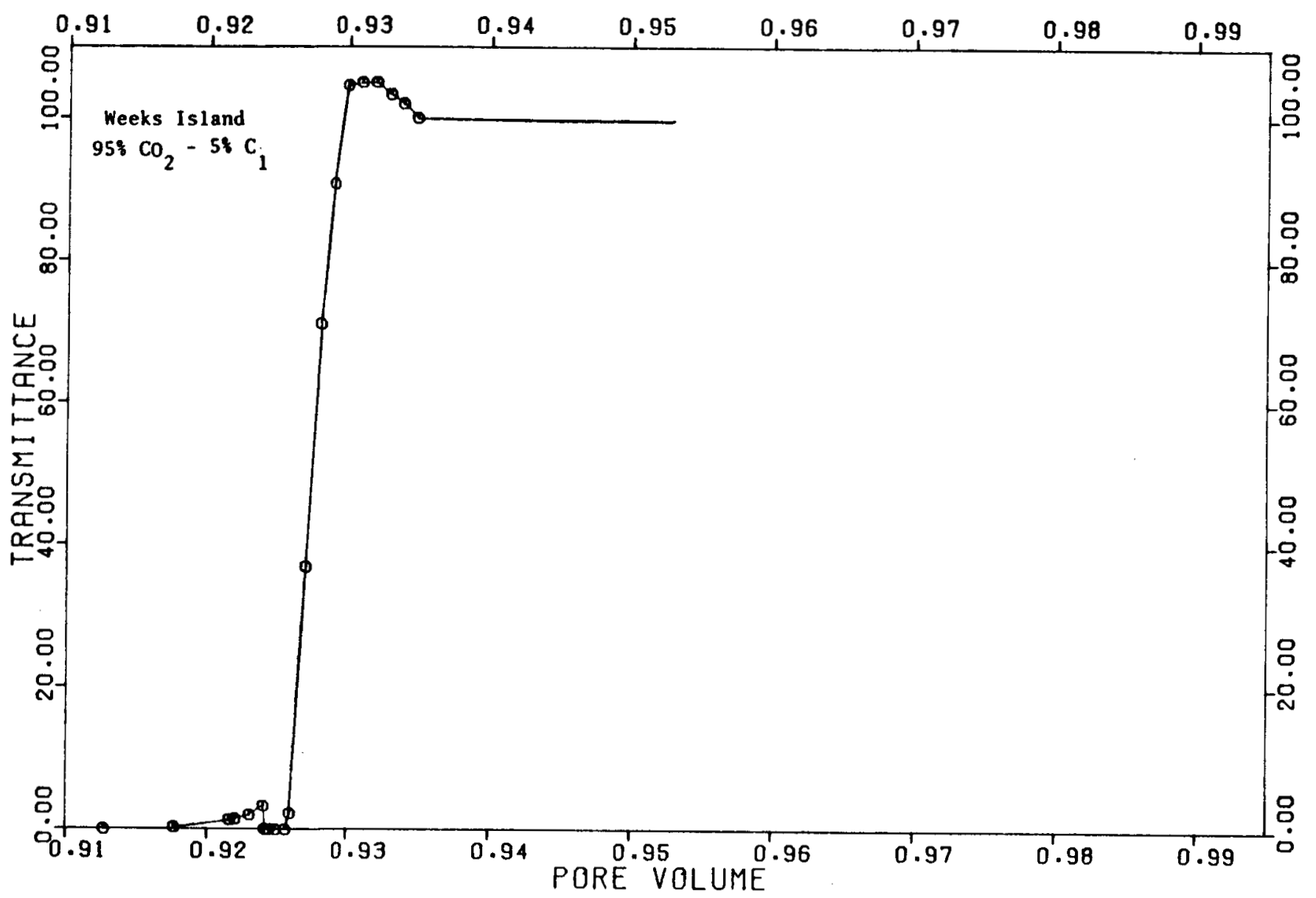

Fig. A-4 - Sandpack displacement - light transmittance vs pore volumes injected - SRB crude with $95 \% \mathrm{CO}_{2}-5 \%$ PG at about $1.2 \mathrm{ft} / \mathrm{day}$. 


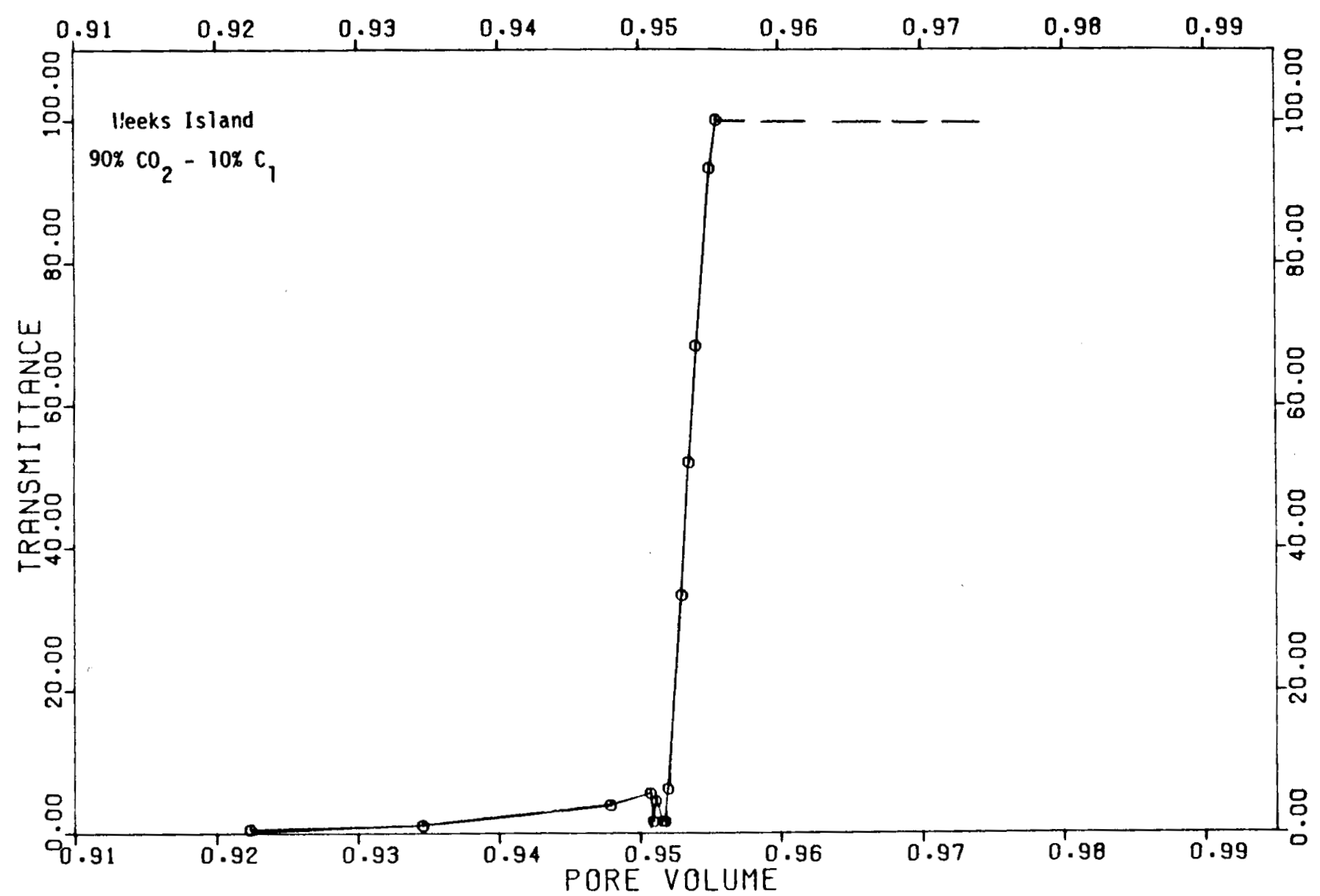

Fig. A-5 - Sandpack displacement - light transmittacne vs pore volumes injected - SRB crude with $90 \% \mathrm{v} \mathrm{CO}_{2}-10 \%$ PG at about $1.2 \mathrm{ft} / \mathrm{day}$. 


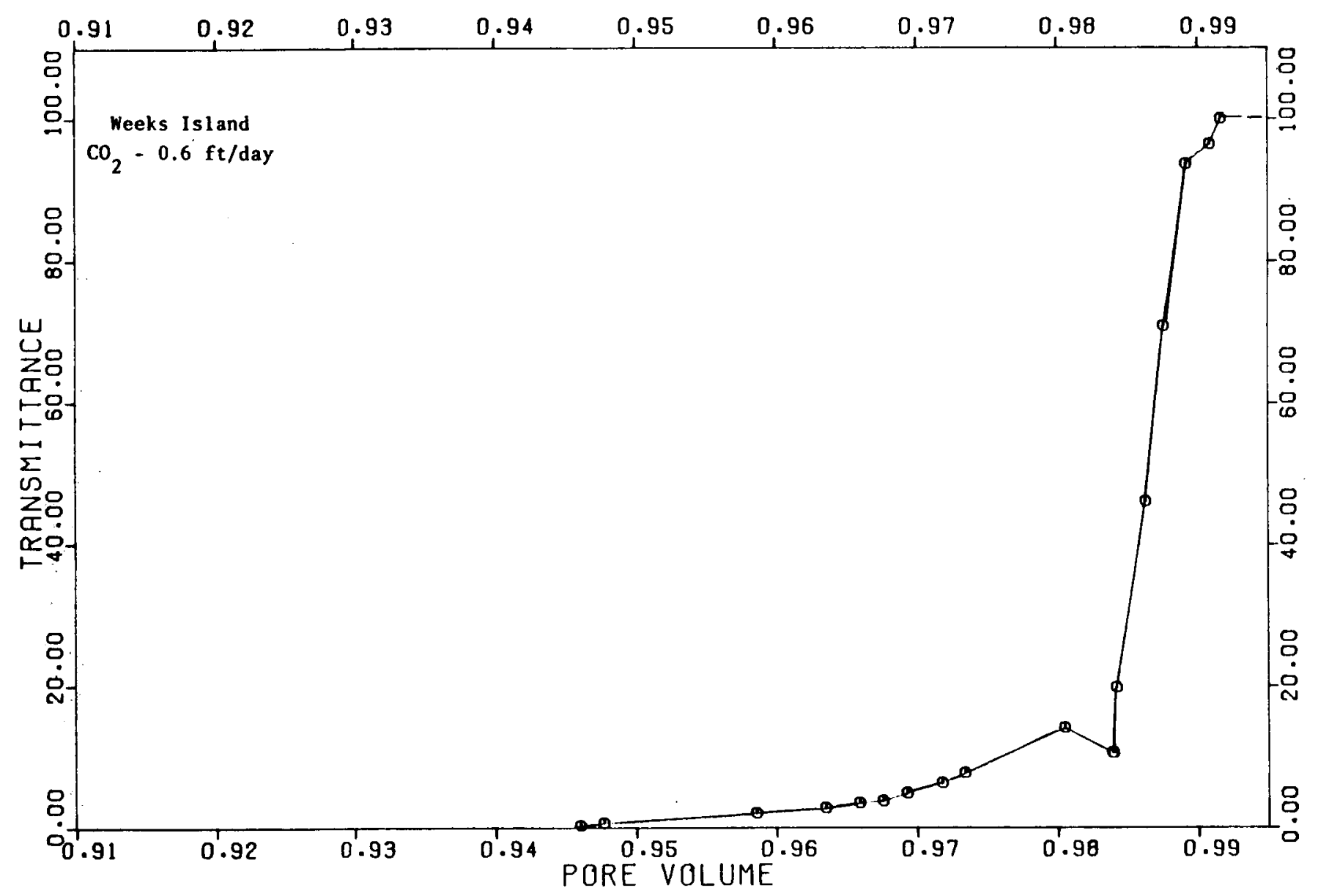

Fig. A-6 - Sandpack displacement - light transmittance vs pore volumes injected - SRB crude with $\mathrm{CO}_{2}$ at about $0.6 \mathrm{ft} /$ day. 


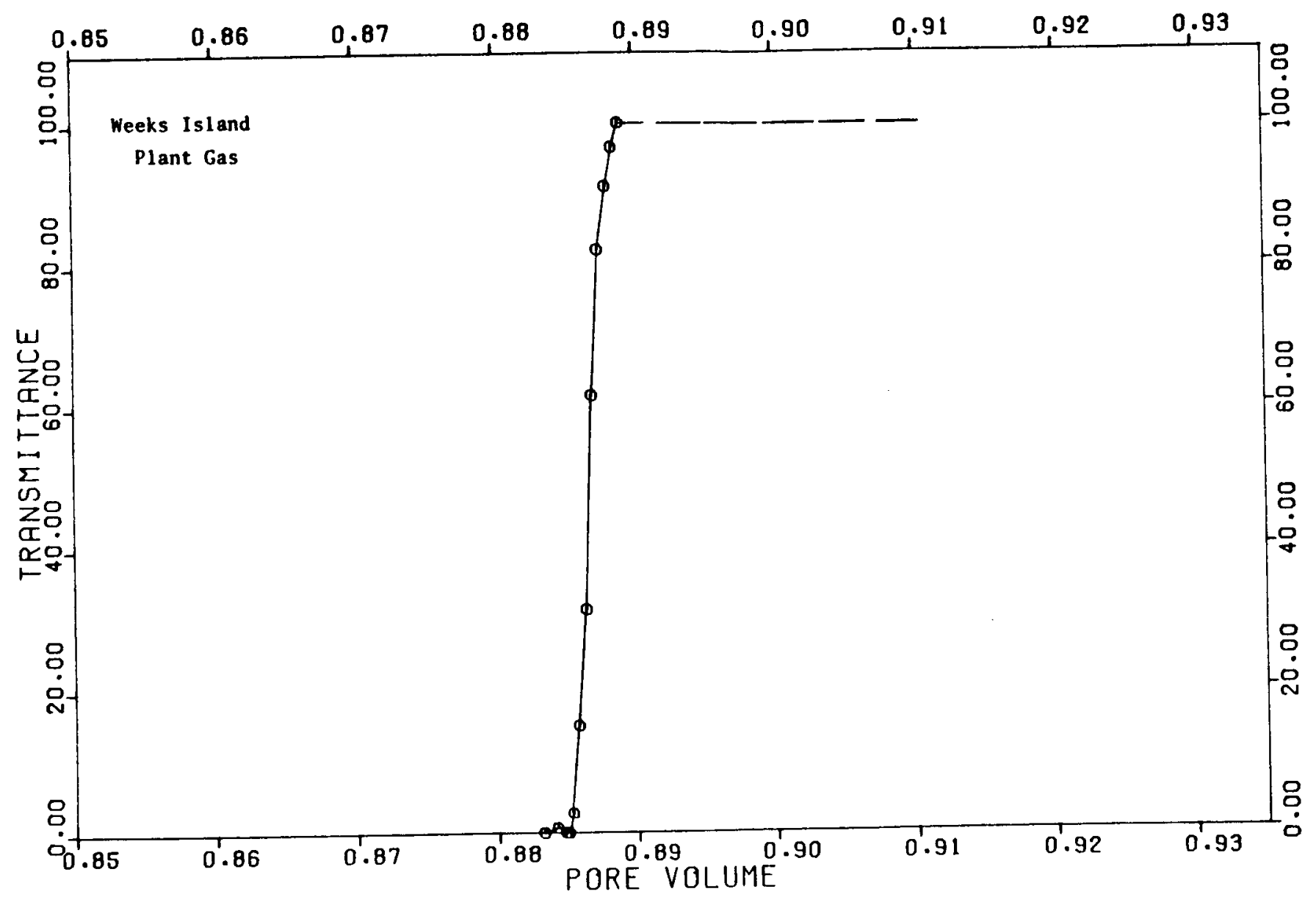

Fig. A-7 - Sandpack displacement - light transmittance vs pore volumes injected - SRB crude with plant gas at about $1.2 \mathrm{ft} / \mathrm{day}$. 


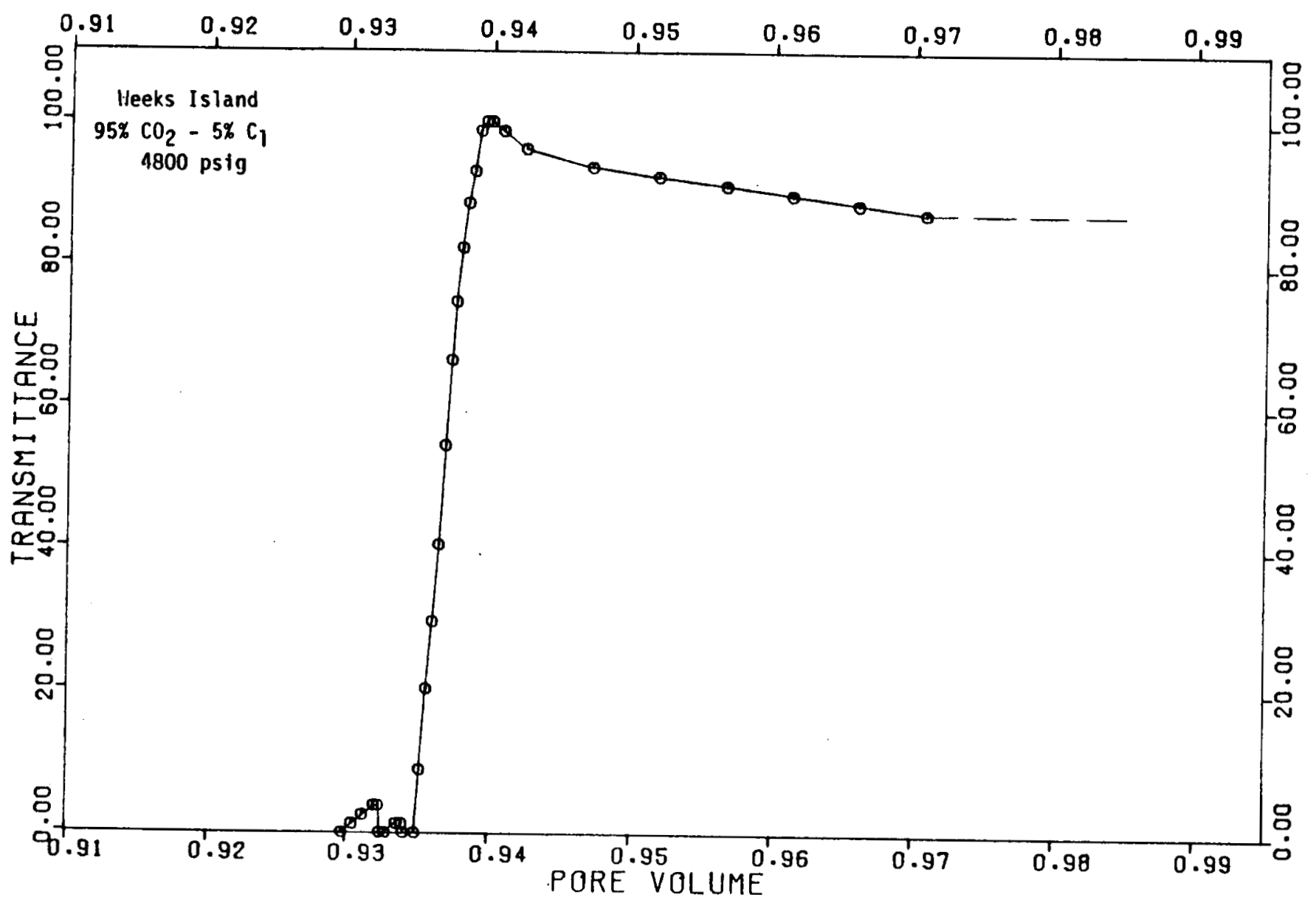

Fig. A-8 - Sandpack displacement - 1ight transmittance vs pore volumes injected - SRB crude with $95 \% \mathrm{~V} \mathrm{CO}_{2}-5 \% \mathrm{C}_{1}$ at about $1.2 \mathrm{ft} / \mathrm{day}$ and 4800 psig. 
APPENDIX B

Phase Behavior - Experimentation and Simulation - and Gravity Stability, Weeks Island $\mathrm{CO}_{2}$ Injection Project

\section{Introduction}

In this appendix the effect of phase behavior on the gravity stability of the Weeks Island $\mathrm{CO}_{2}$ pilot is considered. An equilibrium $K$-value fluid along a composition path similar to that which would be followed in the reservoir. The program was first used to match experimental phase behavior data which are also reported in this appendix.

Phase Behavior

One of the distinguishing features of the Weeks Island $\mathrm{SRB} \mathrm{CO}_{2}$ pilot is the fact that the $\mathrm{CO}_{2}$ flood will be conducted with a saturated ${ }^{2}$ crude. In order to evaluate the significance of this, consider the single contact phase diagram based on experimental data for recombined Weeks Island SRB crude (RRF) and a mixture of $95 \% \mathrm{CO}_{2}$ and $5 \%$ plant gas $\left(\mathrm{CO}_{2} \mathrm{PG}\right)$ shown in Fig. $\mathrm{B}-1$. Table B-1 gives the composition of the two fluids used in the experiments. Section $A-A^{\prime}$ is the composition path which would be followed for $\mathrm{CO}_{2} P . \mathrm{G}$ additions to the RRF at a constant pressure $P_{A}$ equal to the bubble point pressure ( $\left.P_{b}\right)$ of the oil. Section $B-B^{\prime}$ shows the composition path taken for additions at a pressure above $P_{b p}$ but below the critical pressure $P_{c r i t}$ and $C-C$ ' shows the path for a pressure $\mathrm{P}_{\mathrm{C}}^{\mathrm{b}}>\mathrm{P}_{\text {crit }}$.

In Figure B-2 the volume percent of "second phase" is plotted versus mole $\% \mathrm{CO}_{2} P G$ for the above three pressures. The term "second phase" is used since the character of the phase split depends on whether the two phase region is entered through a dewpoint, in which case the new phase which appears is a liquid, or through a bubble point, in which case the second phase is a vapor.

Figure $B-2$ shows that for $P_{A}=P_{b p}$, the very first $\mathrm{CO}_{2} P G$ addition results in the formation of two phases, and in this case the second phase is a vapor. On continued addition of $\mathrm{CO}_{2} \mathrm{PG}$, the volume fraction of the second phase grows until at high $\mathrm{CO}_{2} P G$ concentrations essentially all of the liquid has been extracted into the vapor phase. For pressure $P_{B}$ where $P_{b p}<P_{B}<P_{C}$, it is possible to dissolve appreciable amounts of the ${ }^{B} \mathrm{CO}_{2} P G$ into the undersaturated oil before a phase split occurs, as illustrated by the curve marked $P_{B}$ in Figure B-2. Again, since we are below the critical pressure for the system, the second phase is a vapor, and continued $\mathrm{CO}_{2} \mathrm{PG}$ addition results in an increasing volume fraction of second phase.

The situation is considerably different when the operating pressure is above the critical pressure (e.g., $\mathrm{P}$ on Figures $\mathrm{B}-1$ and $\mathrm{B}-2)$. In this case, a large amount of the $\mathrm{CO}_{2} \mathrm{PG}$ can be dissolved in the RRF before the two phase region 
is entered, and the two phase region is entered through a dewpoint so the second phase will be a liquid. Furthermore, the volume fraction of second phase goes through a maximum (as shown on Figure B-2) at about 10-20\%, depending on the pressure.

While the single cell equilibrium data do not fully describe the complex compositional paths which would occur in the reservoir, they do indicate a fundamental difference between a $\mathrm{CO}_{2}$ flood at a pressure above the critical pressure, where the displacement is essentially single phase, and a flood at the bubble point of the oil, where two phases form immediately and persist over the entire range of compositions. The operating pressure for the Weeks Island pilot falls in the second category where two phases are expected to persist during the $\mathrm{CO}_{2}$ displacement process.

Phase Behavior Simulation

An equilibrium K-value type fluid properties computer program has been used to model a sequence of multiple contact equilibrium experiments. The parameters in the phase package were modified to better describe the measured single cell equilibrium data. The cell to cell calculations were designed to follow the compositional path which might be followed in a gravity stable displacement. The procedure was to "mix" by simulation a volume $V_{L}$ of a reservoir fluid (RRF) with a volume $\mathrm{V}_{\mathrm{G}}$ of injection fluid $\left(\mathrm{CO}_{2} \mathrm{PG}\right)$ and calculate the resulting phase volumes, compositions, densities and viscosities. For the next step, a volume $\Delta V$ of liquid was "removed" while an equal volume of $\mathrm{CO}_{2} \mathrm{PG}$ was added to simulate at least part of the fluid mixing sequence which occurs in the reservoir. The phase volumes, etc. were again calculated and the procedure repeated for each. contact. Figure B-3 illustrates this procedure.

The first contact fluid was made up of 10 volume $\% \mathrm{CO}_{2} \mathrm{PG}, 90 \% \mathrm{RRF}$. For subsequent contacts, the volume of 1 iquid removed (and the volume of $\mathrm{CO}_{2} \mathrm{PG}$ added) was equal to $10 \%$ of the total system volume (i.e., $\Delta \mathrm{V}=0.1\left(\mathrm{~V}_{\mathrm{G}}+\mathrm{V}_{\mathrm{L}}\right)$.

Results of Phase Behavior Simulation

Figure B-4 shows the volume fraction liquid calculated for each of the contacts simulated. Note that even after 10 contacts, the liquid saturation is still about $15 \%$, indicating the degree to which the $\mathrm{CO}_{2} \mathrm{PG}$ has swelled the oil.

Figure B-5 shows the densities calculated for the liquid and vapor phases for each contact. The points shown for contact number 0 are the densities of the RRF and the $\mathrm{CO}_{2} P G$. Note that there is a gradual increase in the liquid density resulting from the exchange of $\mathrm{CO}_{2}$ for the $\mathrm{CH}_{4}$ in the liquid phase. The more significant fact is that the gas phase resulting from the first contact $\left(90 \% \mathrm{RRF}\right.$ and $\left.10 \% \mathrm{CO}{ }_{2} \mathrm{PG}\right)$ is much lighter than the injected fluid. Although the gas phase density does increase with each subsequent contact, it has not gotten as high as the injected $\mathrm{CO}_{2} \mathrm{PG}$ density after 10 contacts. 
Figure B-6 shows the calculated viscosities for the two phases as a function of contact. Here we see that, as a result of the transfer of $\mathrm{CO}_{2}$ from the vapor to liquid phase and the resulting net movement of lighter components from the liquid to vapor phase, the liquid viscosity decreases with the contacts while the vapor phase viscosities increase up to seven contacts after which little change is observed.

Effect of Phase Behavior on Gravity Stability

Because of the high permeability $(\sim 3500 \mathrm{md})$, high dip $\left(\sim 34^{\circ}\right)$ and low displacement rate $(\sim 0.03 \mathrm{ft} /$ day), it is hoped that gravity forces will stabilize the $\mathrm{CO}_{2}$ displacement front.

In order to achieve gravity stability, the original pilot design called for dilution of the injected $\mathrm{CO}_{2}$ with Weeks Island plant gas to increase the density difference between the injected gas and the reservoir oil. Using Dumore's analysis for estimating the stable and critical velocities for gravity dominated miscible displacements, it was estimated that at least $5 \%$ plant gas be added to the $\mathrm{CO}_{2}$. However, in light of the phase behavior discussed above, it appears that 3 using a two phase stability analysis, is in order. According to Chuoke, et al, for immiscible displacements the critical or maximum stable rate is given by

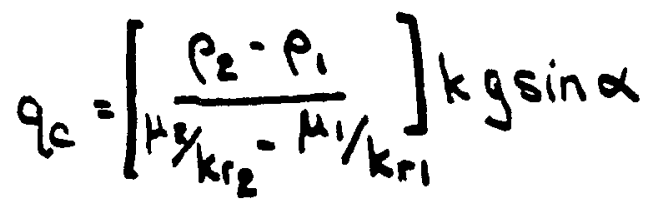

where subscript 2 refers to the displaced fluid and subscript 1 refers to the displacing fluid. Figure $B-7$ shows the critical rate calculated from eqn (1) as a function of contact number using the data of Table B-2 and Figures B-5 and B-6. Although the critical rate for $\mathrm{CO}_{2} P G$ vapor displacing RRF (contact " $O$ " on Figure $\mathrm{B}-7$ ) is about $0.4 \mathrm{ft} /$ day, mass transfer between the phases leads to an immediate increase in the critical rate, up to nearly $4.0 \mathrm{ft} /$ day after the first contact. As the density difference between the two phases becomes less on subsequent contacts, the critical rate slowly decreases until it appears to stabilize at about $2 \mathrm{ft} / \mathrm{day}$.

Also shown on Figure $B-7$ are the critical rates for oil displacing water $(0.63 \mathrm{ft} /$ day) and $\mathrm{CO} P$ PG displacing water $(0.58 \mathrm{ft} / \mathrm{day})$. These data indicate that it is the water displacement front which determines tbe maximum rate at which gravity forces will stabilize the process rather than the gasoil front. Furthermore, since the proposed displacement rate for the pilot of $0.03 \mathrm{ft} /$ day is well below the critical rate for $\mathrm{CO}_{2}$ PG displacing water, the process should be gravity stable. 
For comparison, the lowest critical rate line in Figure B-7 shows the stable rate for $\mathrm{CO}_{2} P G$ displacing RRF assuming complete miscibility. If (contrary to the phase behavior obtained experimentally or predicted) the $\mathrm{CO}_{2} \mathrm{PG}$ was completely miscible with the oil, $5 \%$ dilution of the injected $\mathrm{CO}_{2}$ by plant gas should be adequate to ensure gravity stability at a designed field displacement rate of $.03 \mathrm{ft} /$ day provided the permeability is on the order of $3500 \mathrm{md}$.

Some qualification of this analysis is necessary because there has been no distinction between secondary and tertiary displacements. The analysis presented above applies primarily to a secondary displacement, the Weeks Island pilot will be primarily a tertiary displacement. The stability of the SRB displacement will not depend only on hydrocarbon-rich liquid phase- $\mathrm{CO}_{2}$ rich gas phase density differences, but also on the density difference between the water and the gas phases. This particularily applies during a tertiary displacement because moveable water saturation must be displaced before residual oil is mobilized and displaced by $\mathrm{CO}_{2}$. Further, in the oil bank, some water will be transported simultaneously with oil, at least over much of the traverse.

The density difference which is the most important to the stability of the displacement is probably something intermediate to the $\mathrm{CO}_{2}$-oil (phase behavior) differences and the $\mathrm{CO}_{2}$-water difference. Therefore, the $5 \%$ plant gas dilution is really more adequate for stability for the SRB pilot than implied from Figure B-7. 
Composition of Weeks Island Reservoir

Fluid and Injection Gas
$\underline{\mathrm{RRF}}$

.0083

.5677

.0322

.0181

.0106

.0111

.0117

$\mathrm{C7}^{+}$

.3404

$\mathrm{P}_{\mathrm{bp}} \Subset 225^{\circ} \mathrm{F}=5100 \mathrm{psia}$ 
TABLE B-2

Data Used in Estimating Critical Rates

$$
\begin{aligned}
& k=3500 \mathrm{md} \\
& \alpha=34^{\circ} \\
& k_{r o}=0.5 \\
& k_{r g}=1.0 \\
& k_{r w}=0.1 \\
& \rho_{w}=0.94 \mathrm{~g} / \mathrm{cc} \\
& \mu_{w}=0.28 \mathrm{cp}
\end{aligned}
$$




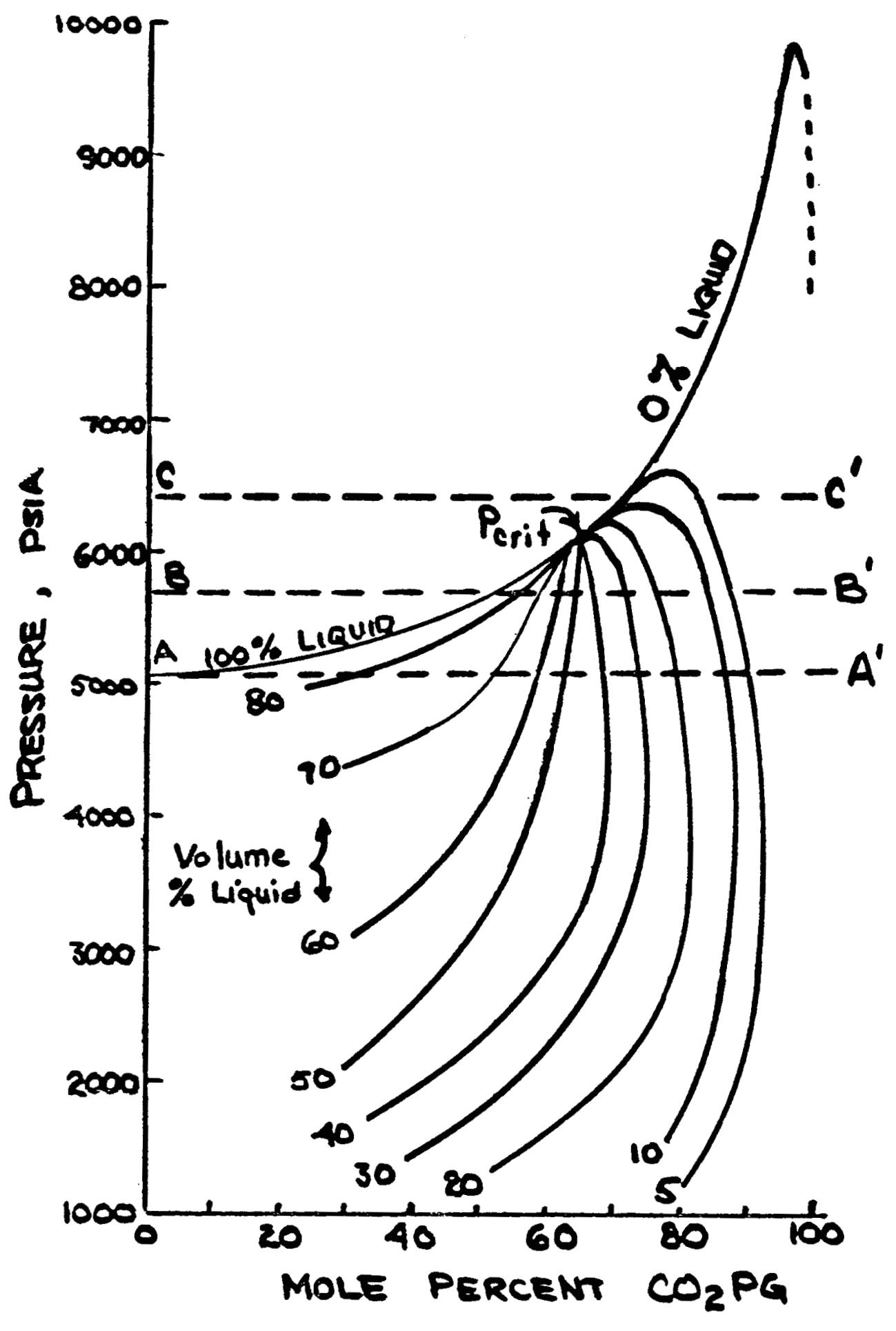

48

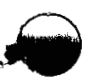


49

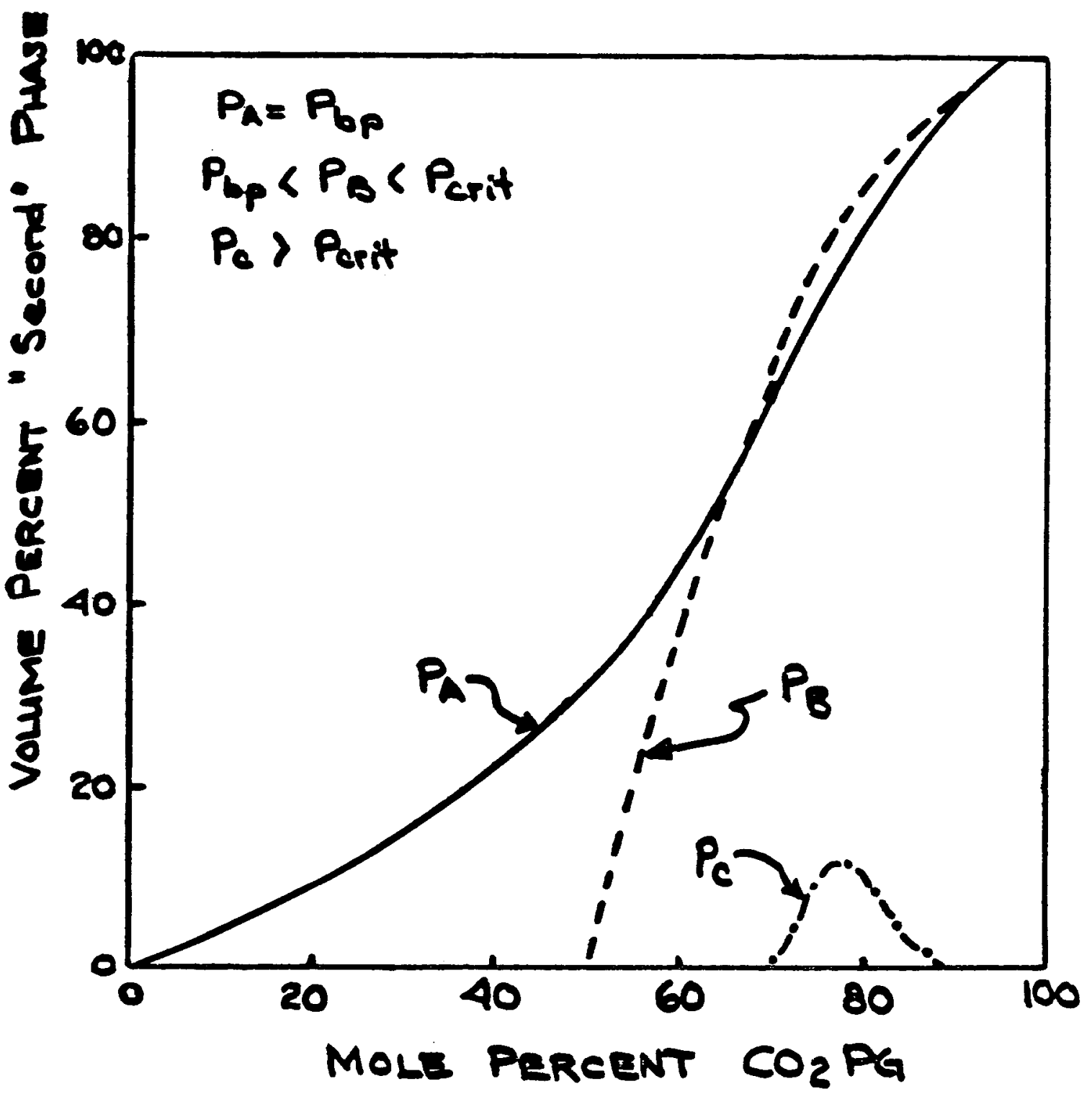

Fig. B-2 - Volume percent "second" phase for various pressures based on single contact equilibrium experiments.

FIGURE BD 


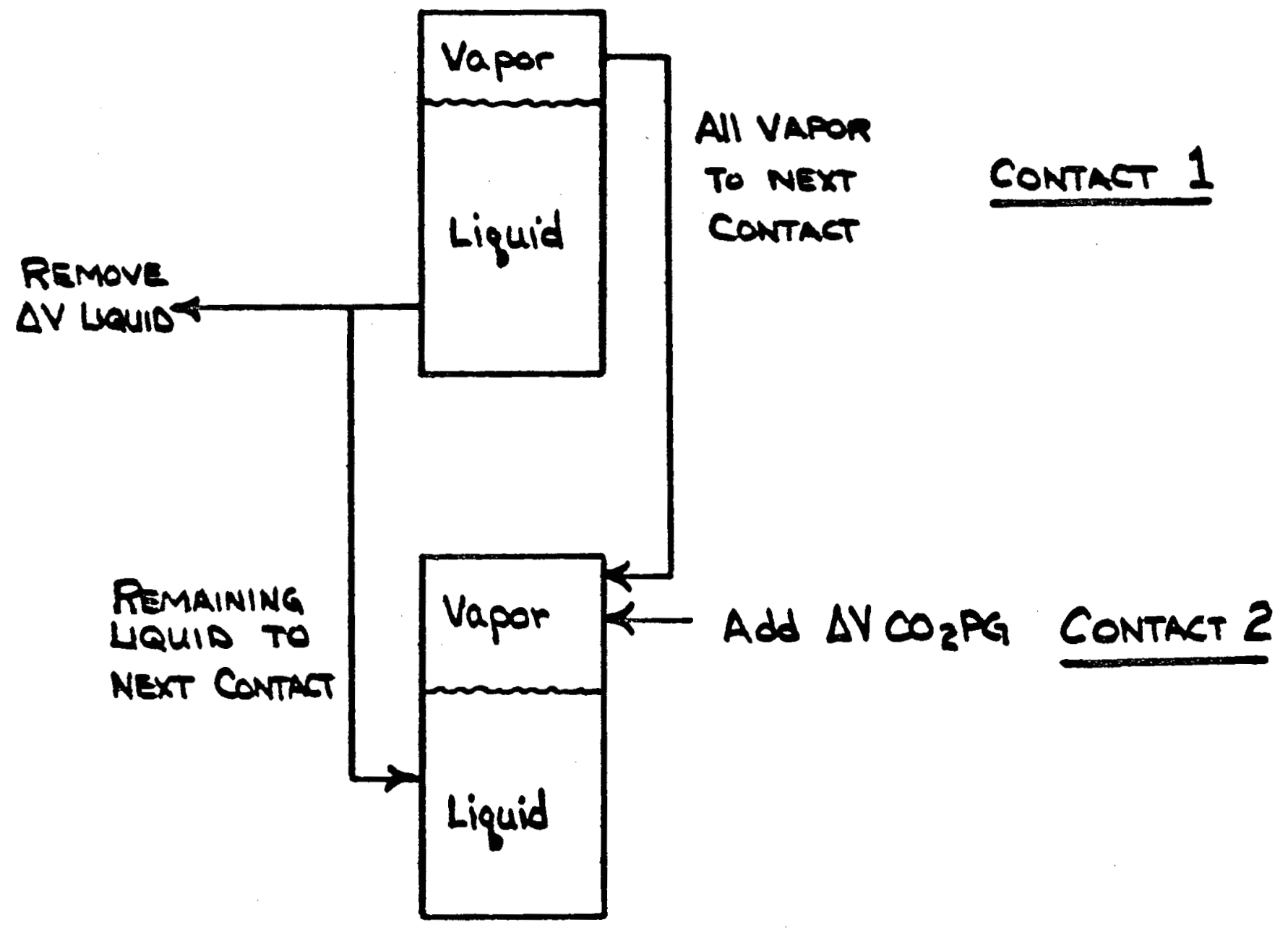

Fig. B-3 - Schematic of fluid transfers for multiple contact simulations. 


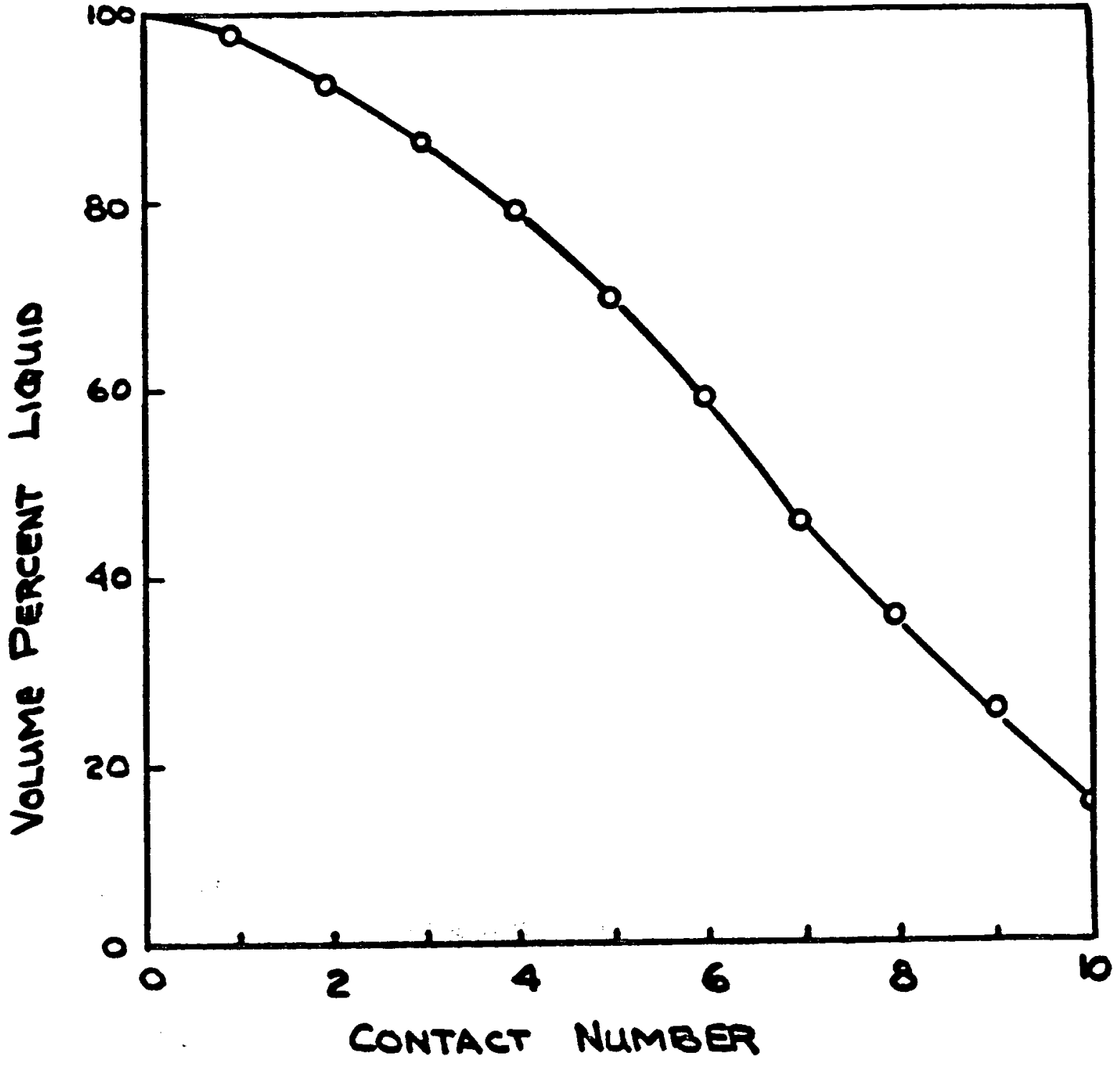

Fig. B-4 - Volume percent liquid calculated for multiple contact simulations. i 
52

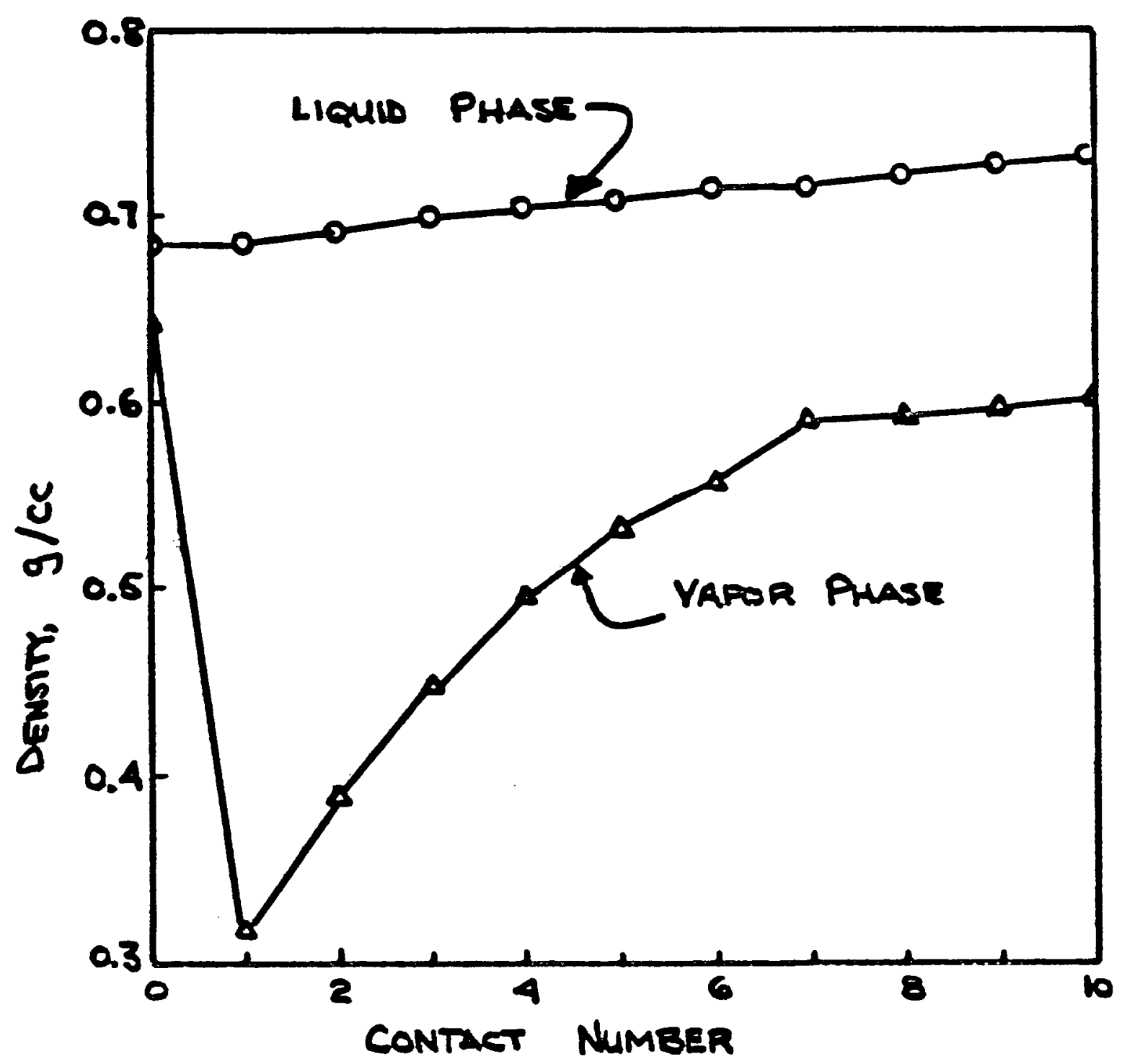

Fig. B-5 - Phase densities calculated for multiple contacts.

FIGURE BD 


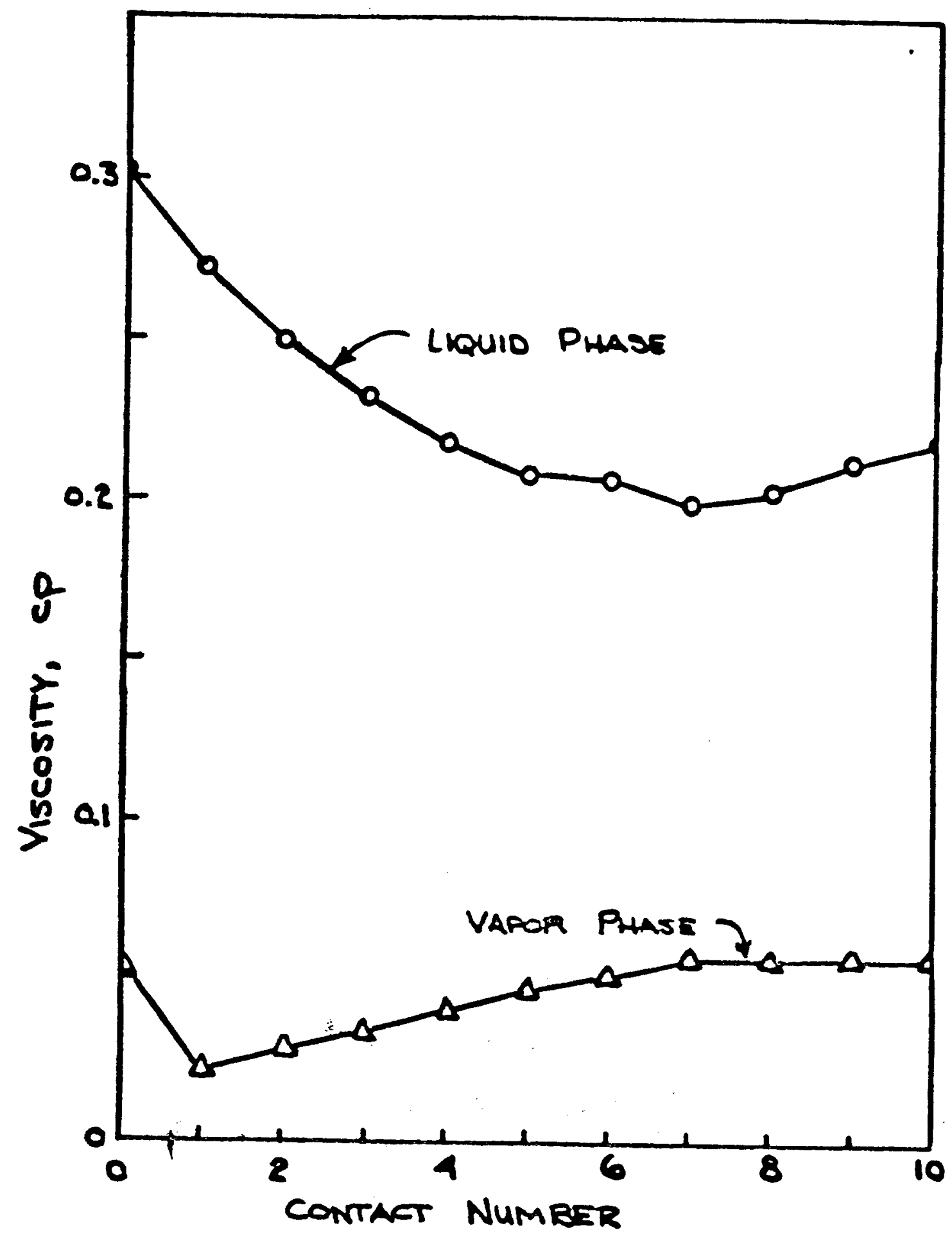

Fig. B-6 - Phase viscosities calculated for multiple contacts. 


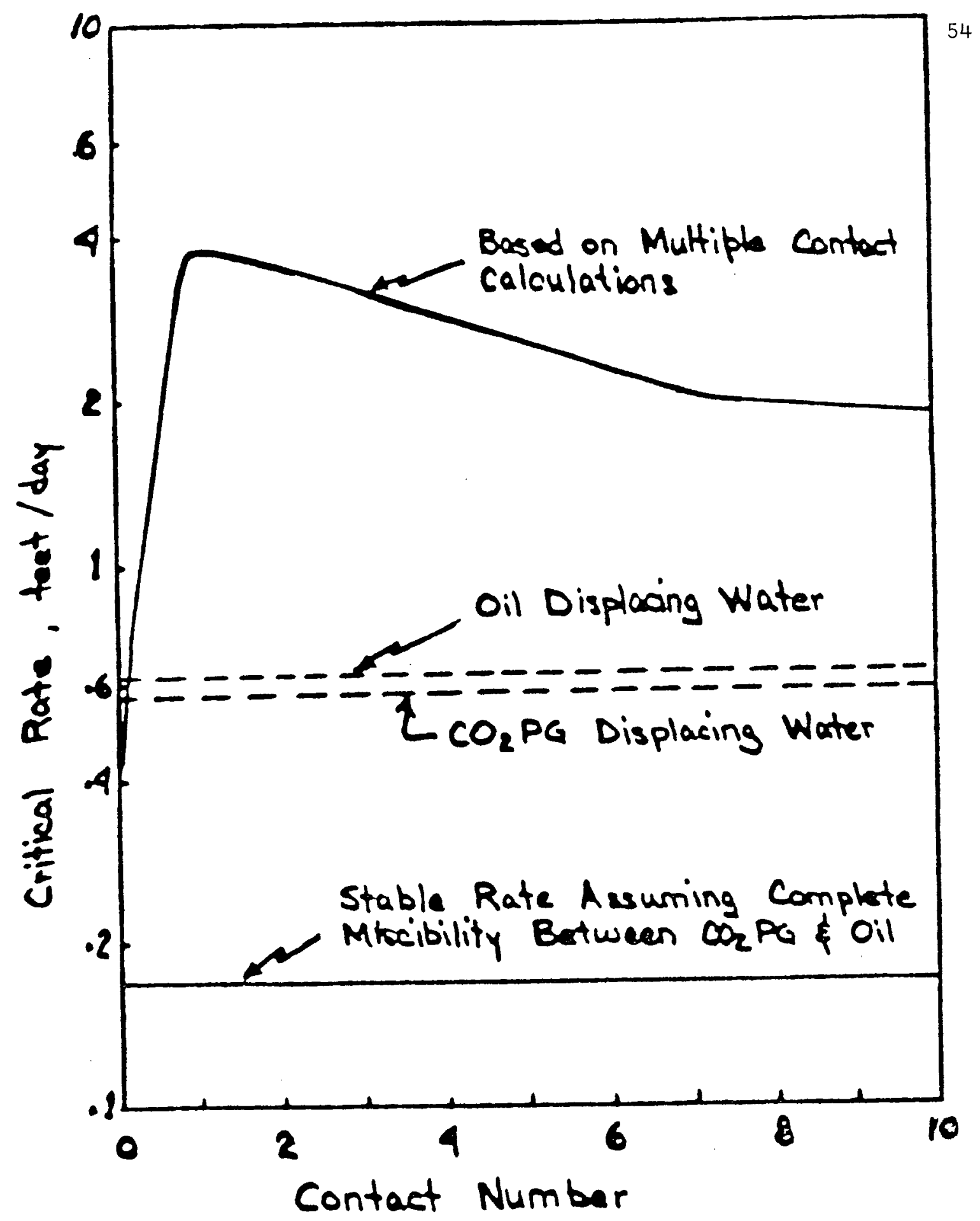

Fig. B-7 - Critical rates calculated from multiple contact calculations.

FIGURE B-7 


\author{
APPENDIX C \\ One-Dimensional Numerical Simulator for "S" Sand \\ Reservoir B, Weeks Island Field
}

$\underline{\text { Introduction }}$

As part of the technical support to the proposed $\mathrm{CO}_{2}$ pilot in the $S R B$, a one-dimensional reservoir model was constructed and tested. Preliminary runs included in this appendix indicate a fairly accurate description of the $B$ reservoir based on the data from the A reservoir. The model is one-dimensional and assumes segregated flow; coning effects are not included.

\title{
Reservoir Description
}

The model is a $1-D 20 \times 1 \times 1$ grid system. The curvilinear coordinates were used with input data consisting of

- vertical depth of the top of the center of each grid block

- thickness of each grid block (measured vertically)

- width of each grid block

- length of each grid block (measured horizontally)

This data was extracted from structure maps. Figure C-1 shows an approximation of the grid system being used in the $X-Z$ (or vertical plane). Figure C-2 shows an $X-Y$ (or areal) plane through the grid system. Values of permeability and porosity were based on core data from the A reservoir. These values are $k_{x}=k_{y}=k_{2}=2485 \mathrm{md}$ and $\emptyset=0.236$. Grid block $(20,1,1)$ was intended to represent the majority of the gas cap volume, and hence its porosity was input to be 0.350 .

Relative Permeabilities

Since a 1-D model was used, and since gravity forces dominate capillary and viscous forces, segregated flow was assumed in this model. For this case, when there is no layering in the reservoir, straight line relative permeabilities are appropriate. Figures $\mathrm{C}-3$ and $\mathrm{C}-4$ show the curves input to the simulator. Pseudo capillary pressures are calculated by the simulator.

\section{PVT Data}

Since no PVT data were available for the Weeks Island SRB crude oil when this study was conducted, it was necessary to estimate the appropriate data. An early analysis of SRA crude taken from Smith State Unit No. 1, Well No. 1 on August 27, 1947, was used since the measured bubble point of the recombined sample $\left(5880 \mathrm{psia}\right.$ at $236^{\circ} \mathrm{F}$ ) was reasonably close to the original reservoir $\mathrm{B}$ conditions $\left(5878\right.$ psia at $\left.215^{\circ} \mathrm{F}\right)$. The oil formation volume factor, $B_{0}$, was adjusted to give 
a value of $1.484 \mathrm{RB} / \mathrm{STB}$ at the bubble point. This value was obtained from Exhibit 7 of the Technical Proposal for the Weeks Island Pilot. Figures C-5 through $C-7$ show the PVT data input to the simulator.

Well Data

The partial completion option was used in the model since the grid block heights ( \pm 300 feet) are much greater than the completed interval ( \pm 10 feet) and since the fluids were assumed to be in gravity equilibrium. Table C-1 summarizes the well data used. Note that pseudo skin factors are used with the partial completion option while the value for well kh input is the permeability thickness product for the entire grid block. The well rates were taken from a computer data file prepared from production records.

Results

Figure $\mathrm{C}-8$ shows the calculated average reservoir pressure as compared to actual field well pressures. Figure C-9 shows the calculated and actual production history, and Figure $\mathrm{C}-10$ shows the calculated movement of the gas-oil and water-oil contacts. While this run does not represent the final history match, it does indicate that the model is capable of describing the past performance with a fair degree of accuracy and can be used for subsequent studies as new data are available. 


\section{TABLE C-1}

Summary of Well Data Used in Simulation Model

\begin{tabular}{|c|c|c|c|c|c|}
\hline We11 & $\begin{array}{l}\text { Location } \\
\text { (grid b1k) } \\
\end{array}$ & Skin & $\begin{array}{c}\mathrm{kh} \\
(\mathrm{Darcy}-\mathrm{feet}) \\
\end{array}$ & $\begin{array}{r}r_{w} \\
\text { (feet) }\end{array}$ & $\begin{array}{l}\text { Completion Interval } \\
\text { (feet subsea) }\end{array}$ \\
\hline $16 \mathrm{~A}$ & $(11,1,1)$ & 30.0 & 808 & 0.25 & $\begin{array}{l}12822 \text { to } 12832(2-68 \text { to } 7-75) \\
12778 \text { to } 12788(7-75 \text { to } 3-77)\end{array}$ \\
\hline 25 & $(20,1,1)$ & 30.0 & 1407 & 0.25 & 11995 to 12001 \\
\hline 22 & $(20,1,1)$ & 30.0 & 1407 & 0.25 & 11735 to 11765 \\
\hline 2 & $(1,1,1)$ & 30.0 & 1419 & 0.25 & 13230 to 13294 \\
\hline
\end{tabular}




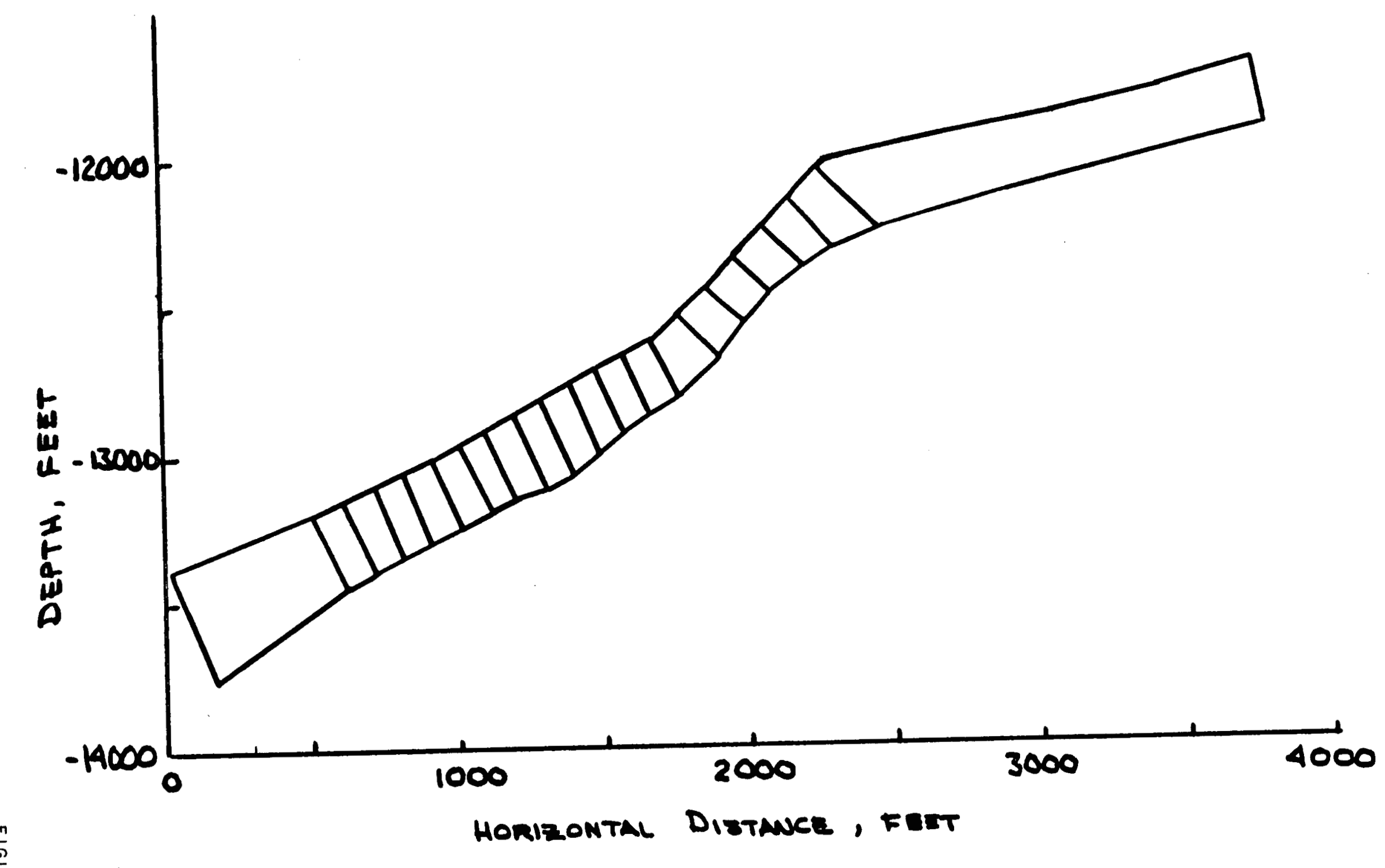

Fig. C-1 - Vertical plane of grid system. 
I

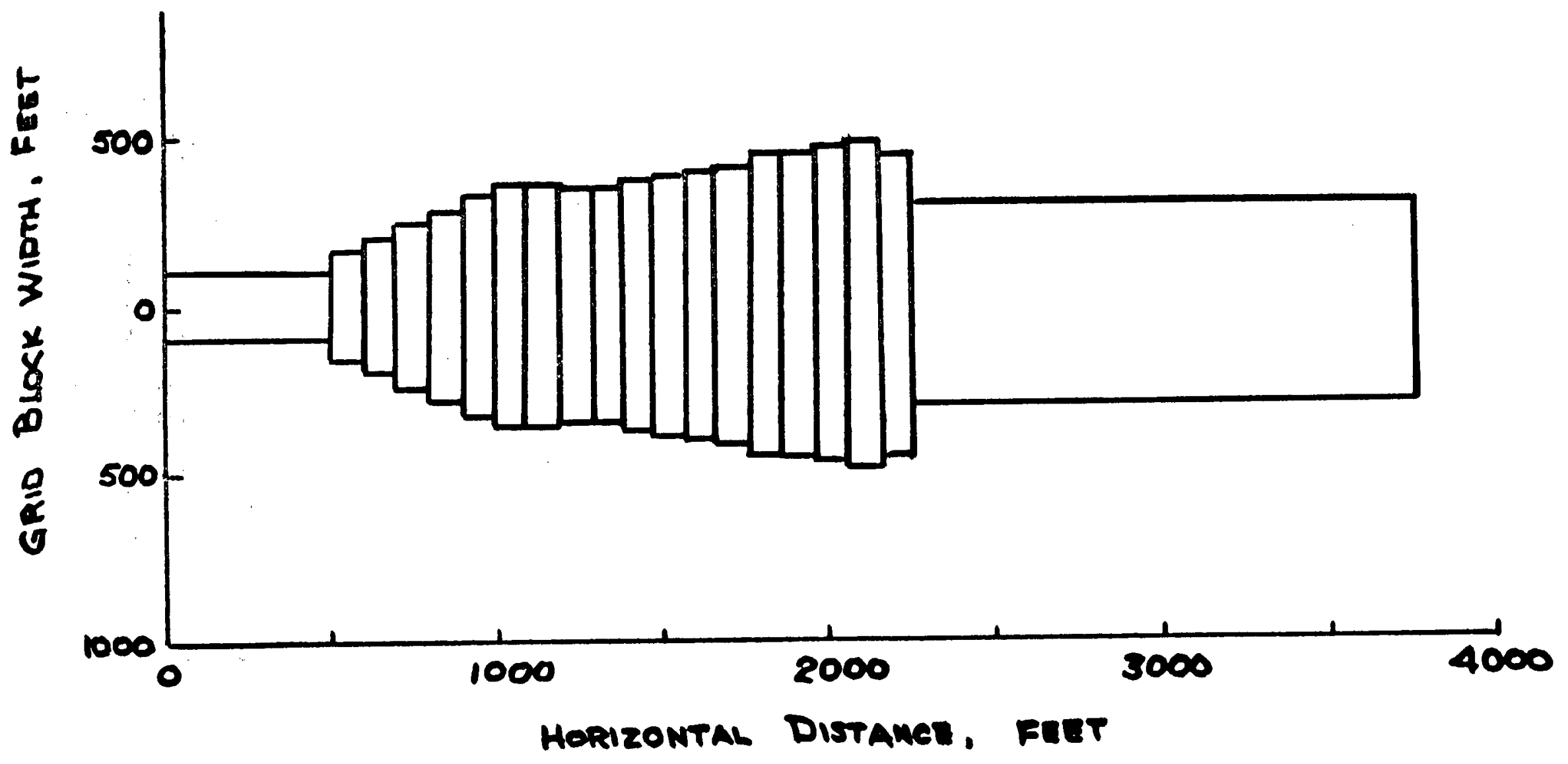

Fig. C-2 - Areal plane of grid system. 


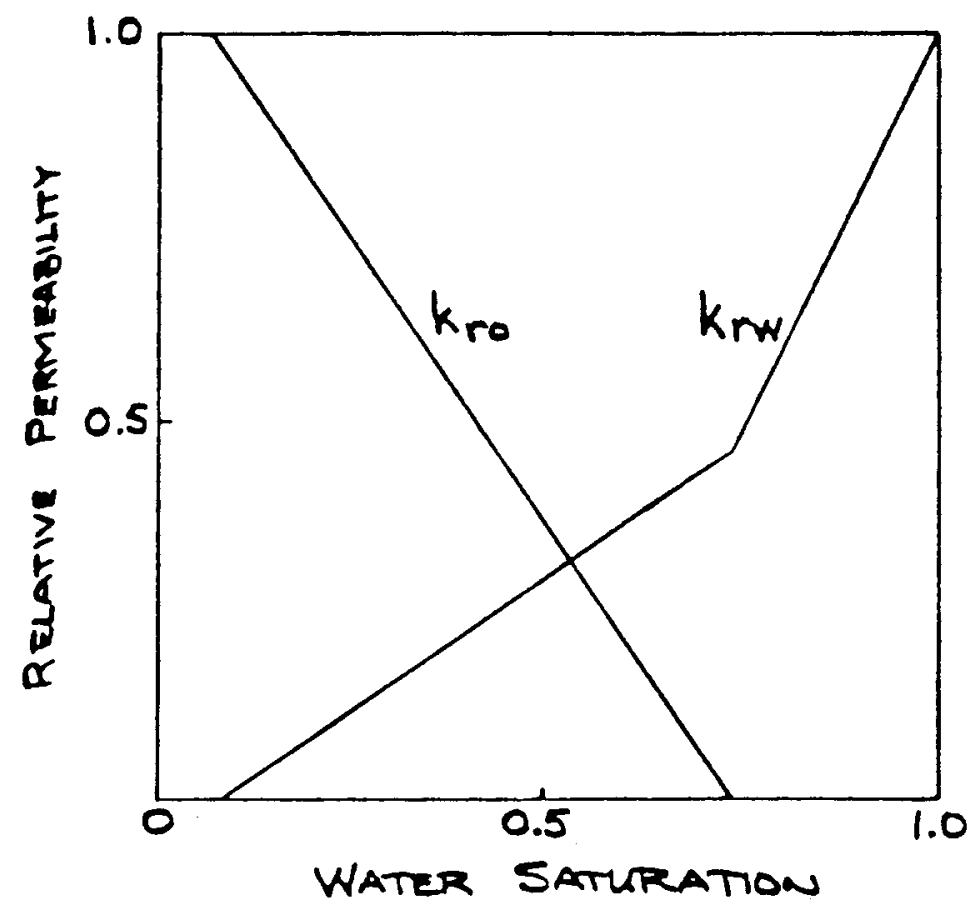

60

Fig. C-3 - Water-oil relative permeability curves.

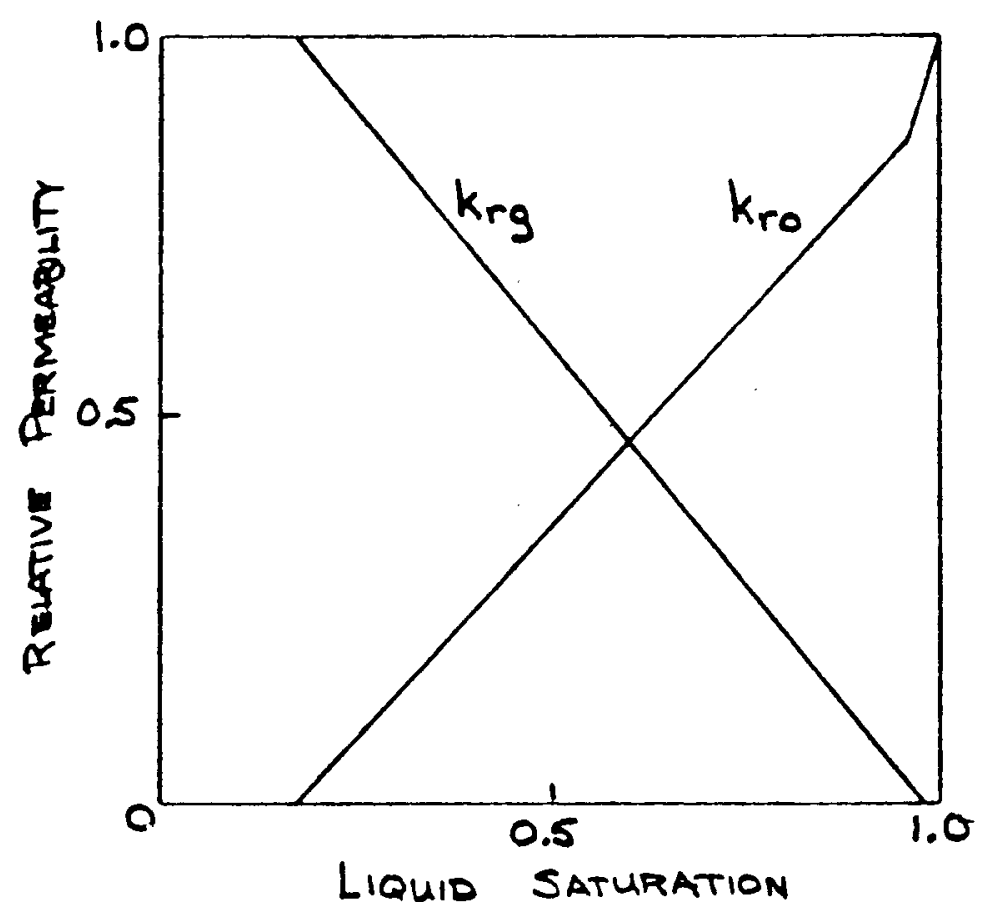

Fig. C-4 - Gas-oil relative permeability curves. 


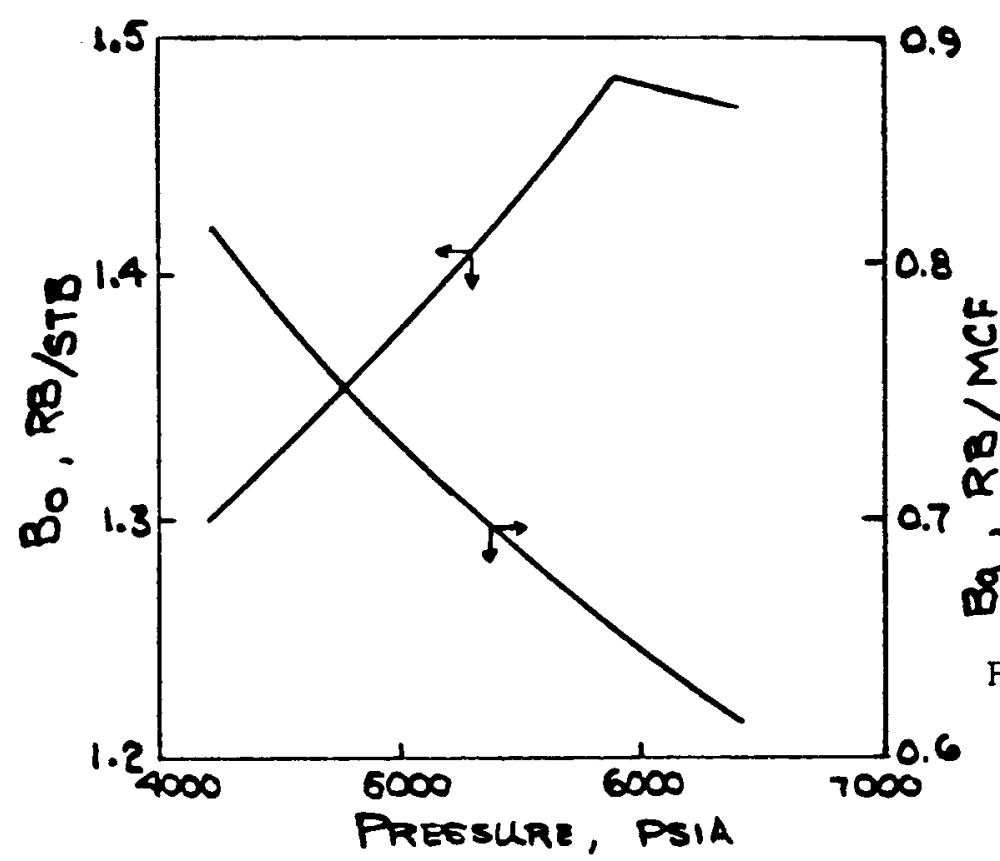

61

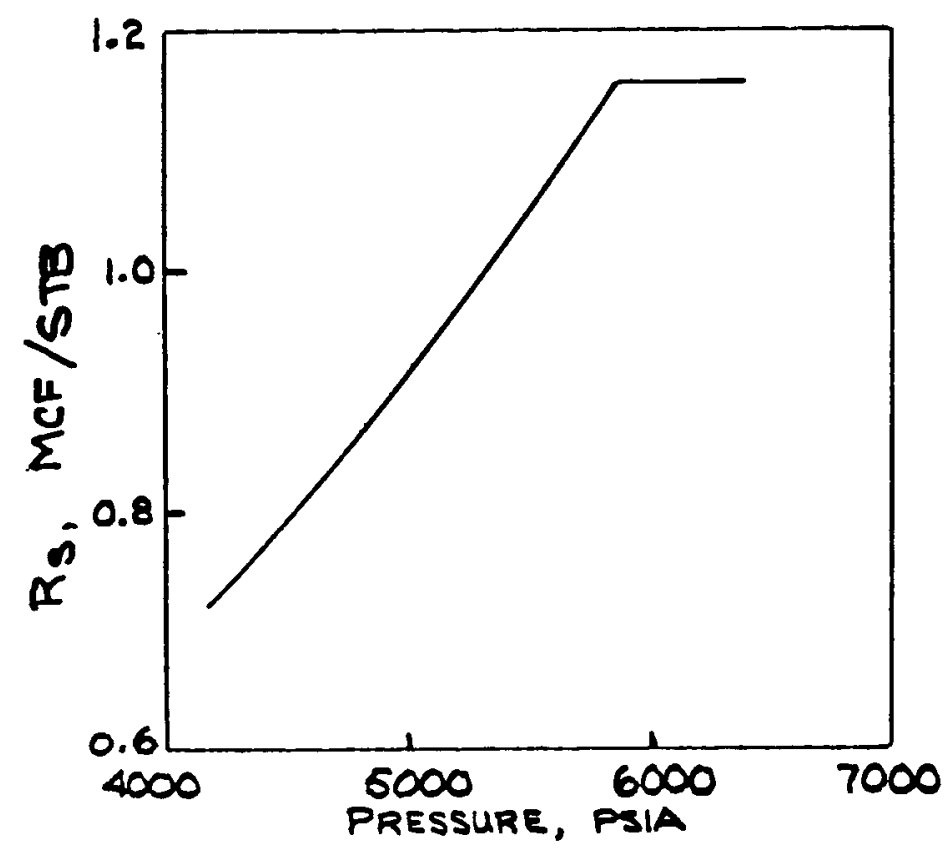

Fig. C-6 - Solution gas.

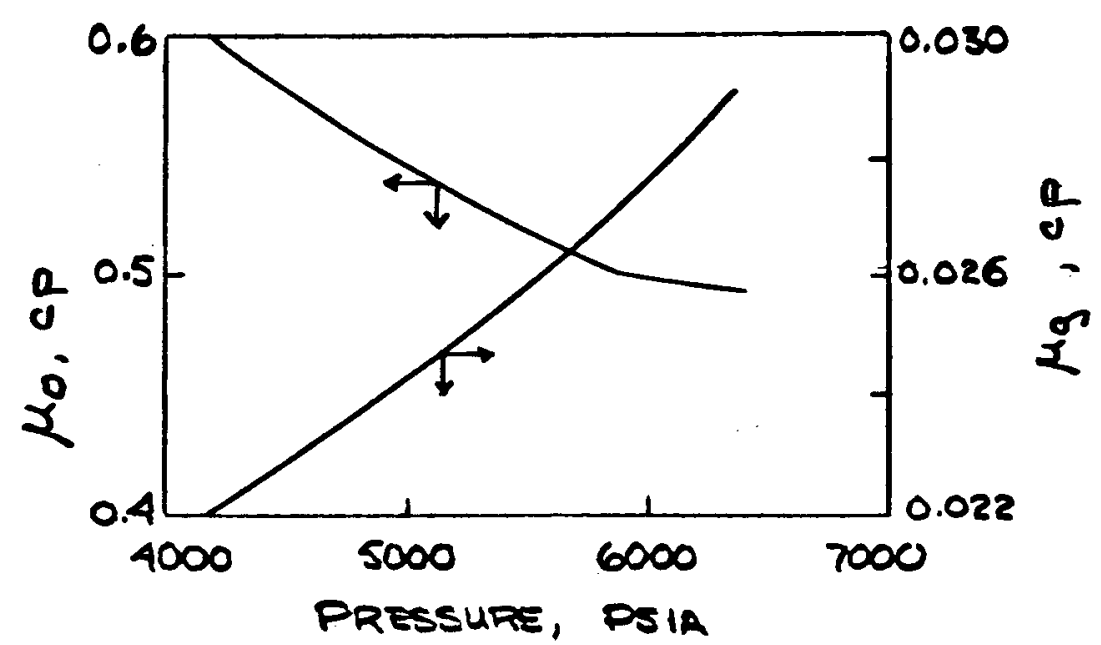

Fig. C-7 - Fluid viscosities.

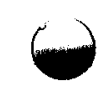




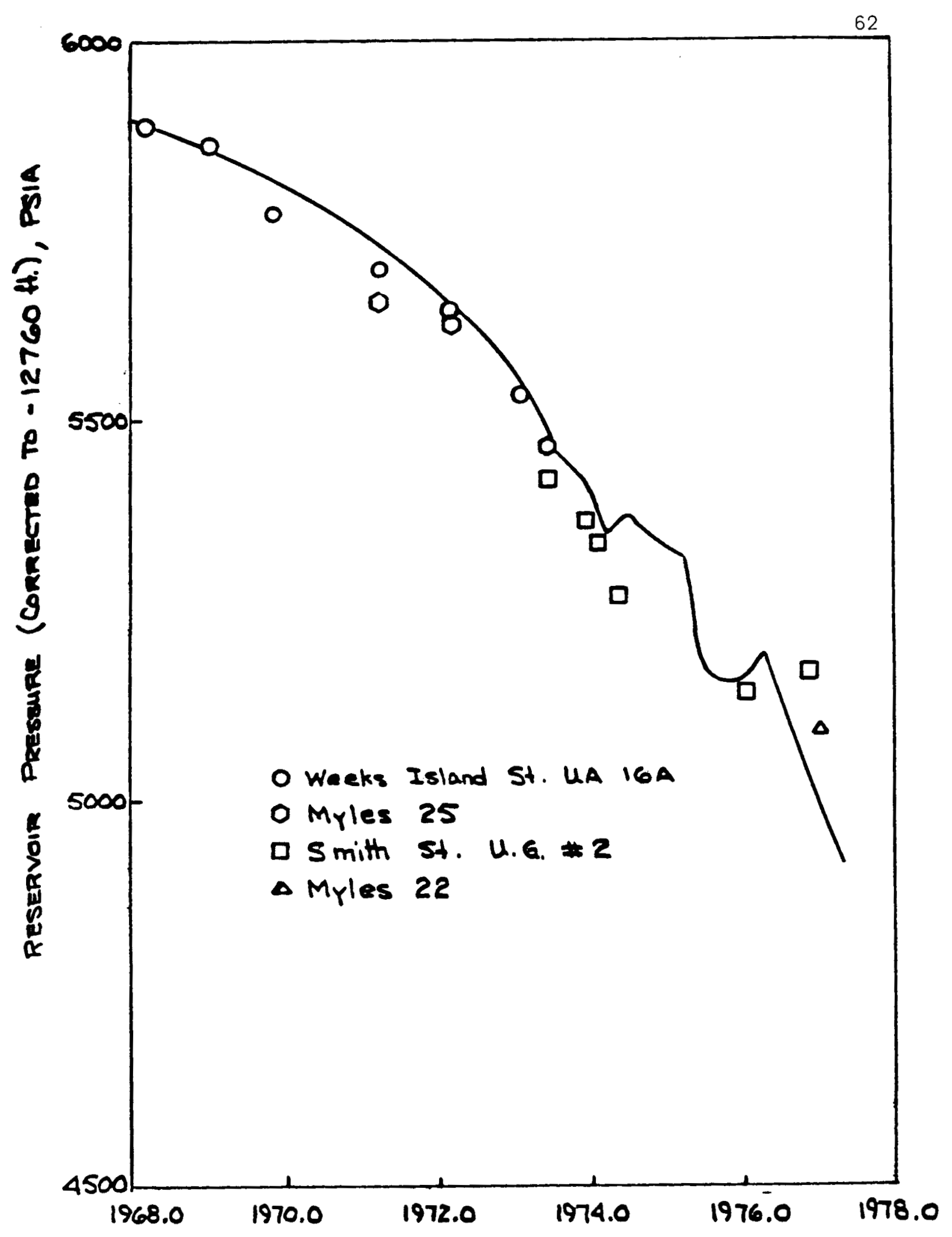

Fig. C-8 - Pressure history. 

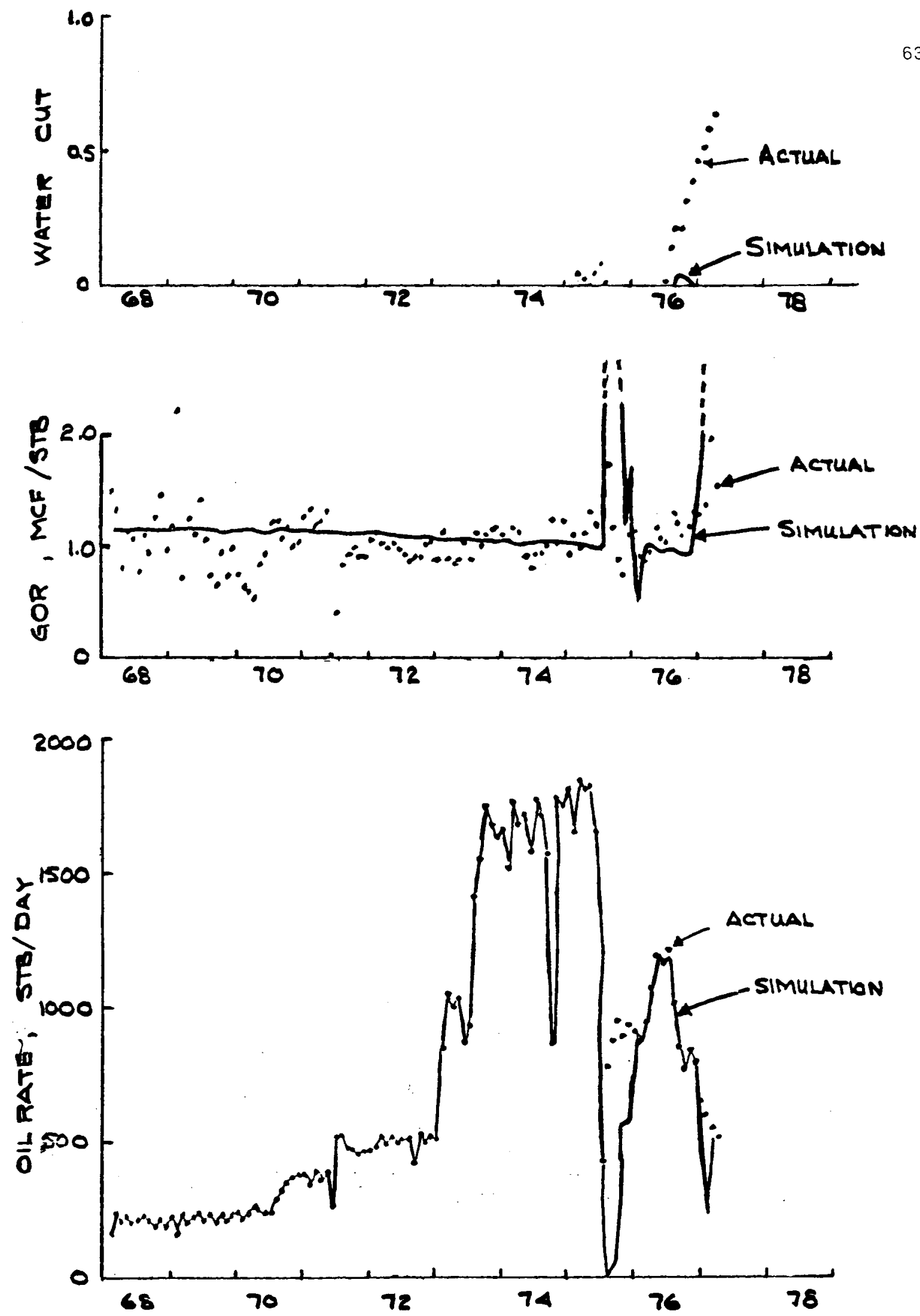

Fig. C-9 - Comparison of actual and simulated production rates for Weeks Island SRB Well 16A. 


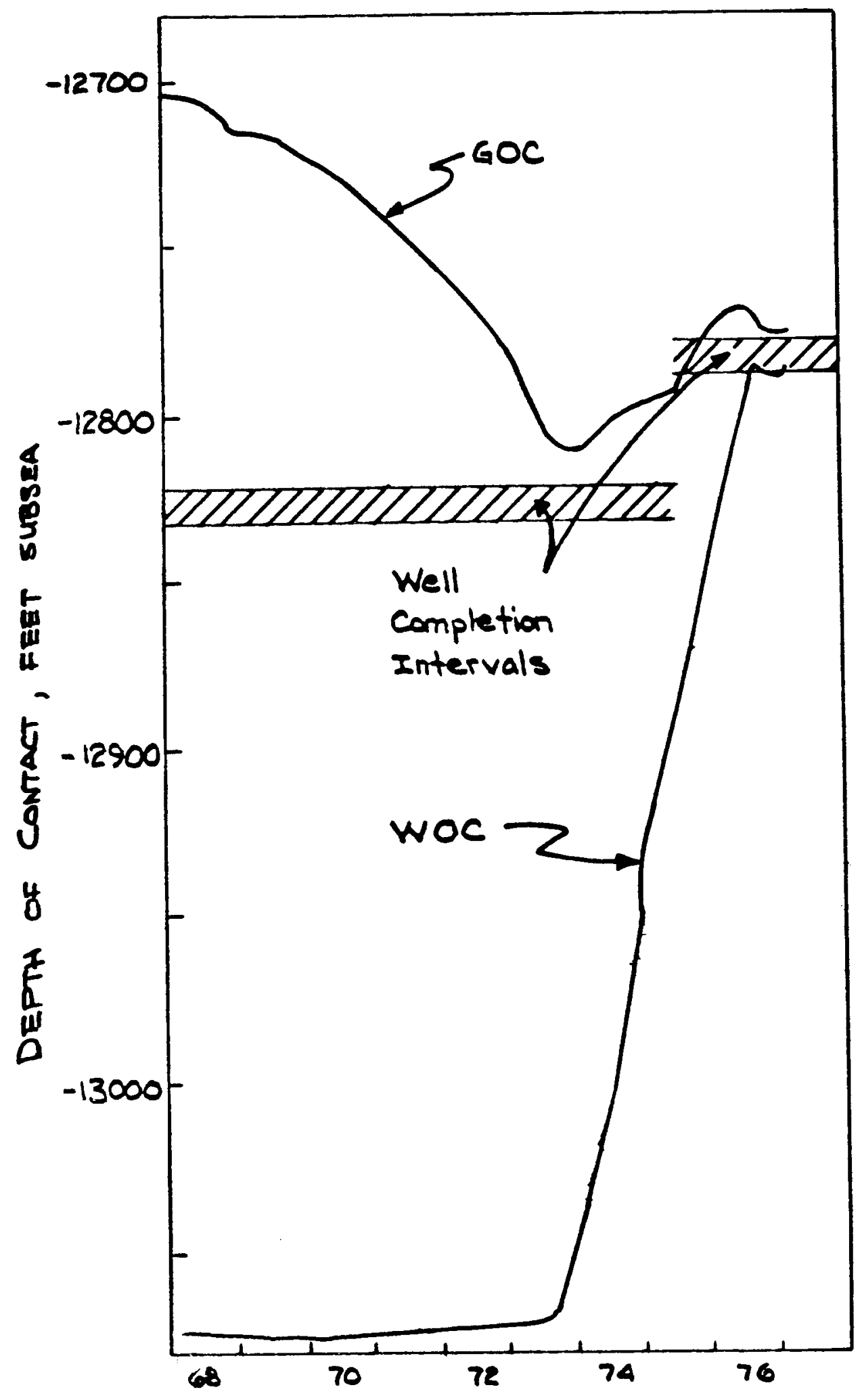

64 


\section{APPENDIX D \\ Sweep Efficiency as Influenced by Density of Injected Gas}

As identified earlier, $\mathrm{CO}_{2}$ is more dense than $\mathrm{SRB}$ crude at reservoir conditions. After mixing $\mathrm{CO}_{2}$ and $\mathrm{SkB}$ crude, gaseous and liquid phases are observed and, fortunately, the gaseous phase is less dense than the liquid phase. As shown in Appendix B, stable rate calculations for miscible and immiscible vertical displacements indicate that even under the most unfavorable conditions which were examined, stability is expected with an injected gas mixture of 95 percent by volume $\mathrm{CO}_{2}$ and $5 \%$ plant gas. Conceptually, we know that in a three dimensional reservoir the oil recovery will increase if the difference in densities of the displacing and displaced fluids is high. To qualitatively assess the importance of density differences between the gas and crude on sweep efficiency for the Weeks Island $\mathrm{CO}_{2}$ injection field test, two simple simulation studies were conducted.

\section{Simulation Models}

A numerical simulation model similar to the one used in Appendix $C$ was employed for this study. The model was two dimensional in the areal view with 15 grid blocks in the dip direction $(x), 13$ grid blocks along strike ( $y$ direction) and one block to represent the thickness ( $z$ direction). The model is for the portion of the reservoir which should be influenced by injection into Well A-16 and production from Well A-17. Dimensions were 750 feet, 650 feet and 185 feet in the $x, y$ and $z$ directions respectively. Constant dip of $30^{\circ}$ and constant permeabilty of $3000 \mathrm{md}$ were assumed. Figure D-1 shows the selected grid system and well locations. The displacement rate was about $0.03 \mathrm{ft} /$ day ( $\mathrm{q} / \mathrm{A}$ assuming horizontal displacement front) using injection and production rates of 1500 barrels/day (reservoir conditions).

Fluid properties and relative permeability relationships were the same as those shown in Appendix C. Segregated flow within a grid block was also assumed for this simulation. The segregated flow assumption should be valid as long as the difference in densities between the displaced and displacing phases exceeds about $0.003 \mathrm{~g} / \mathrm{cc}$ or $0.0013 \mathrm{psi} / \mathrm{ft}$.

Injection was in the gas cap in Well A-16. The oil-water contact was set below the perforations in Well A-17 and the oil column was assumed not to be watered out (i.e., at $S_{o i}$ or $1-S_{w c}$ ). The injection and production rates were balanced at 1500 barrels per day (reservoir conditions) to result in a constant pressure displacement. The simulations were made with varying gas densities to determine the time until gas breakthrough in Well A-17.

A second simulation model was constructed because the rather coarse grid system used in the 2-D areal simulation can lead to solutions which can be erroneous in some circumstances. A two-dimensional vertical grid system 
with many more grid blocks between injector and producer was selected. The area modeled was 200 feet in the $x$ direction and 140 feet in the $z$ direction using ten foot square grid blocks. Relative permeability curves used in the study represent laboratory measurements which are appropriate for this type of simulation. The capillary pressure transition zone was assumed negligible. Figure D-2 shows the grid system and relative permeability curves used for this model. The injection well was located in the upper corner (Block 1,1,1) and the production well was located in the opposite lower corner (Block 20,1, 14). Other simulation assumptions were the same as those used in the 2-D areal model described above.

Several sensitivity simulations were made to test model assumptions. These included changing the grid block size and using three blocks in the $z$ direction with the areal model; changing the relative permeability curves and altering the relative position of the injector and producer with the vertical model; and conducting displacements with the oil column oil saturation at the assumed waterflood residual value using both simulation models.

Results

These simulations are intended for conceptual application because compositional effects are not included. Two points should be emphasized. First, the mixing of $\mathrm{CO}_{2}$ plus plant gas and $S R B$ oil yields a gaseous phase which is less dense than the liquid. This phenomena persists with addition of $\mathrm{CO}_{2} P G$ as shown in Appendix $B$. Therefore, not a single density difference exists along an imagined compositional route from injector to producer. Further, any density difference variation that exists along this route could act to the benefit of the process by enhancing the mixing which in turn could increase the effectiveness of the vaporization mechansism and improve hydrocarbon recovery.

The second point that is emphasized is that in the model, Well A-17 is produced continuously but during the field test Well A-17 will be produced only when an oil bank is in proximity to the well. This fact makes the simlation results pessimistic until such time as the well is put on production upon arrival of an oil bank. A separate simulation was conducted using the areal model to observe the shape of the displacement front (gas-oil contact) when only Well G-2 is produced. The simulation was conducted using a density difference of $0.02 \mathrm{psi} / \mathrm{ft}$ between the oil and the displacing phase. The calculated gas-oil contact, when the displacement front was just above the A-17 perforations in the row of grid blocks where the A-17 perforations are located, was almost flat. The interface was depressed no more than six feet in the vertical direction over the $650 \mathrm{ft}$ width of the model grid system.

Figure D-3 shows the calculated sweep efficiency at gas breakthrough for an immiscible displacement of SRB oil by gas as a function of the difference in density of displaced and displacing phases for both simulation models. The sweep efficiency and hence oil recovery is very sensitive to the difference in density. Indirectly, these results show that producing Well A-17 
only when an oil bank is present to minimize gas coning can materially effect recovery. As a first approximation of the sweep that can be expected from the project, we observe that using the density difference after seven contacts of $\mathrm{CO}_{2} P G$ and oil from Figure $\mathrm{B}-5$ (about $0.14 \mathrm{~g} / \mathrm{cc}$ or $0.06 \mathrm{psi} / \mathrm{ft}$ ) which might represent an average for the displacement, the sweep at breakthrough is between 60 and 80 percent from the $2-D$ areal and the 2-D vertical simulations (Figure D-3).

Additional simulations are planned when compositional effects of the process can be more completely modeled. 

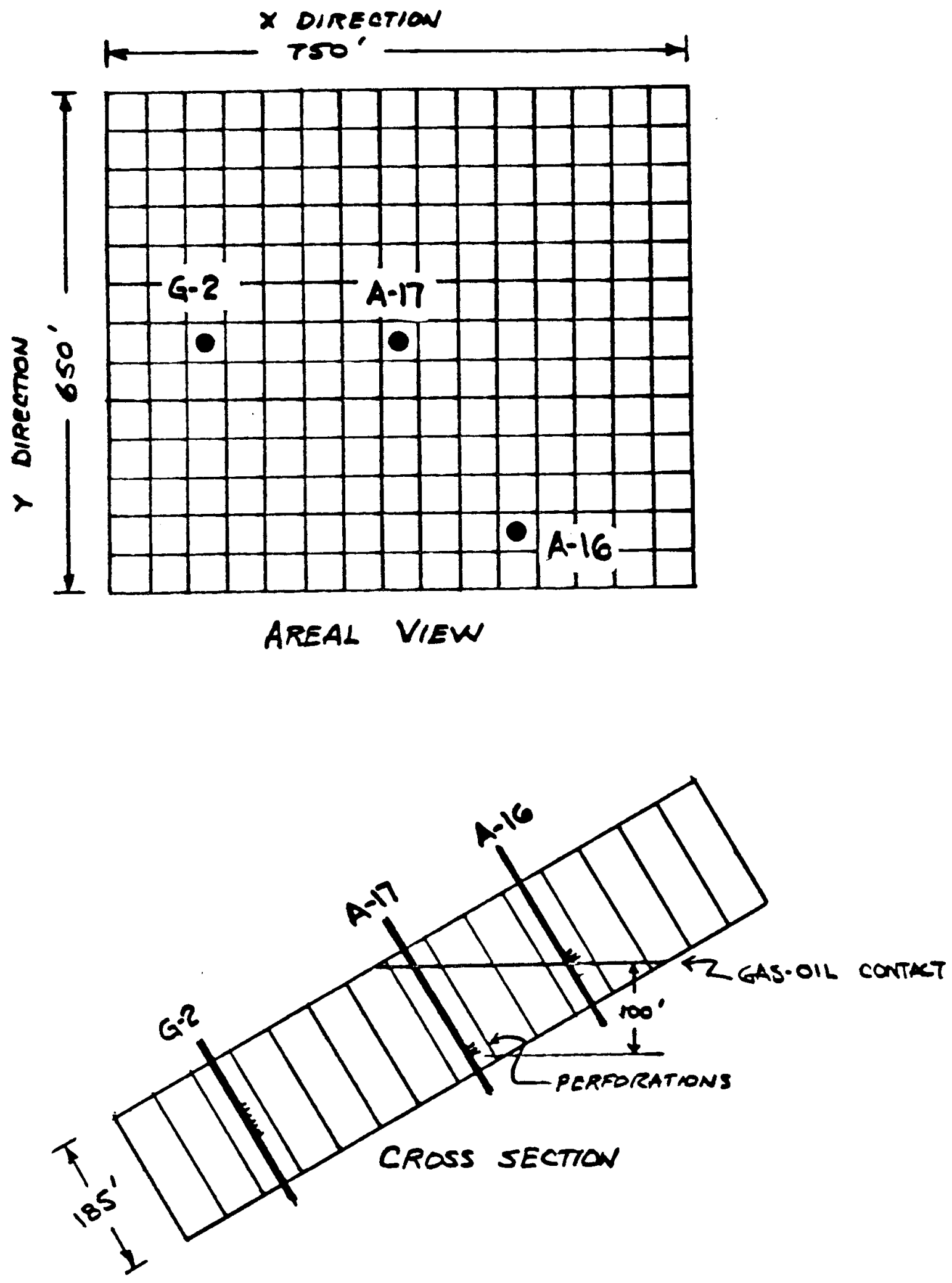

Fig. D-1 - 2-D Areal simulation grid. 

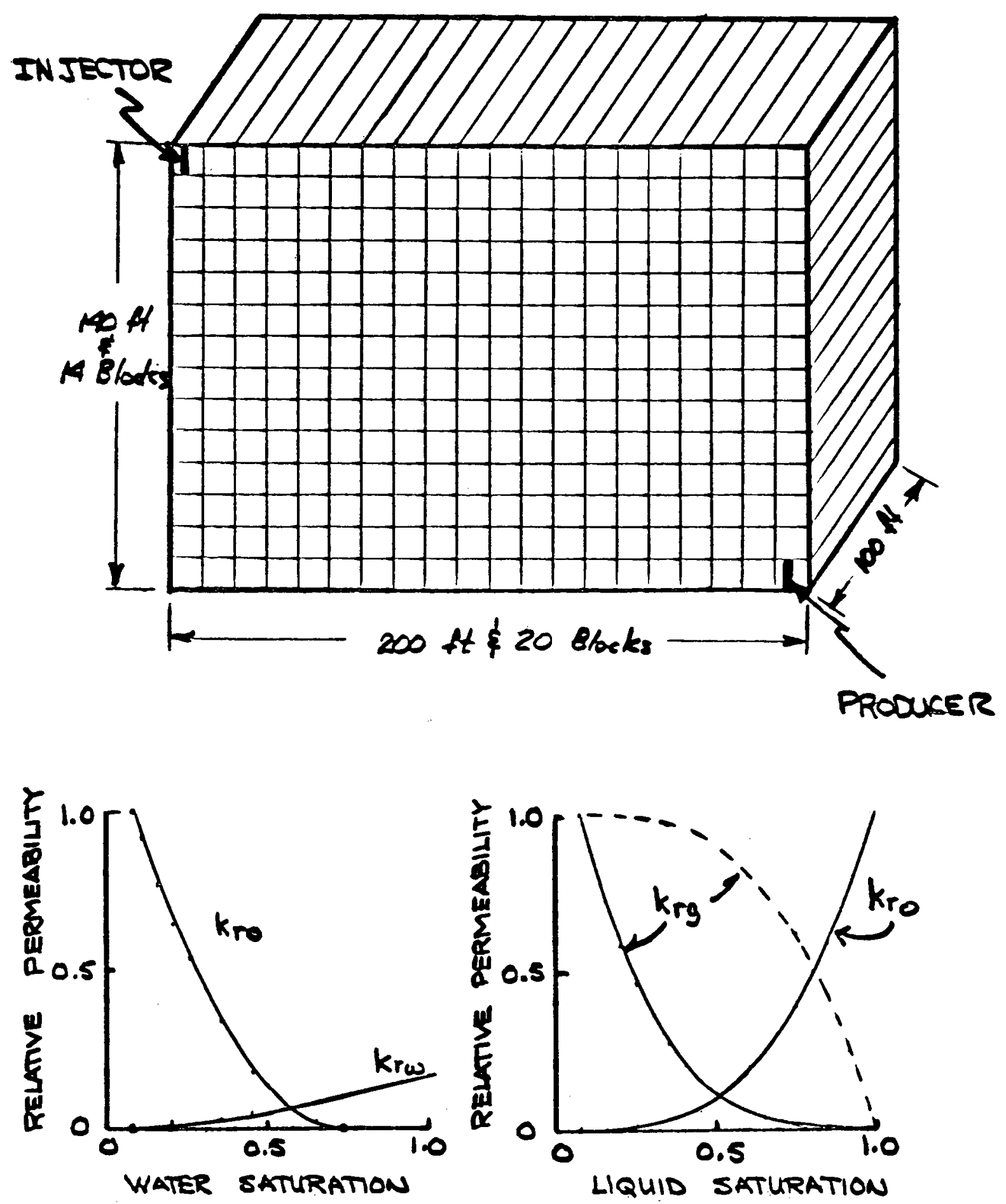

Fig. D-2 - 2-D Vertical simulation grid and relative permeability curves. 


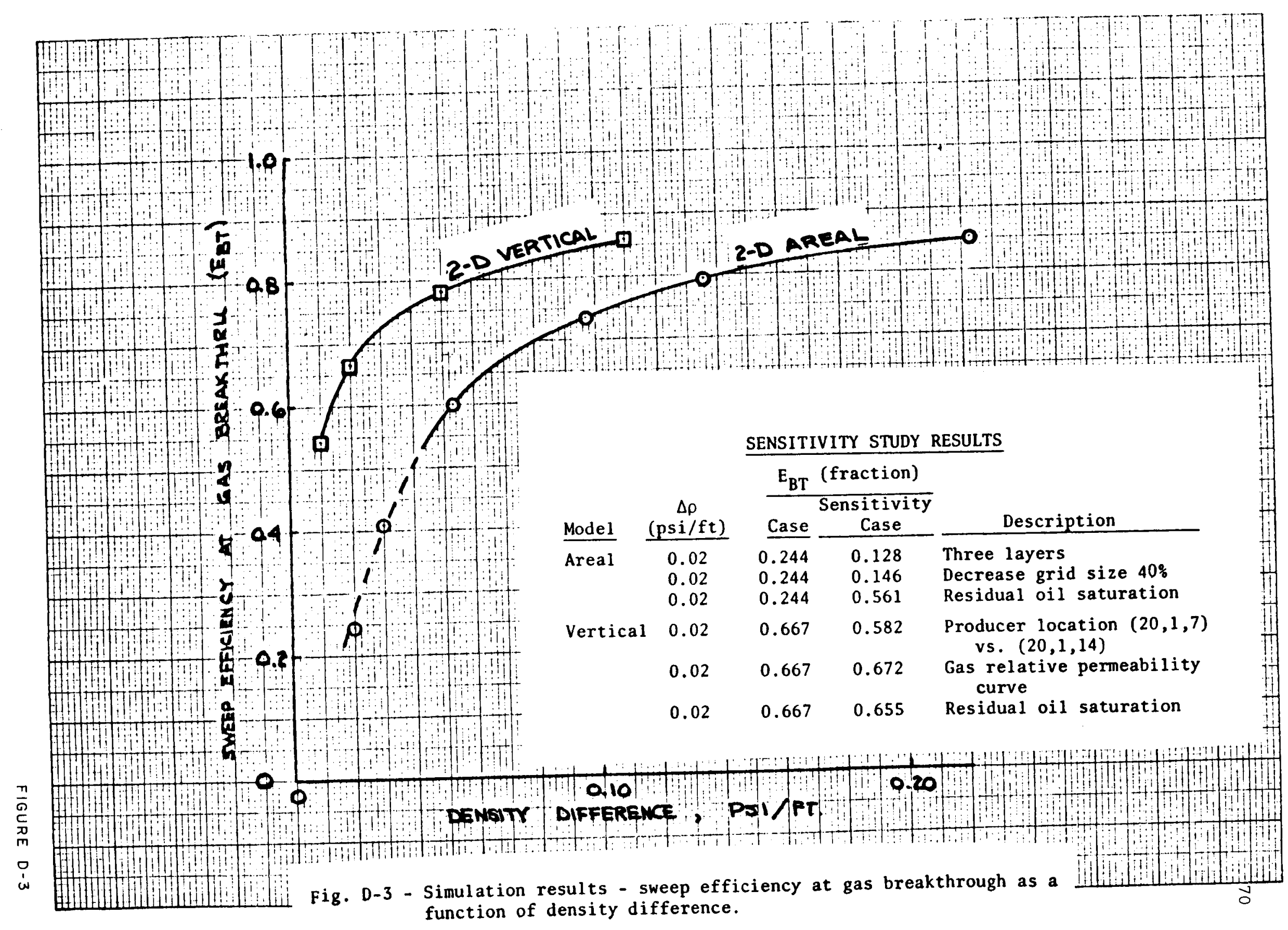
function of density difference. 
APPENDIX E

Residual Oil Saturation in the Interval 12,910-20 ft

of Well SU A-17

Log-Inject-Log $S_{0 r}$ Determination with Pulsed Neutron Capture Devices

A $\log$-inject-log procedure similar to that described in references

5 and 6 , using stationary measurements with a pulsed neutron-capture sonde and time-of-flight analyzer was carried out at five stations in a ten foot interval of SU A-17. At each station the time-of-flight data were analyzed to yield $\tau_{a}, A$, the apparent neutron decay time in the formation containing injected brine $A$, and $\tau_{a, B}$, the apparent neutron decay time in the formation containing injected brine $B$. Both $\tau_{a, A}$ and $\tau_{a, B}$ are determined in a selfconsistent way from the slope of neutron decay data in the time interval from $2-1 / 2 \tau_{\mathrm{a}, \mathrm{A}}$ to $5 \tau_{\mathrm{a}, \mathrm{A}}$ and $2-1 / 2 \tau_{\mathrm{a}, \mathrm{B}}$ to $5 \tau_{\mathrm{a}, \mathrm{B}}$.

The values of $\tau_{a, B}$ and $\tau_{a, A}$ from each station were combined with the values of $\tau_{w, B}$ and $\tau_{w, A}$ derived from measurements (corrected to formation temperature and pressure) of the neutron capture cross-section of samples of the injection brines to compute $\phi_{w}$, the fraction of the bulk volume of the formation occupied by the aqueous phase, $\left(\phi_{w}=S_{w} \times \phi_{\text {total }}\right)$ from the relation

$$
\phi_{w}=\frac{\tau_{a, B}^{-1}-\tau_{a, A}^{-1}}{\tau_{w, B}^{-1}-\tau_{w, A}^{-1}}
$$

At each station, $\phi_{w}$ was divided by the average stressed porosity $(.256)$, derived from measurements on samples from the core, to give $S_{w}$. The value of $S_{\text {or }}$ was computed by multiplying $\left(1-S_{w}\right)$ by $1.54^{* \star}$ to take account of the volume change of the live oil when all of the gas was removed from it by the injection of $340 \mathrm{bbls}$ of fluid $\mathrm{A}$ over a ten-foot interval. The results are summarized in Table E- 1 and indicate an average $S_{\text {or }}$ in the log-inject-log interval of .221 (or .200 if station 12,915 is omitted) with a maximum standard deviation of \pm .028 . At three of the five stations $(12,911 \mathrm{ft}, 12,913 \mathrm{ft}$ and $12,917 \mathrm{ft}$ ) the time dependence of the time-of-flight data was consistent

**Derived from data contained in $\mathrm{P}-\mathrm{V}-\mathrm{T}$, Inc. Laboratory Report $\mathrm{AB}-78068$ dated February 20, 1978. 
with that reported in references 5 and 6 . At $12,915 \mathrm{ft}$, the slope of the neutron decay curve following the injection of fluid B did not become constant until the interval $\left(2.9 \tau_{a, B}-5 \tau_{a, B}\right)$ rather than $\left(2.5 \tau_{a, B}-5 \tau_{a, B}\right)$. Therefore, the value of $\phi_{w}$ derived for this station is possibly subject to a systematic error of unknown magnitude. The slope of the neutron decay data at $12,919 \mathrm{ft}$ following the injection of brine A did not become constant in time, and data from this station have been omitted.

It may be of interest to compare the values of $S_{\text {or }}$ in Table E-1 with the one that can be calculated from the conventional Schlumberger TDT-K measurements over the same interval. The average $\tau_{a}$ across the interval 12,910-20 ft after fluid A injection from 4 passes with a conventional TDT-K sonde is $256 \pm 4 \stackrel{\star}{\mu}$. This value corrected according to the latest (1976) Schlumberger publication gives $\tau_{a, A}=330 \pm 4 \stackrel{*}{\mu}$. The average $\tau_{a}$ after fluid $B$ injection from 4 passes with the TDT-K sonde is $162 \pm 2 \stackrel{*}{\mu}$, and when similarily corrected gives $\tau_{a, B}=193 \pm 2 \stackrel{*}{\mu}$. From these corrected TDT-K apparent decay time values and the value of $\left(\tau_{w, B}^{-1}-\tau_{w, A}^{-1}\right)$ given in Table E-1 $\phi_{w}$ is computed to be $.2210 \pm .0069^{*}$. Further, from this value of $\phi_{w}$ and the previously stated values of average stressed porosity (.256) and "shrinkage" factor (1.54) there results an $S_{\text {or }}$ of $.211 \pm .042^{*}$.

The values marked with an asterisk are uncertainties which take account only of the variation found on four repeat passes and do not include any systematic errors resulting from the use of corrections from the 1976 Schlumberger publication.

Prior to the injection of brine A, the middle two feet of the loginject-log interval was perforated and swabbed at the rate of $10 \mathrm{bbls} / \mathrm{hr}$. No oil was produced. Therefore, it is plausible to assume that the oil was immobile and $S_{\text {or }}$ was not reduced as a result of the injections.

Sor from Core Analysis

The value of $S_{\text {or }}$ found in the core recovered from the log-inject-log interval, corrected to in-situ conditions, should be less than or equal to the values in Table E-1. The average value of $S_{\text {or }}$ from core analysis (see Table E-2) is .149 using a dead oil density of $.862 \mathrm{~g} / \mathrm{cm}^{3}$ and an average unstressed porosity of .267 . If the live oil under in-situ conditions has a formation volume factor of 1.545 and the stressed porosity is .256 , then the core analysis gives a corrected average value of $\mathrm{S}_{\text {or }}$ over the $\log$-inject-log interval of .244 (or .230 if anomalous sample at 12,918 is deleted). 
Determination of $S_{\text {or }}$ from Open Hole Log Suite

Prior to the log-inject-log (L-I-L) test described above, two intervals in the Weeks Island State Unit A-17 were perforated and swab tested: 12915 to $12917 \mathrm{ft}$ and 12960 to $12970 \mathrm{ft}$ (referenced to Dual Induction Log dated January 1, 1978). The intervals tested were located in the waterflooded portion of the "S" Sand Reservoir B (SRB) and were believed to be at swept zone residual conditions. Approximately one hundred and fifty barrels of formation water with no shows of hydrocarbons were recovered from each zone indicating the assumption of swept zone residual conditions is reasonable. Both intervals were conventionally cored during the drilling operations and laboratory stressed core measurements have been made. As a result, sufficient petrophysical data are available to permit quantitative water saturation calculations to be made in these two intervals. These calculations then provide two additional determinations of waterflood residual oil saturation for the SRB.

The pertinent petrophysical parameters applicable to each tested interval as determined from stressed core measurements, produced water analyses and open hole logs are summarized in Table E-3. Using these parameters and the conventional Archie equation results in calculated water saturation values of $.670 \pm .043$ and $.735 \pm .032$ for the intervals $12915-17 \mathrm{ft}$ and $12960-70 \mathrm{ft}$ respectively. However, in this instance $S_{0}$ is not merely $1.0-S_{w}$. The responses of the open hole Formation Density Compensated and Compensated Neutron logs indicate the presence of a free gas saturation in the SRB from 12890 to $13050 \mathrm{ft}$. Using the density and neutron responses and published Schlumberger charts, this saturation is determined to be approximately .10. The conventional TDT-K also, though only qualitatively, indicates the presence of gas over the same SRB interval. In addition, after the injection of brine A in the L-I-L interval, subsequent TDT-K logs qualitatively indicate no gas saturation through interval but continue to indicate gas in the remainder of the reservoir, thus confirming the initial interpretation of a free gas phase.

The gas saturation in the intervals of interest (12915-17 ft and 12960-70 ft) can be quantified by use of the density $10 \mathrm{~g}$ equation and accompanying identities:

$$
\begin{gathered}
\rho_{b}=\rho_{m a}-\phi\left(\rho_{m a}-\rho_{f}\right) \\
\rho_{f}=s_{w} \rho_{w}+s_{o} \rho_{o}+s_{g} \rho_{g} \\
1=s_{w}+s_{o}+s_{g}
\end{gathered}
$$


In-situ porosity $(\phi)$ is known from the stressed core analyses. Given $\rho_{\text {ma }}$ from the core and $\rho_{b}$ from the averaged open hole density $\log$ (see Table $E-2$ ), $\rho_{f}$ can be determined. As $S_{w}$ has been previously determined from the Archie equation and $\rho_{w}, \rho_{o}$ and $\rho_{g}$ are known from laboratory PVT or handbook data, $\mathrm{S}_{\mathrm{o}}$ and $\mathrm{S}_{\mathrm{g}}$ can be calculated:

$\begin{array}{lll} & \underline{12915-17 \mathrm{ft}} & \underline{12960-70 \mathrm{ft}} \\ S_{w} & .670 \pm .043 & .735 \pm .032 \\ S_{g} & .087 \pm .032 & .068 \pm .033 \\ S_{0} & .243 \pm .054 & .197 \pm .046\end{array}$

It should be noted that the above assigned uncertainties to $\mathrm{S}_{\mathrm{g}}$ are tenuous and certainly minima. Consequently, the cited uncertainty in the log calculated value of $\mathrm{S}_{0}$ is also a minimum.

The value of $\mathrm{S}_{\text {or }}$ determined from open hole $\mathrm{log}$ analysis in the interval 12915-17 ft (which is in the center of L-I-L interval 12910-20 ft) is then $.243 \pm .05$ which compares favorably with the Table E-1 values of $S_{\text {or }}$ as determined using the L-I-L technique. However, the log calculated $S_{\text {or }}$ has a larger uncertainty than the L-I-L value and is susceptible to possible systematic errors. For example, the interval 12915-17 ft was not swab tested until two months after the open hole resistivity data were obtained. As the SRB was being waterflooded during these two months, the formation water salinity could have changed from the salinity which was in-place when the open hole resistivity $10 \mathrm{~g}$ was run. A relatively minor salinity change during the two months of $\pm 1000 \mathrm{ppm} \mathrm{Cl}^{-}$ would change the previously calculated $S_{\text {or }}$ value $(.243)$ by \pm .025 . It can be noted that the updip producer, Weeks Island State Unit A-16A, is completed in an interval approximately equivalent to the 12915-17 ft interval and its produced water salinity has varied as much as $2500 \mathrm{ppm} \mathrm{Cl}^{-}$during some two-month periods. 
Table E-1

Summary of Results from Stationary Measurements

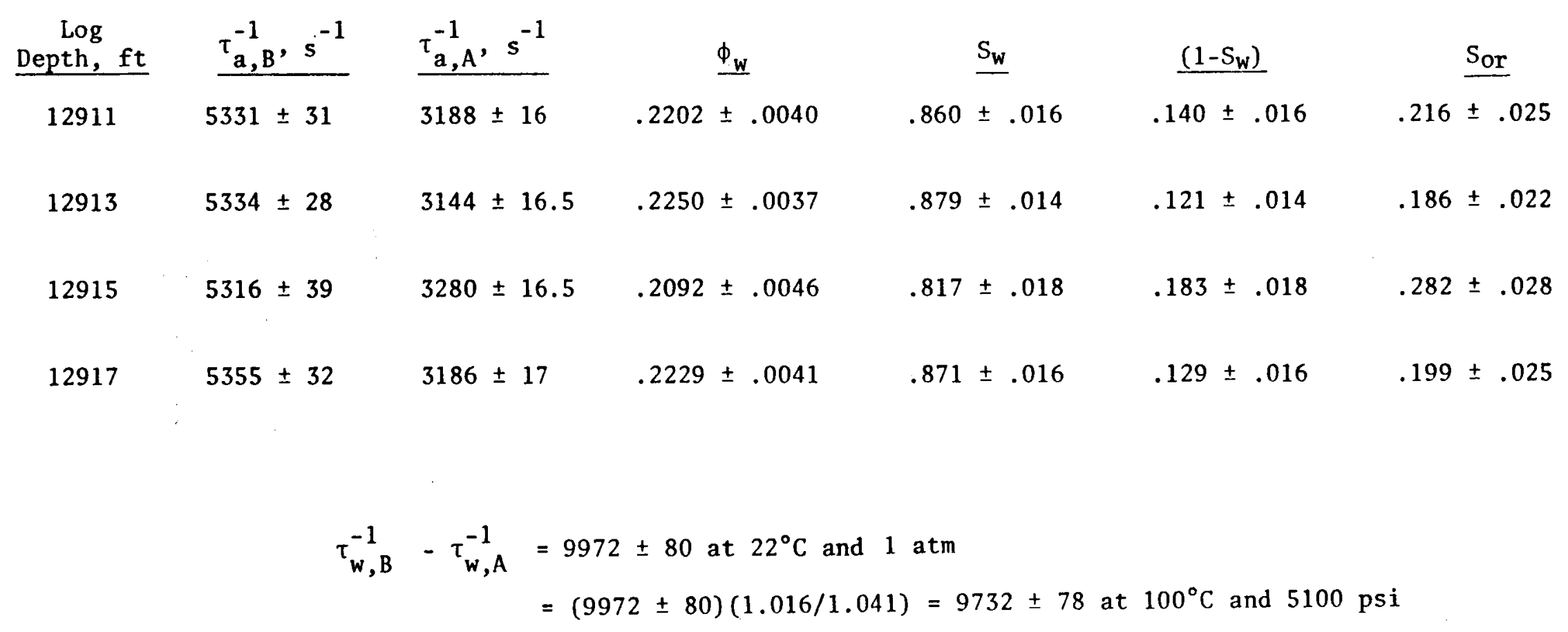


Table E-2

Core Analyses

BRC Petrophysical Services Laboratory

$\begin{array}{lllllll}1_{\text {Depth }} & { }^{2} \phi & { }^{3} \phi & \underline{\rho_{\text {ma }}\left(\mathrm{g} / \mathrm{cm}^{3}\right)} & \underline{S_{w}} & { }^{4} S_{0} & { }^{5} S_{\text {or }} \\ 12910 & .264 & & 2.644 & .763 & .166 & .272 \\ 12911 & .266 & .256 & 2.644 & .760 & .136 & .222 \\ 12912 & .269 & & 2.644 & .793 & .117 & .191 \\ 12913 & .261 & .248 & 2.645 & .731 & .172 & .282 \\ 12914 & .265 & & 2.641 & .771 & .174 & .285 \\ 12915 & .267 & & 2.645 & .617 & .166 & .272 \\ 12916 & .274 & .264 & 2.641 & .793 & .117 & .191 \\ 12917 & .268 & & 2.641 & .765 & .124 & .203 \\ 12918 & .253 & .243 & 2.638 & .721 & .232 & .380 \\ 12919 & .270 & & 2.644 & .783 & .122 & .199 \\ 12920 & .269 & & 2.644 & .781 & .115 & .188\end{array}$

${ }^{1}$ Adjusted to Dual Induction Log dated January 1, 1978.

2 Unstressed.

${ }^{3}$ Isostatic stress $=7800$ psi.

${ }^{4}$ Laboratory measurement corrected using a stock tank oil density of $.862 \mathrm{~g} / \mathrm{cm}^{3}$.

5

Corrected to in-situ values as follows:

$$
S_{o r}=S_{0} \times \frac{\phi_{1}}{\phi_{s}} \times \frac{1-\phi_{s}}{1-\phi_{1}} \times B_{0}
$$

$\mathrm{S}_{\mathrm{o}}=$ column 6 above

$\phi_{1}=$ unstressed porosity, column 2 above

$\phi_{\mathbf{S}}=$ stressed porosity which is unstressed porosity minus average porosity reduction due to stress (.011)

$B_{0}=$ formation volume factor, $1.545 \mathrm{bbls} / \mathrm{bbls}$ 
Table E-3

Summary of Petrophysical Parameters

\begin{tabular}{|c|c|c|}
\hline Parameter & $12915-12917 \mathrm{ft}$ & $12960-12970 \mathrm{ft}$ \\
\hline${ }^{1}$ Formation water salinity & $10825 \mathrm{ppm} \mathrm{C1}^{-}$ & $35,500 \mathrm{ppm} \mathrm{Cl}^{-}$ \\
\hline In-situ porosity & .256 & .261 \\
\hline 3 & 1.70 & 1.70 \\
\hline$n$ & 2.60 & 2.75 \\
\hline${ }^{4} R_{t}(o h m-m)$ & 3.3 & .99 \\
\hline${ }^{4} \rho_{b}\left(g / \mathrm{cm}^{3}\right)$ & 2.18 & 2.18 \\
\hline $5^{\rho_{\text {ma }}}\left(\mathrm{g} / \mathrm{cm}^{3}\right)$ & 2.644 & 2.645 \\
\hline
\end{tabular}

${ }^{1}$ Determined from analytical analysis of the swabbed formation water, BRC Analytical Chemistry Laboratory.

2 Average unstressed core porosity across interval minus average porosity reduction due to stress equals in-situ porosity (see Table E-2).

3 Average values of $\mathrm{m}$ and $\mathrm{n}$ from stressed (7800 psi and formation brine) laboratory measurements, BRC PSL.

${ }^{4}$ Appropriately corrected $\log$ values from four repeat passes.

$5_{\text {Laboratory measurements, BRC PSL. }}$ 
ATTACHMENT 2

Shell Development Company Reservoir Fluid Analysis of

Recombined Fluid from Weeks Island

Lab. No. AB-78068

February 20, 1978 


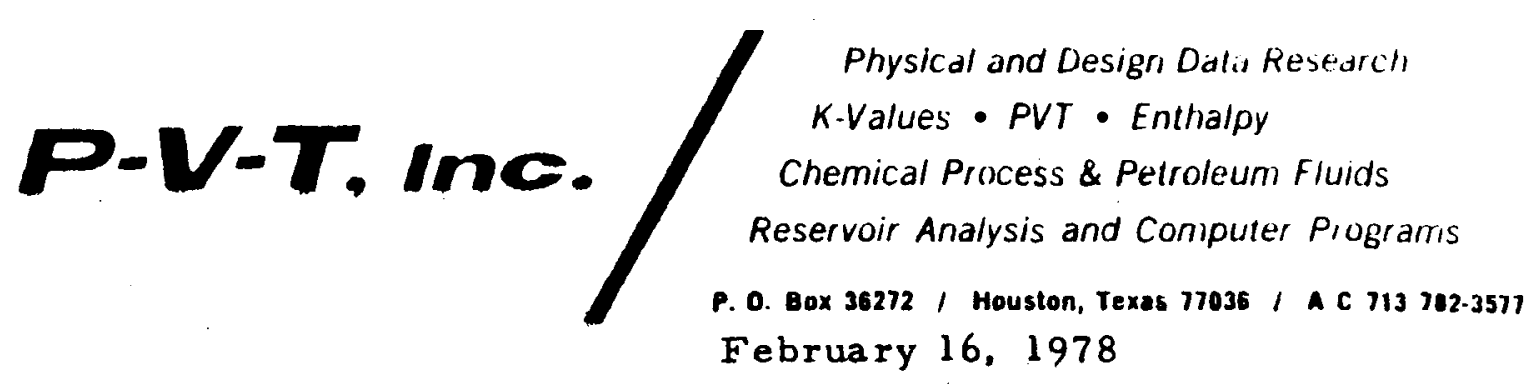

\section{February 16, 1978}

Shell Development Company

P. O. Box 1382

Houston, Texas 77001

Attn: Mr. Mike Moranville

Subject: Reservoir fluid analysis of recombined fluid from Weeks Island

Dear Mr. Moranville:

This report presents the results of laboratory tests upon a recombined reservoir fluid prepared with separator products from the above field. The composition of these are presented on pages five and $s i x$ of this report. These samples were then recombined to a saturation pressure of 5880 psia at the reservoir temperature of $225^{\circ} \mathrm{F}$. The resultant fluid mixture was then used for a reservoir fluid study.

The recombined fluid was found to contain 1386 SCF of gas per barrel of stock tank oil and a formation volume factor of 1.652 barrels of oil at Ps per barrel os stock tank oil during differential vaporization. The viscosity was measured to be 0.599 centipoise at saturation pressure and reached a maximum of 1.492 centipoises at the reservoir temperature of $225^{\circ} \mathrm{F}$. The tabulated data of these tests are presented on pages one through four of this report. The composition of the mixture is presented on page seven of this report.

The remaining sample was then adjusted to a saturation pressure of 5100 psia at $225^{\circ} \mathrm{F}$. The composition of both gas and liquid phases a re presented on pages 8 and 9 of this report. The remaining fluid will be used for phase contact work and will be reported separately.

It has been a pleasure serving Shell Development. Should you have any questions concerning this or any other matter, please feel free to call on us.

Very truly yours,

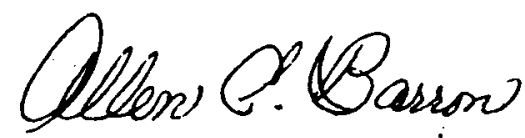

Allen E. Barron

AEB/jm 
Shell

P-V - T Summary

Weeks Island $16 \mathrm{~A}$

Reservoir T emperature, ${ }^{\circ} \mathrm{F} \quad 225$

Saturation Pressure at $225^{\circ} \mathrm{F}$, Psia $\quad 5880$

Compressibility of Reservoir Oil at $255^{\circ} \mathrm{F}$

Vol. per Vol. per Psi $\times 10^{6}$

From 6500 Psia to 6200 Psia 15.4197

From 6200 Psia to 5880 Psia 17.5001

Siturated Oil at 5830 Psia, $225^{\circ} \mathrm{F}$

Density, Gms. per Ml. $\quad 0.6540$

Lbs. per Bbl. $\quad 229.227$

Specific Volume, Cu. Ft. per Lb. $\quad 0.02445$

Viscosity, Centipoise 0.559

Formation Volume Factor, Bbls. per Bbl.

"Residual Stock Tank Oil" at $60^{\circ} \mathrm{F} \quad 1.652$

Solution Gas-Oil Ratio, Cu. Ft. per Bbl.

"Residual Stock Tank Oil" at $60^{\circ} \mathrm{F}$

Reservoir Oil at 5100 Psia $225^{\circ} \mathrm{F}$

Density, Gms. per Ml. 0.6689

Lbs. per Bbl. $\quad 234.450$

Specific Volume, Cu. Ft. per Lb. $\quad 0.02395$

Viscosity, Centipoise

0.582

Formation Volume Factor, Bbl. per Bbl.

"Residual Stock Tank Oil" at $60^{\circ} \mathrm{F}$

Lab. No. AB-7806́8

Page 1 of 12 
Shell Oil Co.

Weeks Island I6A

\section{CQMPOSITE LABORATORY DATA AT $225^{\circ}$ 'F}

\begin{tabular}{|c|c|c|c|c|c|c|c|c|}
\hline \multirow{3}{*}{ 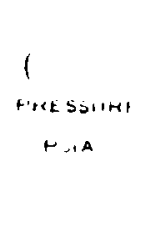 } & \multicolumn{3}{|c|}{ WRE SSURE VULUME RELATMNE } & \multirow{3}{*}{$\begin{array}{c}\text { OIL } \\
\text { Viscosity } \\
\text { Centipoises }\end{array}$} & \multicolumn{4}{|c|}{ DIFFEAENTIAL LIBERATION } \\
\hline & \multirow[b]{2}{*}{$\begin{array}{c}\text { PELATIVE } \\
\text { VOLUME } \\
\text { Y VIAI } \\
\text { B. }\end{array}$} & \multirow{2}{*}{$\begin{array}{l}\text { SFECIFIC } \\
\text { VOLUME } \\
\text { Ca. II. } \\
\text { PoI } \\
\text { Pound }\end{array}$} & \multirow{2}{*}{ 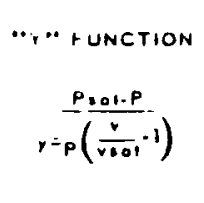 } & & \multirow{2}{*}{$\begin{array}{l}\text { FORMATION } \\
\text { VOLUME } \\
\text { FACTOR } \\
\text { Bo }\end{array}$} & \multirow[b]{2}{*}{$\begin{array}{c}\text { RELÁTIVE } \\
\text { OIL. } \\
\text { VOLUME }\end{array}$} & \multicolumn{2}{|c|}{$\begin{array}{l}\text { SOLUTION } \\
\text { GAS-OIL RATIO } \\
\end{array}$} \\
\hline & & & & & & & $\begin{array}{c}\text { Per Bbl. } \\
\text { Siock } \\
\text { Tant Oil } \\
\text { ol } 60^{4} \mathrm{~F}\end{array}$ & $\begin{array}{c}\text { Per Bbl. } \\
\text { Oll al } \\
\text { Reservots } \\
\text { Bubbio-Point }\end{array}$ \\
\hline 6500 & 0.9898 & 0.02420 & & 0.568 & 1.635 & & & \\
\hline 6400 & 0.9914 & 0.02424 & & & 1.638 & & & \\
\hline 6300 & 0.9929 & 0.02428 & & 0.564 & 1.640 & & & \\
\hline 6200 & 0.9944 & 0.02431 & & & 1.643 & & & \\
\hline 6100 & 0.9960 & 0.02435 & & 0.561 & 1.645 & & & \\
\hline 6000 & 0.9977 & 0.02439 & & & 1.648 & & & \\
\hline 5900 & 0.9997 & 0.02444 & & & 1.651 & & & \\
\hline ; 5880 & 1.0000 & 0.02445 & & 0.559 & 1.652 & 1.0000 & 1386 & 839 \\
\hline 5800 & 1.0034 & & 4.074 & & & & & \\
\hline 5700 & 1.0078 & & 4.047 & & & & & \\
\hline 5500 & 1.0174 & & 3.977 & & & & & \\
\hline 5300 & 1.0280 & & 3.911 & & & & & \\
\hline 5200 & & & & 0.579 & 1.566 & 0.9479 & 1122 & 679 \\
\hline 4900 & 1.0529 & & 3.779 & & & & & \\
\hline 4600 & 1.0756 & & 3.680 & 0.604 & 1.489 & 0.9013 & 962 & 582 \\
\hline 4300 & 1.1026 & & 3.582 & & & & & \\
\hline$\therefore \quad 10$ & 1.1348 & & 3.486 & 0.639 & 1.418 & 0.8584 & 819 & 496 \\
\hline 3,00 & 1. 2047 & & 3.322 & & & & & \\
\hline 3400 & & & & 0.684 & 1.364 & 0.8257 & 690 & 418 \\
\hline 3000 & 1.3039 & & 3.159 & & & & & \\
\hline 2800 & & & & 0.738 & 1.312 & 0.7942 & 561 & 340 \\
\hline 2500 & 1.4511 & & 2.997 & & & & & \\
\hline 2200 & & & & 0.798 & 1.266 & 0.7663 & 438 & 265 \\
\hline 2000 & 1.6850 & & 2.832 & & & & & \\
\hline 1600 & & & & 0.864 & 1.224 & 0.7409 & 320 & 194 \\
\hline 1500 & 2.0953 & & 2.666 & & & & & \\
\hline 1000 & 2. 9497 & & 2.503 & 0.965 & 1.184 & 0.7167 & 212 & 128 \\
\hline 700 & $\begin{array}{l}\text { Vsat. is } \\
\text { ie volume }\end{array}$ & ated oil & foil and o & $\begin{array}{l}1.049 \\
\text { the indicat } \\
\text { and indic }\end{array}$ & $\begin{array}{l}1.163 \\
\text { emperature } \\
\text { d temperatu }\end{array}$ & $\begin{array}{l}0.7040 \\
\text { pressure }\end{array}$ & $\begin{array}{l}154 \\
\text { arive } 10\end{array}$ & 93 \\
\hline
\end{tabular}

Bo is the volume of oil at reservoir temperature and indicated pressure rolative to the volume of resi. dual stock lank oil measured at $60^{\circ} \mathrm{F}$.

Gos-Oil Ratio, is cubic feet of gas at 14,65 psio and $60^{\circ} \mathrm{F}$, por barrel of residual oil of $60^{\circ} \mathrm{F}$.

Nole: "indicates value measured at $60^{\circ} \mathrm{F}$.

Lab. No. AB-78068

Page 2 of 12 
Shell Oil Co.

COMPOSITE LABORATORY DATA AT $225^{\circ}$ ¿F

Weeks Island 16A

\begin{tabular}{|c|c|c|c|c|c|c|c|c|}
\hline \multirow{3}{*}{$\begin{array}{l}\text { PHESSIIHI } \\
\text { FSIA }\end{array}$} & \multicolumn{3}{|c|}{.lot: sIJHE VOLIUME RELATIUNS } & \multirow{3}{*}{$\begin{array}{c}\text { OIL } \\
\text { VIscositr } \\
\text { Contipoises }\end{array}$} & \multicolumn{4}{|c|}{ DIFFERENTIAL LIEERATION } \\
\hline & \multirow{2}{*}{ 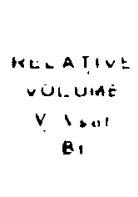 } & \multirow{2}{*}{$\begin{array}{l}\text { SPECIIFIC } \\
\text { VOL UME } \\
\text { Cu. ll. } \\
\text { Per } \\
\text { Pound }\end{array}$} & \multirow{2}{*}{ 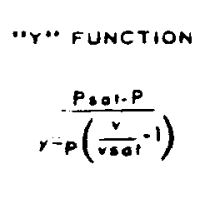 } & & \multirow{2}{*}{$\begin{array}{l}\text { FORMATION } \\
\text { VOLUME } \\
\text { FACTOR } \\
\text { B. }\end{array}$} & \multirow{2}{*}{$\begin{array}{l}\text { RELATIVE } \\
\text { OIL- } \\
\text { VOLUME }\end{array}$} & \multicolumn{2}{|c|}{$\begin{array}{l}\text { SOLUTION } \\
\text { GASOOL HAYIOO }\end{array}$} \\
\hline & & & & & & & $\begin{array}{l}\text { Per obl. } \\
\text { Slock } \\
\text { Tonk Oil } \\
\text { a } 60^{\circ} \mathrm{F}\end{array}$ & $\begin{array}{c}\text { Per Bbl. } \\
\text { Oil of } \\
\text { Ronervoir } \\
\text { Bubble. Point }\end{array}$ \\
\hline 400 & & & & 1.169 & 1.146 & 0.6937 & 96 & 58 \\
\hline 200 & & & & 1.289 & 1.129 & 0.6834 & 53 & 32 \\
\hline 15 & & & & 1.492 & 1.077 & 0.6519 & 0 & 0 \\
\hline $15 @$ & F. & & & & 1.000 & 0.6053 & & \\
\hline
\end{tabular}

NOMENCLATURE:

$V$ Vsat. is the volume of fluids (oil and gas) at the indicated temperature and pressure relative to the volume of soturated oil of bubblepoint prassure and indicoted temperature.

Bo is the volume of oil at reservoir tomperature and indicated pressure relative to the volume of resi. dual stock tank oil mea sured of $60^{\circ} \mathrm{F}$.

Gos-Oil Ratio, is cubic feet of ges at 14.65 psio and $60^{\circ} \mathrm{F}$, per borral of residual oil at $60^{\circ} \mathrm{F}$.

Note: "indicates volue measured at $60^{\circ} \mathrm{F}$.

2. No. AB- 78068

Page 3 of 12 


\section{LABORATORY DATA}

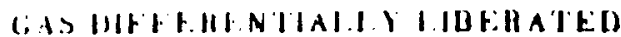

\begin{tabular}{|c|c|c|}
\hline \multicolumn{2}{|c|}{$\begin{array}{l}\text { SPECIFIC: GIIAVITY } \\
\qquad(A I A=1.00)\end{array}$} & \multirow{2}{*}{$\begin{array}{l}\text { DE.VIATION } \\
\text { FACTOH } \\
\text { Z= FV }\end{array}$} \\
\hline Increm & Accun. & \\
\hline- & - & - \\
\hline 0.7068 & 0.7068 & 1.056 \\
\hline 0.7041 & 0.7056 & 0.995 \\
\hline 0.6959 & 0.7031 & 0.955 \\
\hline 0.6899 & 0.7005 & 0.927 \\
\hline 0.6852 & 0.6981 & 0.909 \\
\hline 0.6868 & 0.6966 & 0.902 \\
\hline 0.6995 & 0.6970 & 0.907 \\
\hline 0.7268 & 0.6998 & 0.928 \\
\hline 0.7481 & 0.7021 & 0.942 \\
\hline 0.7937 & 0.7062 & 0.962 \\
\hline 0.8555 & 0.7110 & 0.980 \\
\hline 1.0766 & 0.7251 & - \\
\hline
\end{tabular}

CAS VOLUME FACTOH

BbI. IN

RESER VOIA

Per MACF $\left(B_{B}\right)$

698.02

743.48

820.63

937.14

1115.87

1409.26

1948.48

3189.73

4625.50

8266.49

16842.32

15

Lab. No. A B - 78068

Page 4 of 12 


\begin{tabular}{lrc} 
Component & Mol\% & 14.65 Psia \\
\cline { 2 - 3 } Carbon dioxide & 1.06 & \\
Nitrogen & 0.34 & \\
Methane & 89.63 & 1.149 \\
Ethane & 4.32 & 0.543 \\
Propane & 1.98 & 0.196 \\
iso-Butane & 0.60 & 0.239 \\
n-Butane & 0.76 & 0.138 \\
iso-Pentane & 0.38 & 0.104 \\
n-Pentane & 0.29 & 0.135 \\
Hexanes & 0.33 & 0.147 \\
Heptanes Plus & 0.31 & 2.651
\end{tabular}

Specific gravity @ 60 $\mathrm{F} .($ Air $=1)=0.6558$

Heating Value, BTU/SCF at 14.65 psia

$$
\begin{aligned}
& \text { Dry }=1133 \\
& \text { Wet }=1113
\end{aligned}
$$

Lab. No. AB-78068

Page 5 of 12 
Fractional Hydroca rbon Analys is Of

$93 \mathrm{psi}$ at $148^{\circ} \mathrm{F}$ Separator Liquid

Component

Hydrogen-sulfide

Carbon dioxide

Nitrogen

Methane

Ethane

Propane

iso-Butane

$\mathrm{n}$-Butane

i so-Pentane

n-Pentane

Hexane

Heptanes Plus
Mol\%

$-$

0.04

0.01

1.93

0.66

1.24

0.86

1. 70

2.43

2. 24

6.66

$\frac{82.23}{100.00}$
Wt. $\%$

0.01

Trace

0.16

0.10

0.28

0.25

0.50

0.88

0.81

2. 87

$\frac{94.14}{100.00}$

Heptanes-Plus :

Specific gravity $60^{\circ} / 60^{\circ}-0.8596$

Molecular weight $=228$

Lab. No. AB-78068

Page 6 of 12 
Fractional Hydrocarbon Analysis of Recombined Reservoir Fluid

Component

Hydrogen-sulfide

Carbon dioxide

Nitrogen

Methane

Ethane

Propane

iso-Butane

$\mathrm{n}$-Butane

i so-Pentane

n-Pentane

Hexane

Heptanes Plus

\section{Mol\%}

$-$

0.71

0.24

63.20

3.37

1.67

0.53

0.84

0.56

0.47

0.82

$\frac{27.59}{100.00}$ $\underline{\text { Wt. } \%}$

0.40

0.09

13.24

1.32

0.97

0.40

0.64

0.52

0.44

0.91

$\frac{81.07}{100.00}$

Heptanes Plus:

Specific gravity $60^{\circ} / 60^{\circ}=0.8587$

Molecular weight $=225$

Lab. No. AB-78068

Page 7 of 12 
SA MPLE MARKED:

Component

Carbon dioxide Nitrogen

Methane

Ethane

Propane

iso-Butane

n-Butane

iso-Pentane

$\mathrm{n}$-Pentane

Hexane

Heptanes Plus
Mol\%

0.84

0.44

88.95

3.69

1.67

0.68

0.84

0.64

0.59

- 65

T6 $\frac{01}{.00}$
GPM@

14.65 Psia

Ethane Plus

0.9266

0.4569

0.2211

0.2633

0.2329

0.2125

0.2636

$\frac{0.4559}{3.0328}$

Specific gravity@60 $@($ Air $: 1)=0.6902$

Heating value, BTU/SCF at 14.65 psia

$$
\text { I.ry }=1189
$$

Wet $=1167$

Lab. No. AB-78068

Page 8 of 12 
Shell Oil Company

Weeks Island $16 \mathrm{~A}$

Fractional Hydrocarbon Analysis of

5100 psia and $225^{\circ} \mathrm{F}$. Equilibrium Liq.

Component

Hydrogen-sulfide

Carbon dioxide

Nitrogen

Methane

Ethane

Propane

iso-Butane

n-Butane

i so-Pentane

n-Pentane

Hexanes

Heptanes Plus
Mol\%

0.68

0.37

56.93

3.31

1.66

0.60

0.84

0.56

0.46

0.74

$\frac{33.85}{100.00}$
Wt. $\%$

0.32

0.11

9.78

1.07

0.78

0.37

0.52

0.43

0.35

0.67

85.60

Heptanes-Plus:

Specific gravity $60^{\circ} / 60^{\circ}=0.8657$

Molecular weight $=236$

Lab. No. AB-78068

Page 9 of 12 


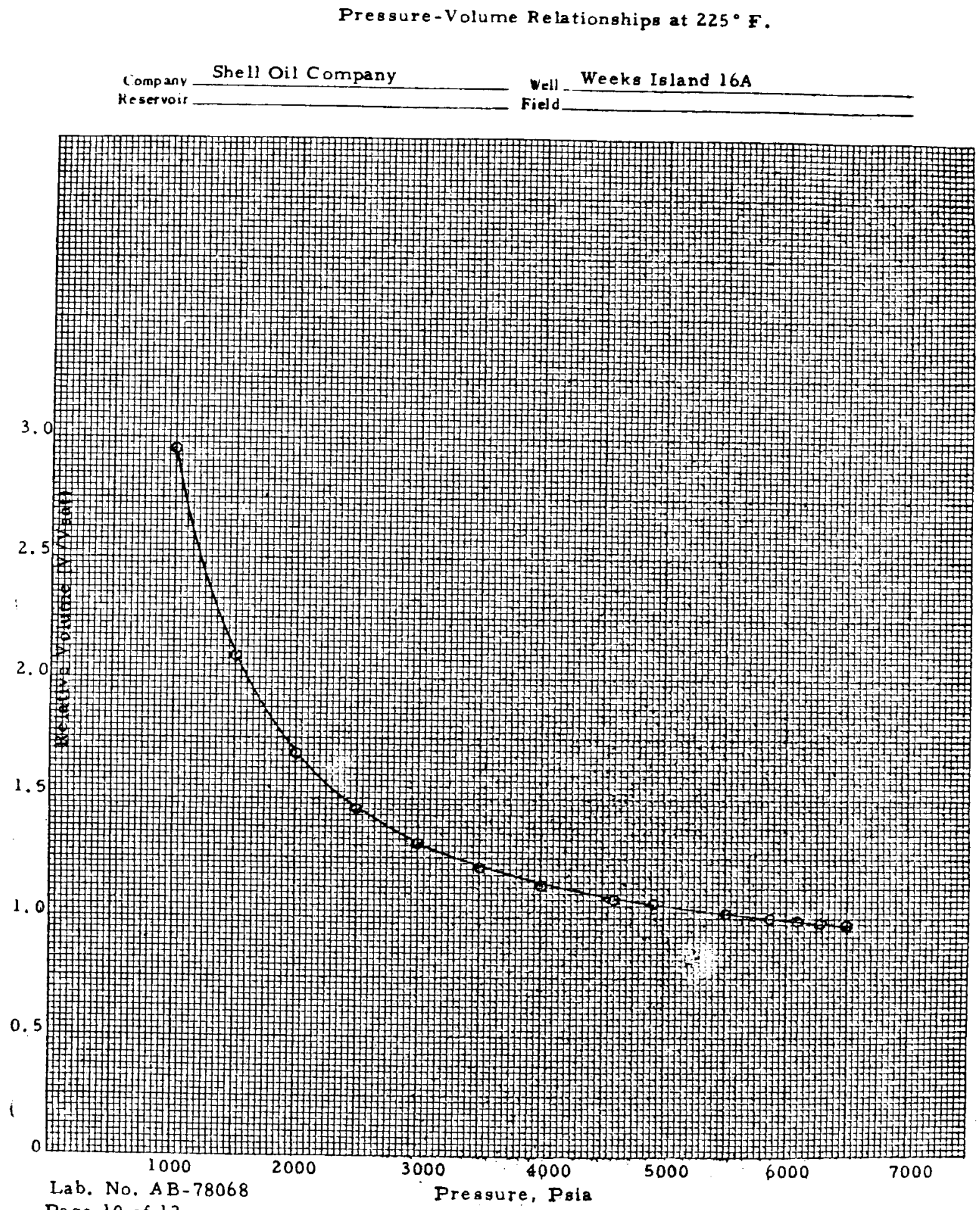


Difierential Vaporization at $225^{\circ} \mathrm{F}$.

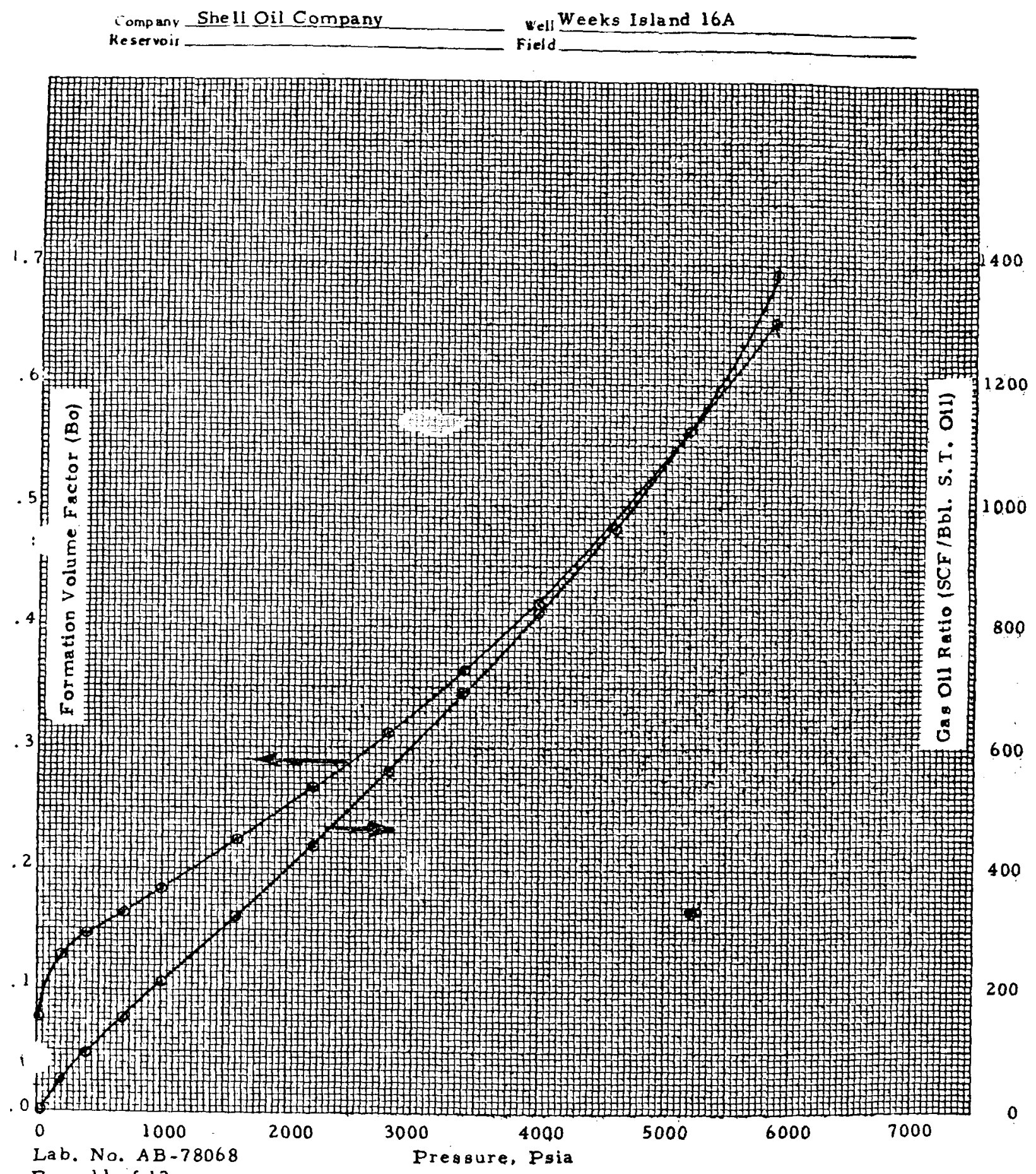

Page 11 of 12 
Viscosity at $225^{\circ} \mathrm{F}$.

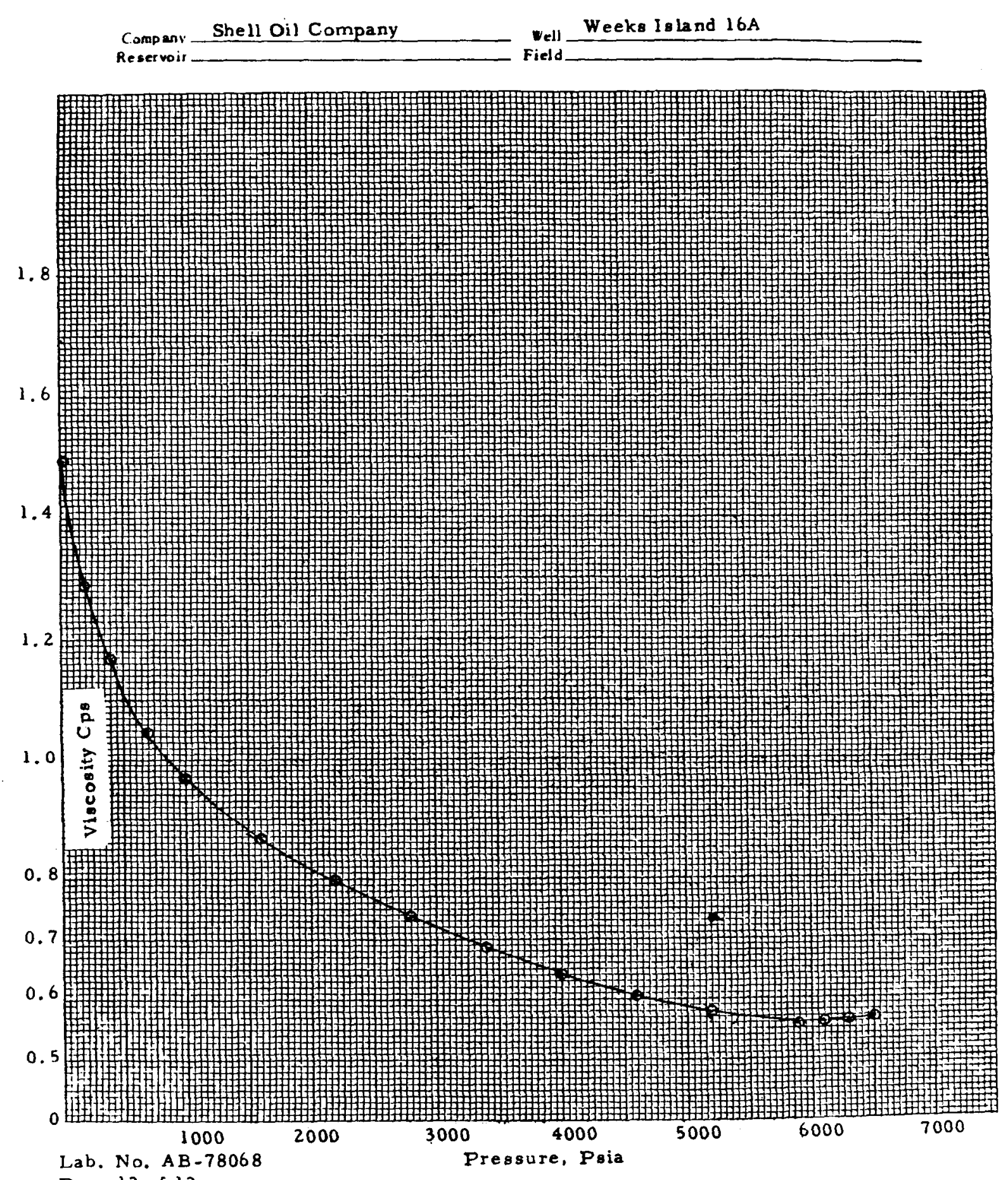

Page 12 of 12 
Shell Development Company

Petrophys 1cal Services laboratory

Core Analyses Data

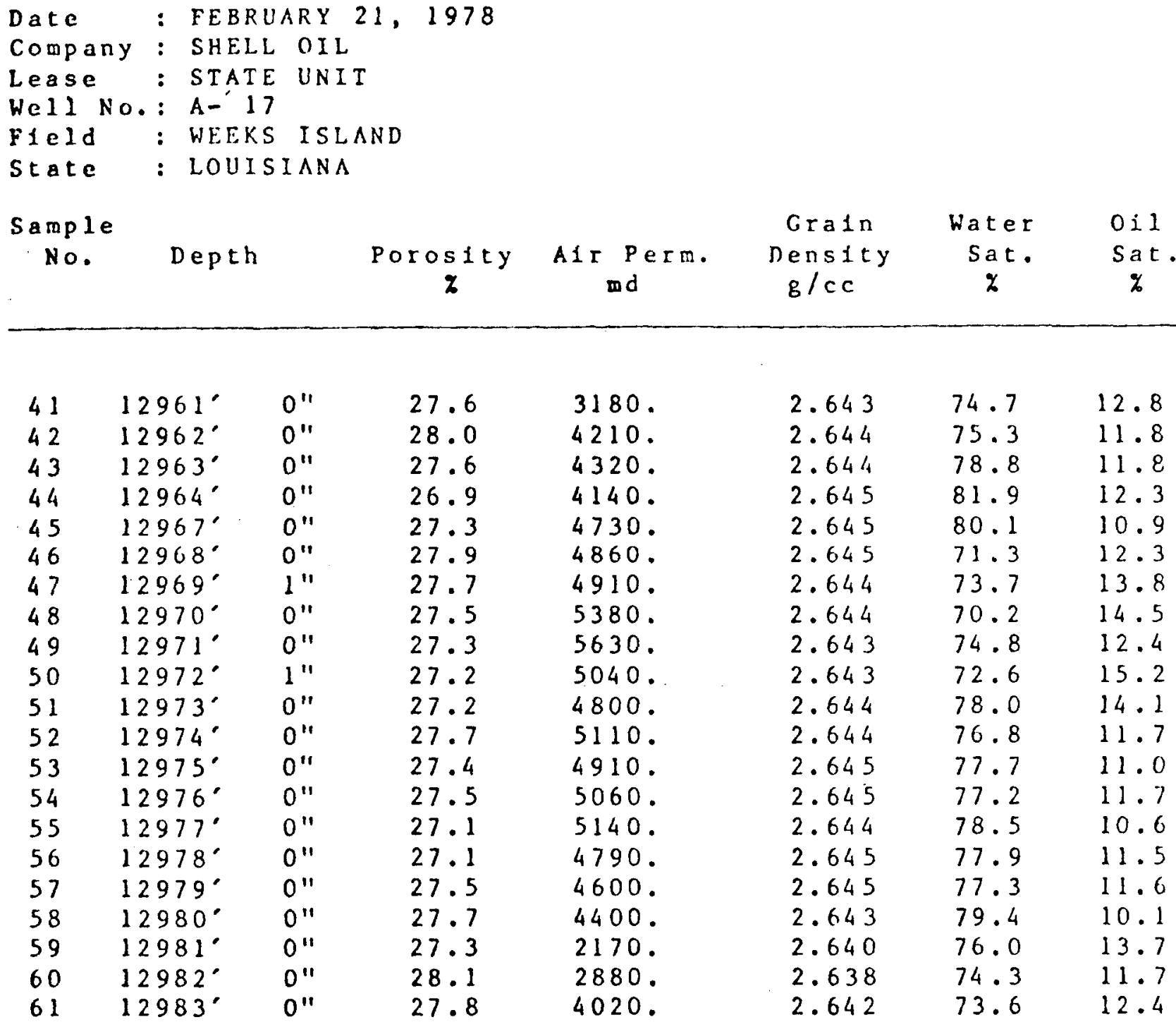


Shell Development Company

Petrophysical Services Laboratory

Core Analyses Data

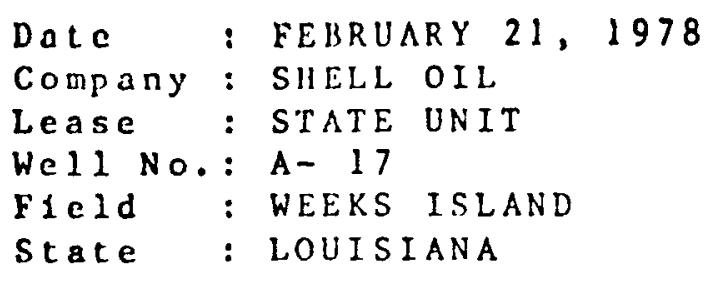

Sample No. Depth

\begin{tabular}{ccccc} 
& Grain & Water & 011 \\
Porosity & A1r Perm. & Density & Sat. & Sat. \\
md & g/cc & $\%$ & $\%$ \\
\hline
\end{tabular}

\begin{tabular}{|c|c|c|c|c|c|c|c|}
\hline 1 & $12910^{\circ}$ & $0^{\prime \prime}$ & 26.0 & 2460 . & 2.644 & 70.9 & 19.3 \\
\hline 2 & $12911^{\circ}$ & $0^{\prime \prime}$ & 26.9 & 2290 & 2.646 & 83.9 & 9.2 \\
\hline 3 & $12912^{\circ}$ & $0^{\prime \prime}$ & 27.8 & 6230 . & 2.643 & 76.7 & 11.3 \\
\hline 4 & $12913^{\circ}$ & $0^{\prime \prime}$ & 27.5 & 5530. & 2.645 & 85.3 & 9.8 \\
\hline 5 & $12914^{\circ}$ & $0^{\prime \prime}$ & 26.4 & 2450 & 2.644 & 76.3 & 15.6 \\
\hline 6 & $12915^{\circ}$ & $0^{\prime \prime}$ & 26.6 & 3110 . & 2.644 & 76.0 & 12.7 \\
\hline 7 & $12916^{\circ}$ & $0^{\prime \prime}$ & 26.9 & 2960 . & 2.644 & 79.3 & 11.0 \\
\hline 8 & $12917^{\circ}$ & $0^{\prime \prime}$ & 26.1 & 2010 . & 2.645 & 73.1 & 16.1 \\
\hline 9 & $12918^{\circ}$ & 0" & 26.5 & 1130. & 2.641 & 77.1 & 16.3 \\
\hline 10 & $12919^{\circ}$ & 0" & 26.7 & 1820. & 2.635 & 61.7 & 15.5 \\
\hline 11 & $12919^{\circ}$ & $10 "$ & 27.4 & 2390. & 2.641 & 79.3 & 11.0 \\
\hline 12 & $12921^{\circ}$ & $0^{\prime \prime}$ & 26.8 & 2190. & 2.641 & 76.5 & 11.6 \\
\hline 13 & $12922^{\circ}$ & $0^{\prime \prime}$ & 25.3 & 1290 & 2.638 & 72.1 & 21.7 \\
\hline 14 & $12923^{\circ}$ & $0^{\prime \prime}$ & 27.0 & 2350 . & 2.644 & 78.3 & $11 . t_{\mathrm{i}}$ \\
\hline 15 & $12924^{\circ}$ & $0^{\prime \prime}$ & 26.9 & 2120 . & 2.644 & 78.1 & 10.8 \\
\hline 16 & $12925^{\circ}$ & $0^{\prime \prime}$ & 27.3 & 1990 & 2.640 & 72.2 & 15.9 \\
\hline 17 & $12926^{\circ}$ & $0^{\prime \prime}$ & 26.4 & 1590. & 2.639 & 72.8 & 14.7 \\
\hline 18 & $12927^{\circ}$ & $0^{\prime \prime}$ & 25.2 & 640 . & 2.639 & 70.8 & 14.8 \\
\hline 19 & $12931^{\circ}$ & $0^{\prime \prime}$ & 26.4 & 2720 . & 2.644 & 81.8 & 11.6 \\
\hline 20 & $12932^{\circ}$ & $0^{\prime \prime}$ & 26.5 & 4620 . & 2.645 & 83.0 & 9.4 \\
\hline 21 & $12933^{\circ}$ & $0^{\prime \prime}$ & 25.4 & 4810. & 2.646 & 78.9 & 10.3 \\
\hline 22 & $12934^{\circ}$ & $0^{\prime \prime}$ & 25.2 & 4630. & 2.644 & 76.7 & 12.0 \\
\hline 23 & $12935^{\circ}$ & $0^{\prime \prime}$ & 27.3 & 2970. & 2.643 & 79.1 & 13.8 \\
\hline 39 & $12940^{\circ}$ & $0^{\prime \prime}$ & 27.2 & NT & 2.651 & 26.2 & 9.8 \\
\hline 40 & $12941^{\circ}$ & $0^{\prime \prime}$ & 26.6 & 4660 . & 2.645 & 25.0 & 11.1 \\
\hline 26 & $12949^{\circ}$ & $0^{\prime \prime}$ & 26.9 & 3760 . & 2.645 & 83.8 & 11.0 \\
\hline 27 & $12950^{\circ}$ & $0^{\prime \prime}$ & 28.0 & 4170. & 2.645 & 86.2 & 10.3 \\
\hline 28 & $12951^{\circ}$ & 0" & 28.3 & 2260 & 2.653 & 73.0 & 20.0 \\
\hline 29 & $12952^{\circ}$ & $0^{\prime \prime}$ & 27.4 & 1890. & 2.642 & 66.2 & 11.7 \\
\hline 30 & $12953^{\circ}$ & $0^{\prime \prime}$ & 26.5 & 2670 & 2.646 & 71.2 & 13.2 \\
\hline 31 & $12954^{\circ}$ & $0^{\prime \prime}$ & 26.8 & 4340. & 2.645 & 74.9 & 12.6 \\
\hline 32 & $12955^{\circ}$ & $2^{\prime \prime}$ & 26.6 & 3920. & 2.646 & 79.7 & 12.0 \\
\hline 33 & $12956^{\circ}$ & $0^{\prime \prime}$ & 26.8 & 3680 . & 2.645 & 81.8 & 11.3 \\
\hline 34 & $12957^{\circ}$ & $0^{\prime \prime}$ & 27.7 & 3480 . & 2.644 & 84.9 & 9.1 \\
\hline 35 & $12958^{\circ}$ & $0^{\prime \prime}$ & 28.0 & 2670 . & 2.649 & 78.2 & 10.7 \\
\hline 36 & $12959^{\circ}$ & $0^{\prime \prime}$ & 27.9 & 2220 . & 2.643 & 73.5 & 13.0 \\
\hline 37 & $12960^{\circ}$ & $0^{\prime \prime}$ & 28.3 & 2850 . & 2.643 & 69.4 & 13.5 \\
\hline
\end{tabular}




\section{Directional Permeability Study State Unit $A-17$ \\ Weeks Island Field, Louislana}

\section{Sample \\ Depth \\ ft.}

12941

12950

$12954^{\prime} 6^{\prime \prime}$

12960

12964

12970

12975

12980

Average
Air Permeabllity, (1) md

\begin{tabular}{lll}
\hline Plug $(2)$ & Plug & Plug \\
No. 1 & No. 2 & No. 3 \\
\hline
\end{tabular}

4350

4840

4660

4680

3990

4170

4130

4410

$4340\left(12954^{\prime}\right)$

$3920\left(12955^{\prime}\right)$

2580

2850

4210

4140

3910

4040

5380

4350

4910

3780

4400

4010

4030

4310

(1) Measured with 200 psi stress on core.

(2) See attached schematic for explanation of plug orientation. 
95

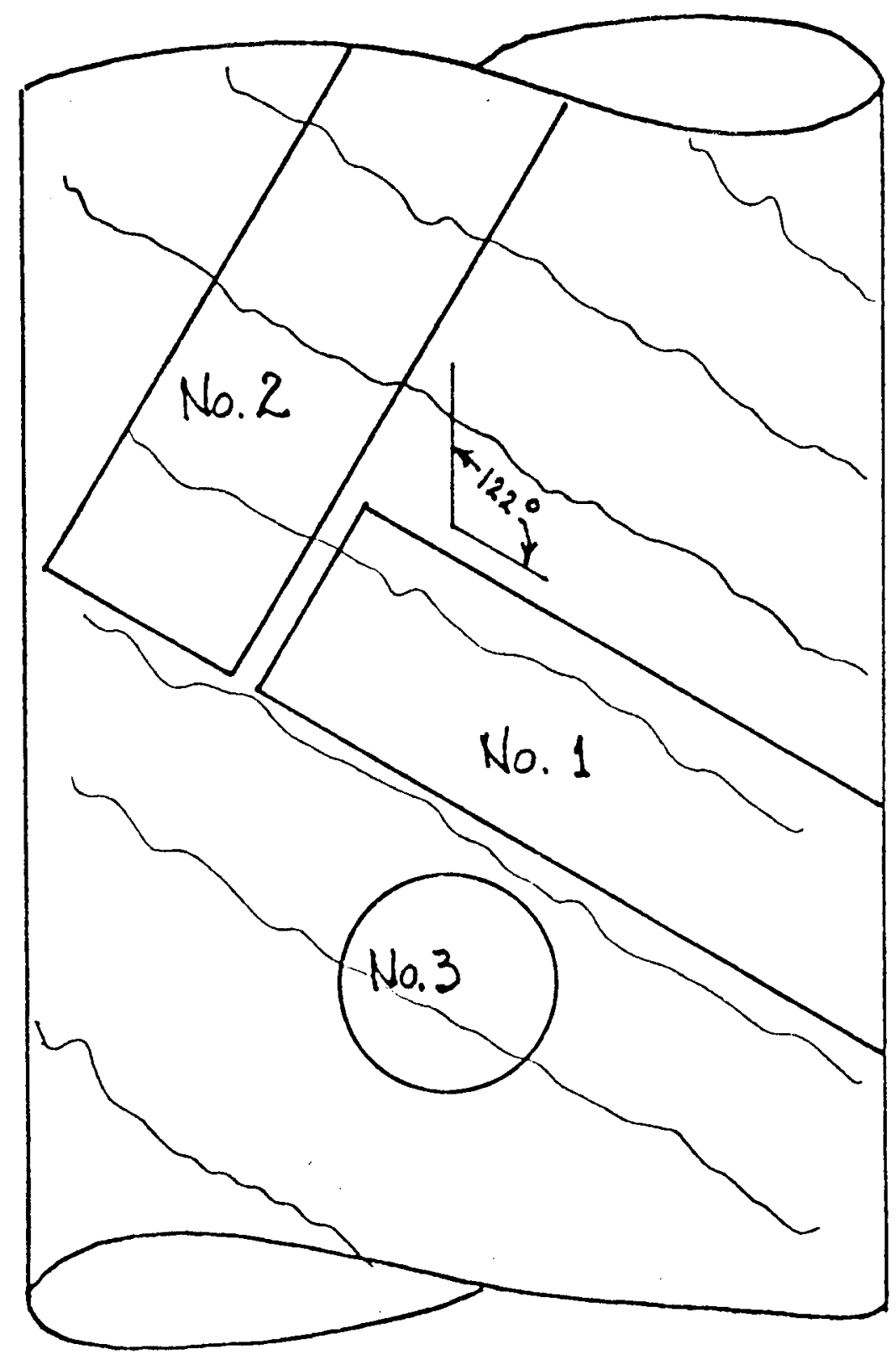

Schematic Showing Orientation of Plugs For Directional Permeability study

Plug No.1: Parallel to Dip

Plug No. 2: Perpendicular to Dib

Plug Nos: Parallel to Strike 


\section{CORE DATA \\ STATE UNIT A-17 \\ WEEKS ISLAND FIELD, LOUISIANA}

\begin{tabular}{clccc}
$\begin{array}{c}\text { Sample } \\
\text { No. }\end{array}$ & $\begin{array}{c}\text { Depth } \\
\mathrm{ft.}\end{array}$ & $\begin{array}{c}\text { Porosity } \\
\%\end{array}$ & $\begin{array}{c}\text { Brine } \\
\text { Perm. } \\
\text { md. }\end{array}$ & $\begin{array}{c}\text { Cation } \\
\text { Exchange } \\
\text { Capacity } \\
\text { MEQ/mI }\end{array}$ \\
\hline 6 & 12915 & 25.6 & 1510 & .018 \\
8 & 12917 & 24.8 & 1330 & .035 \\
11 & $12919^{\prime} 10^{\prime \prime}$ & 26.4 & 1230 & .024 \\
13 & 12922 & 24.2 & 848 & .049 \\
22 & 12934 & 24.0 & 938 & .019 \\
37 & 12960 & 26.6 & 1660 & .026 \\
44 & 12964 & 25.5 & 1530 & .010 \\
45 & 12967 & 26.0 & 1660 & .026 \\
46 & 12968 & 25.9 & 2290 & .013 \\
49 & 12971 & 26.4 & 1680 & .015
\end{tabular}

Porosities and brine permeabilities measured under an applied stress of 7800 psi. CEC values based on stressed porosities.

Samples 6-22: Brine contained $18 \mathrm{~g} \mathrm{NaC1/liter.}$

Samples 37-49: Brine contained $59 \mathrm{~g}$ NaC1/liter. 
SHELL DEVELOPMENT COMPANY

TECHNICAL SERVICE

RESIDUAL-INITIAL AIR SATURATION DATA REPORT

(Liquid-Air Countercurrent Imbibition)

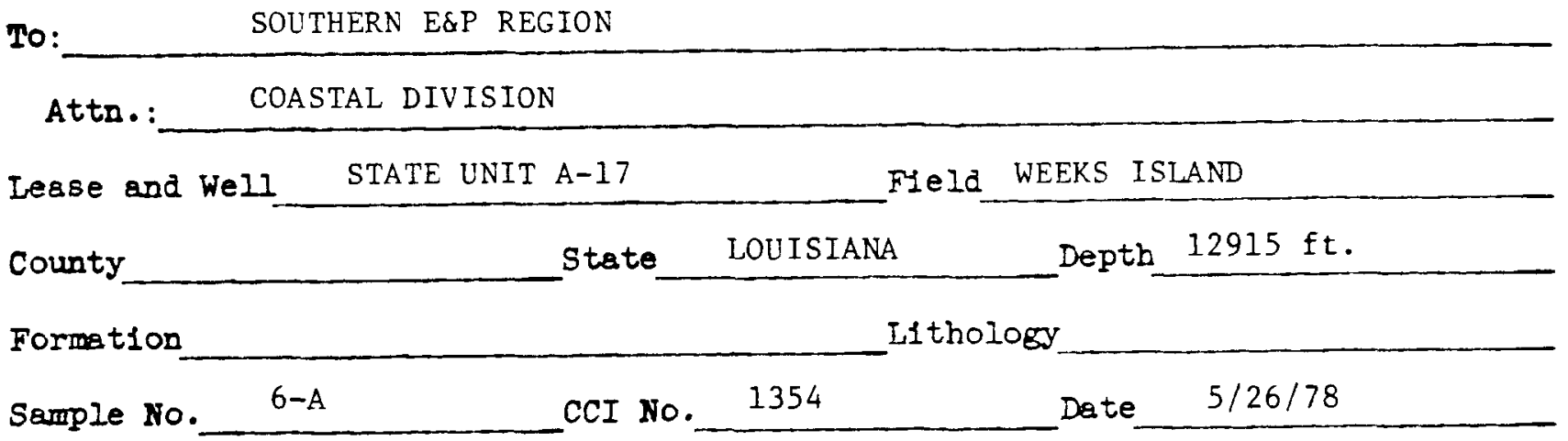

Porosity $(\phi) \quad 26.3 \quad \operatorname{Permeab1lity}(\mathrm{md}) \_$Grain Density $(\mathrm{g} / \mathrm{cc}) \quad 2.640$

Remark8:

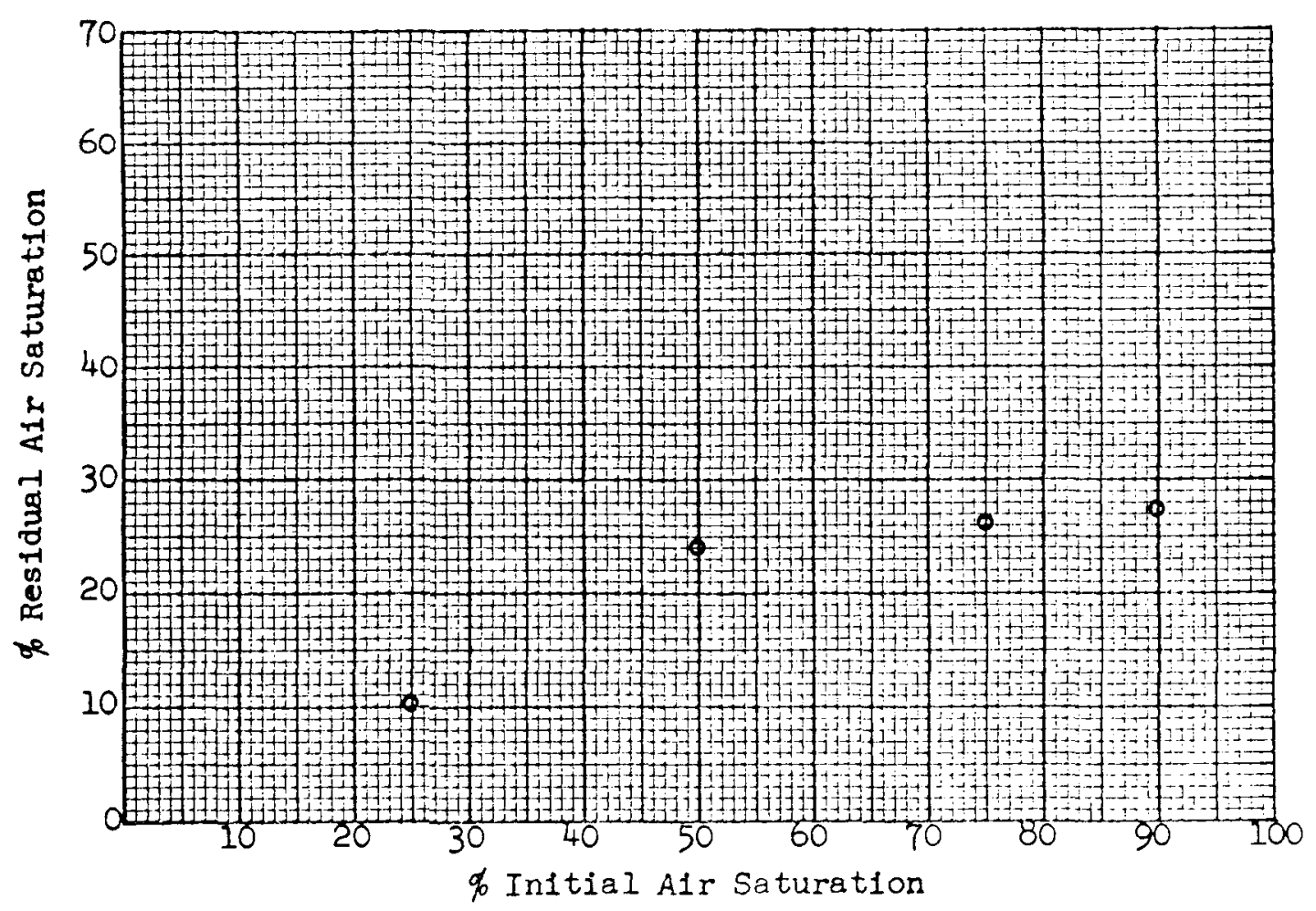


SHELI DEVELOPMENT COMPANY TECHNICAL SERVICE

RESIDUAL-INITIAL AIR SATURATION DATA REPORT

(Liquid-Air Countercurrent Imbibition)

To: $\quad$ SOUTHERN E\&P REGION

Lesse and Well STATE UNIT A-17 FIeld WEEKS ISLAND

County_State LOUISIANA_ Depth $12922 \mathrm{ft}$.

Formation_Lithology

Semple No. 13-A_CCI No. $1355 \quad$ Date $5 / 26 / 78$

$\operatorname{Poros1ty}(\%) \quad 24.9 \quad \operatorname{Permeabil1ty}(\mathrm{md}) \_$_____ain Density $(\mathrm{g} / \mathrm{cc}) \quad 2.591$

Remarks:

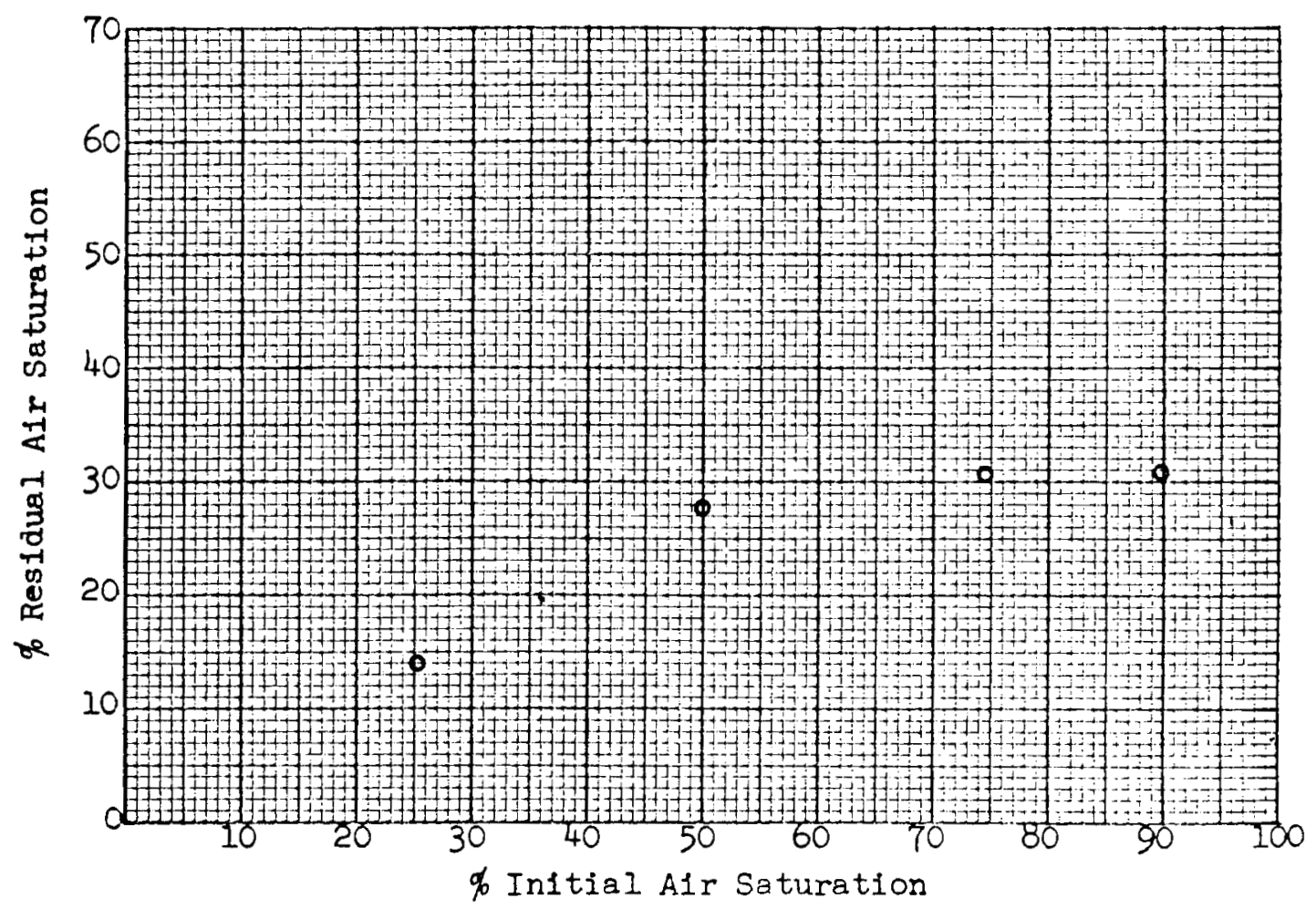


SHELI DEVELOPMENT COMPANY TECHNICAL SERVICE

RESIDUAL-INITIAL AIR SATURATION DATA REPORT

(Iiquid-Air Countercurrent Imbibition)

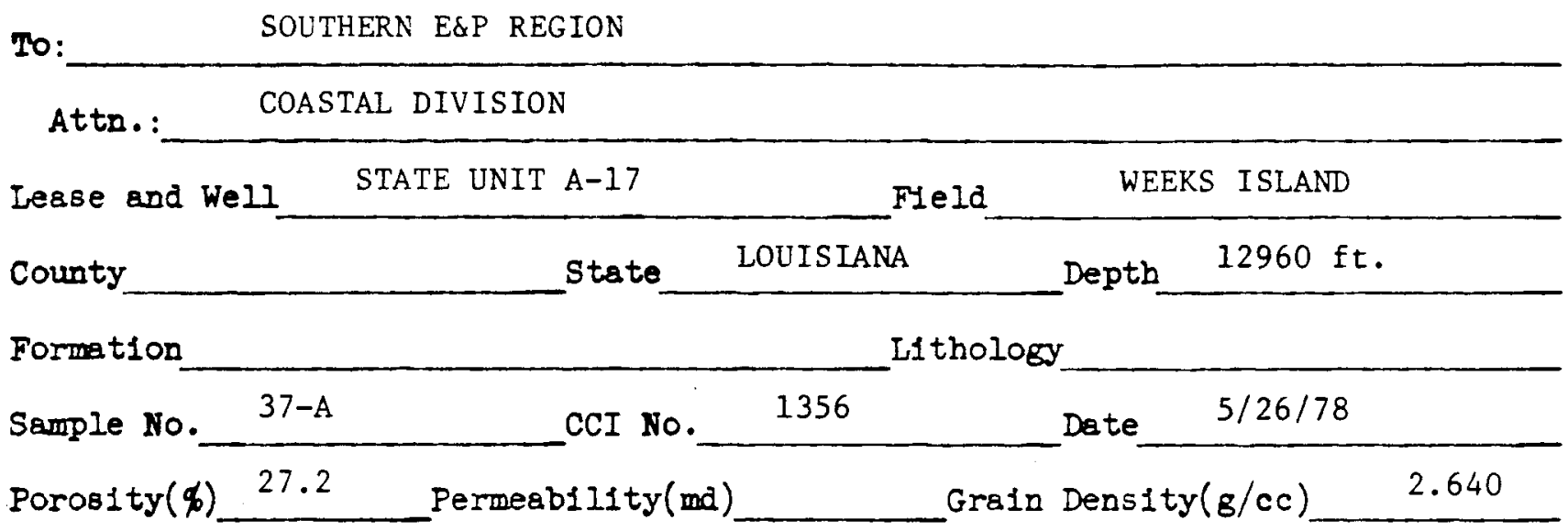

Remarks :

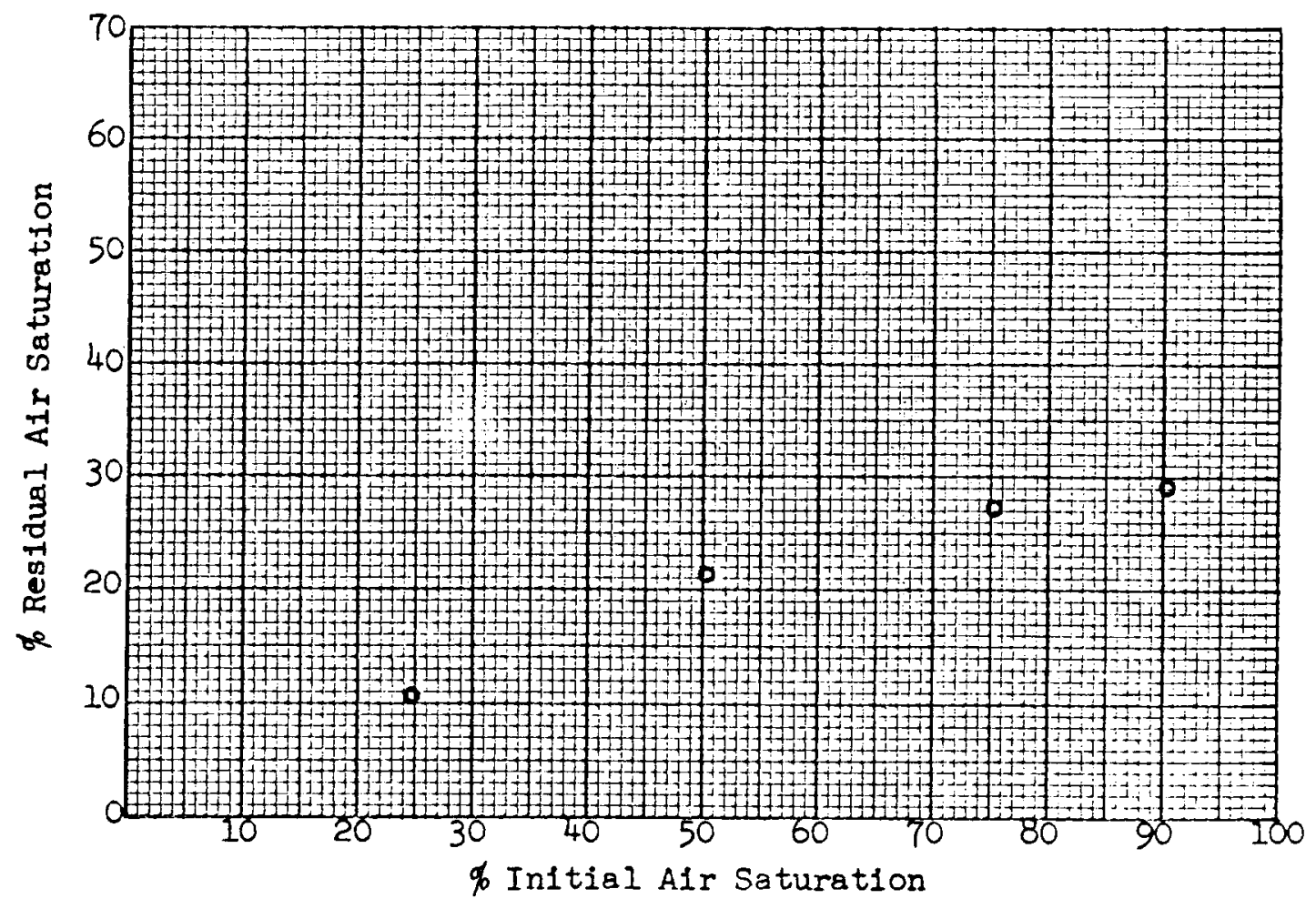


SHELL DEVELOPMENT COMPANY

TECHNICAL SERVICE

RESIDUAL-INITIAL AIR SATURATION DATA REPORT

(Liquid-Air Countercurrent Imbibition)

To: SOUTHERN E\&P REGION

Attn.: COASTAL DIVISION

Lesse and WeIl STATE UNIT A-I7 FIE Id WEERS ISLAND

County State LOUISIANA Depth_ $12968 \mathrm{ft}$.

Formetion Lithology

Sample No. 46-A_CCI No. $\quad$ CCI $1357^{\circ}$ Dete $\quad 5 / 26 / 78$

Porosity (\$) $26.4 \quad$ Permeability(md) Grain Density $(g / c c)$ 2.637

Remarks:

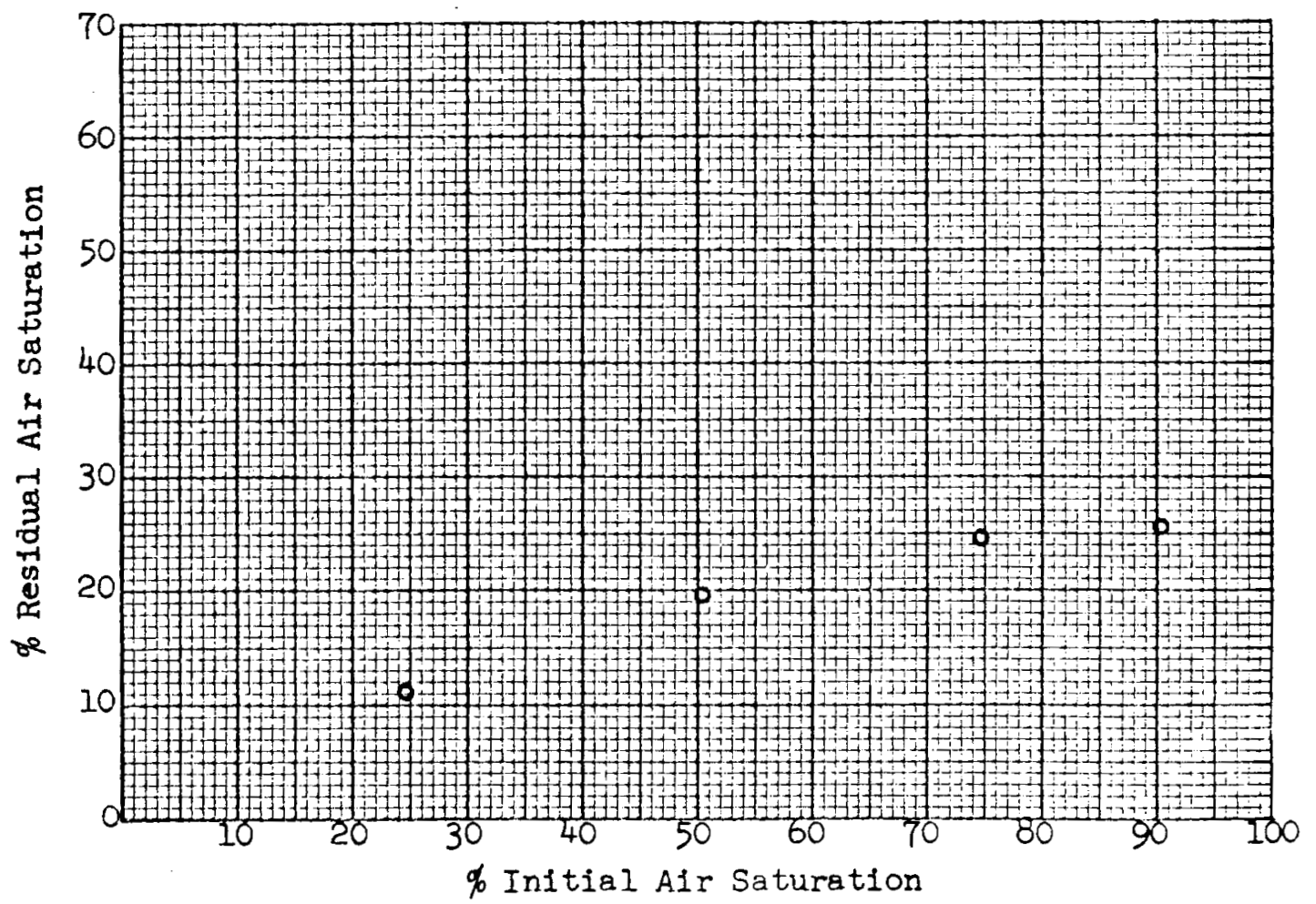




\section{ATTACHMENT 4}

SR-1774 (10/20/42)

Formerls TS 8

D...eed in us.

WEXRIY CORE REPORT

CORRECTED COPY

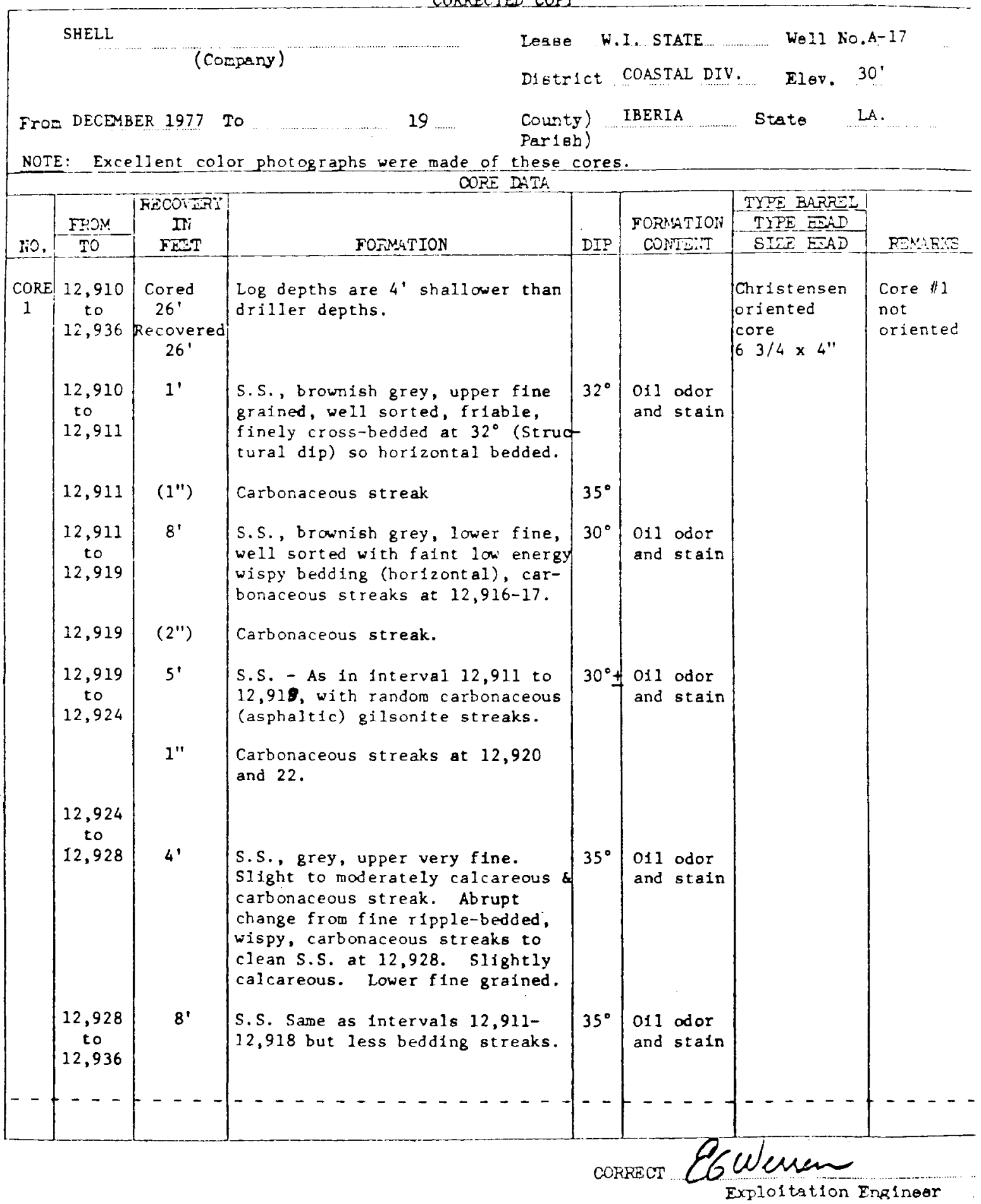


SR-1774 (10/20/42)

Formarly TG 8

pareed in USA

WEEKIY CORE REPORT

CORRECIED COPY

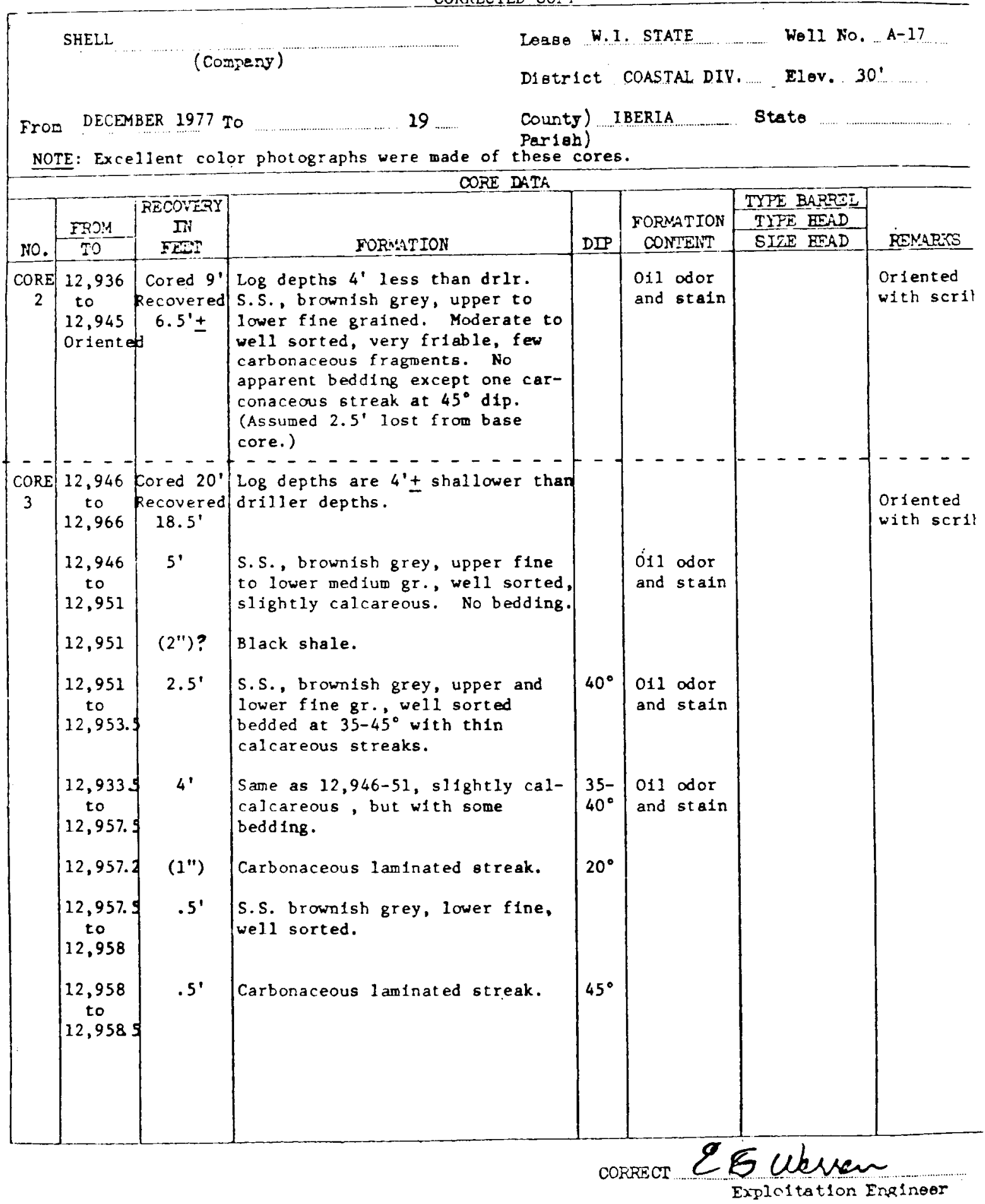


SR-1774 (10/20/42)

Forme: Iy TG 8

punney i.. U.Sa

WEEKIY CORE REPORT

CORRECTED COPY

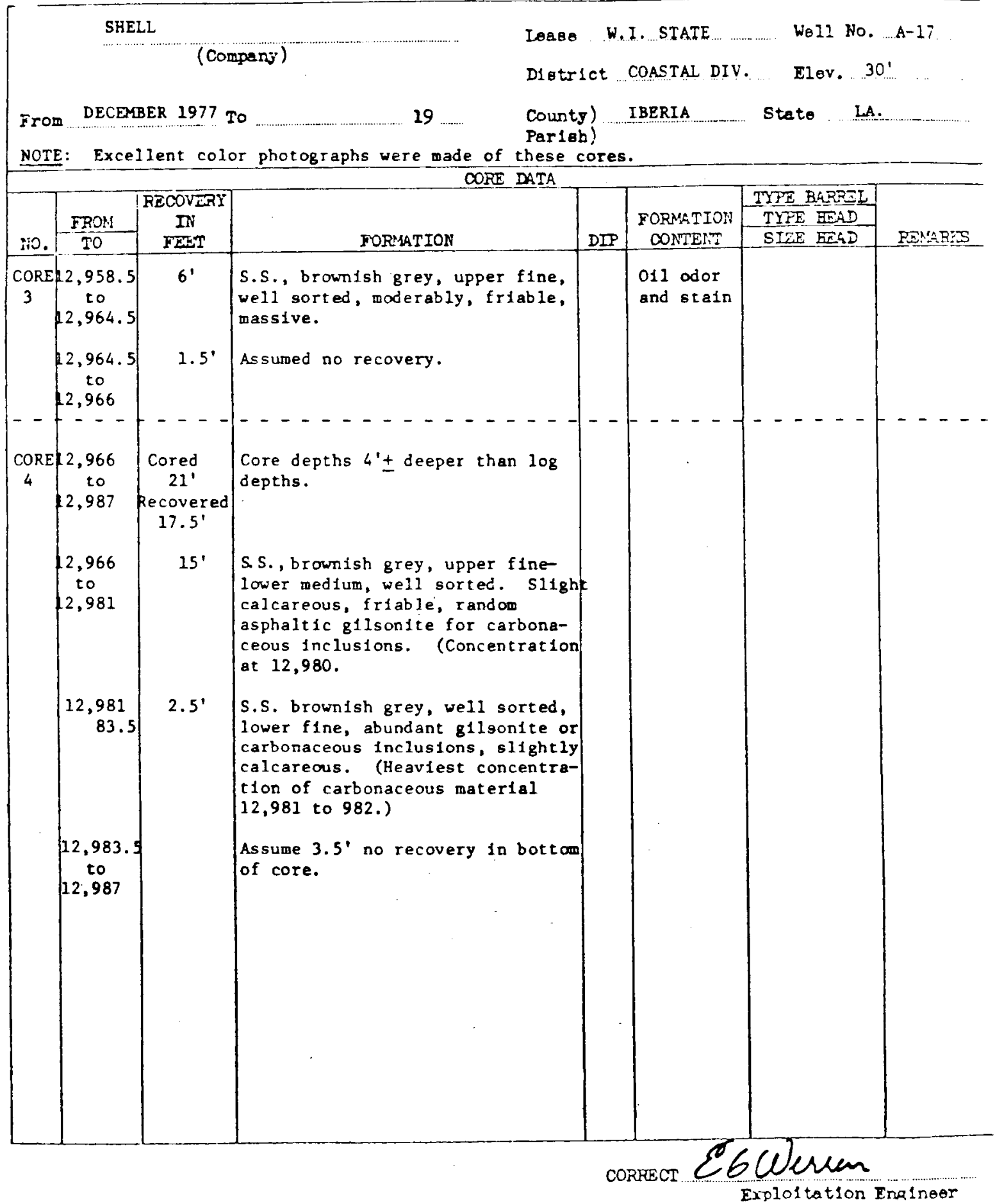


SR-1774 (10/20/42)

Forder 15 TO 8

D...es in use

WESIRLY CORE REPORT

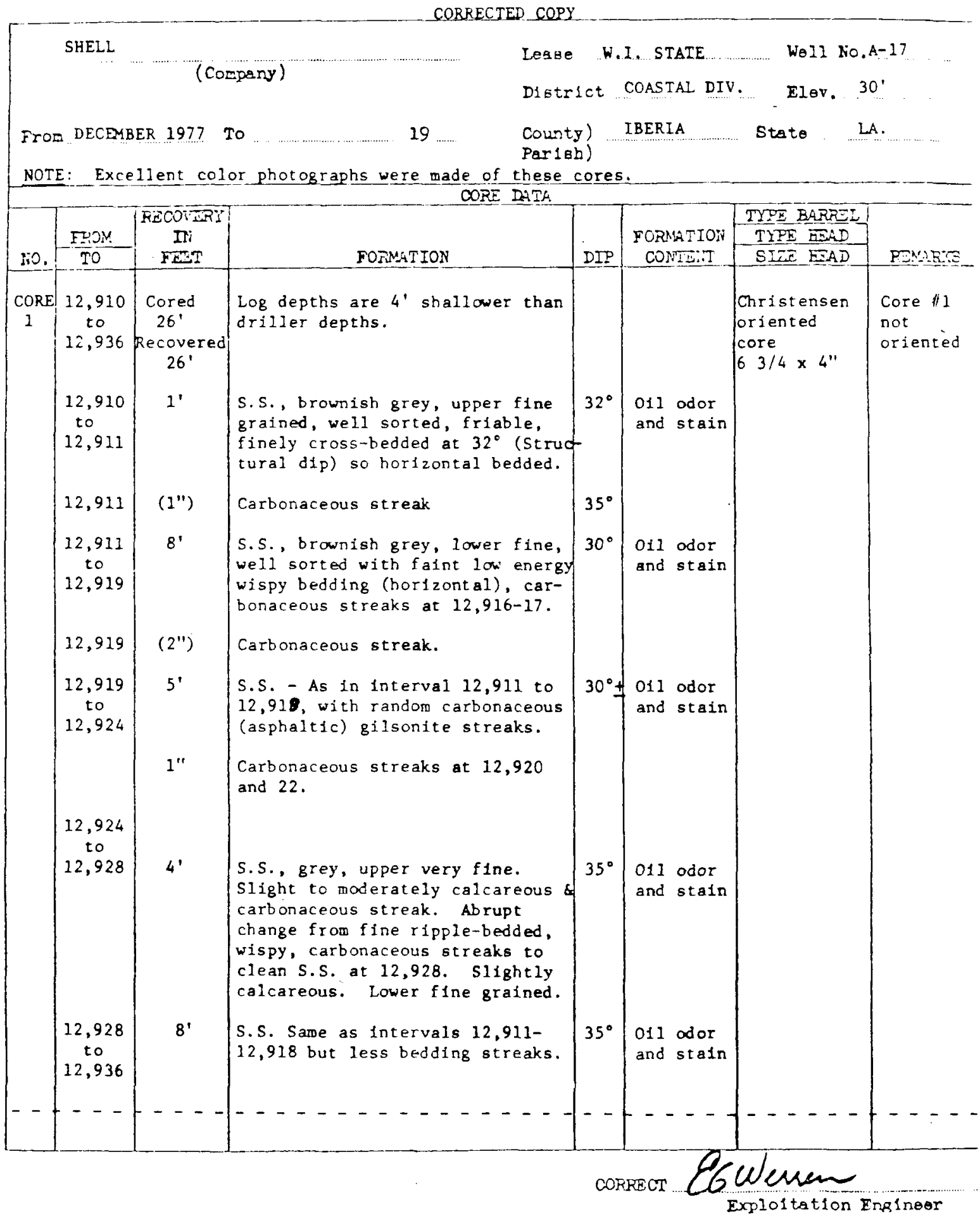


SR-1774 (10/20/42)

Formerls TG 8

puiried in USA

WEEXIY CORE REPORT

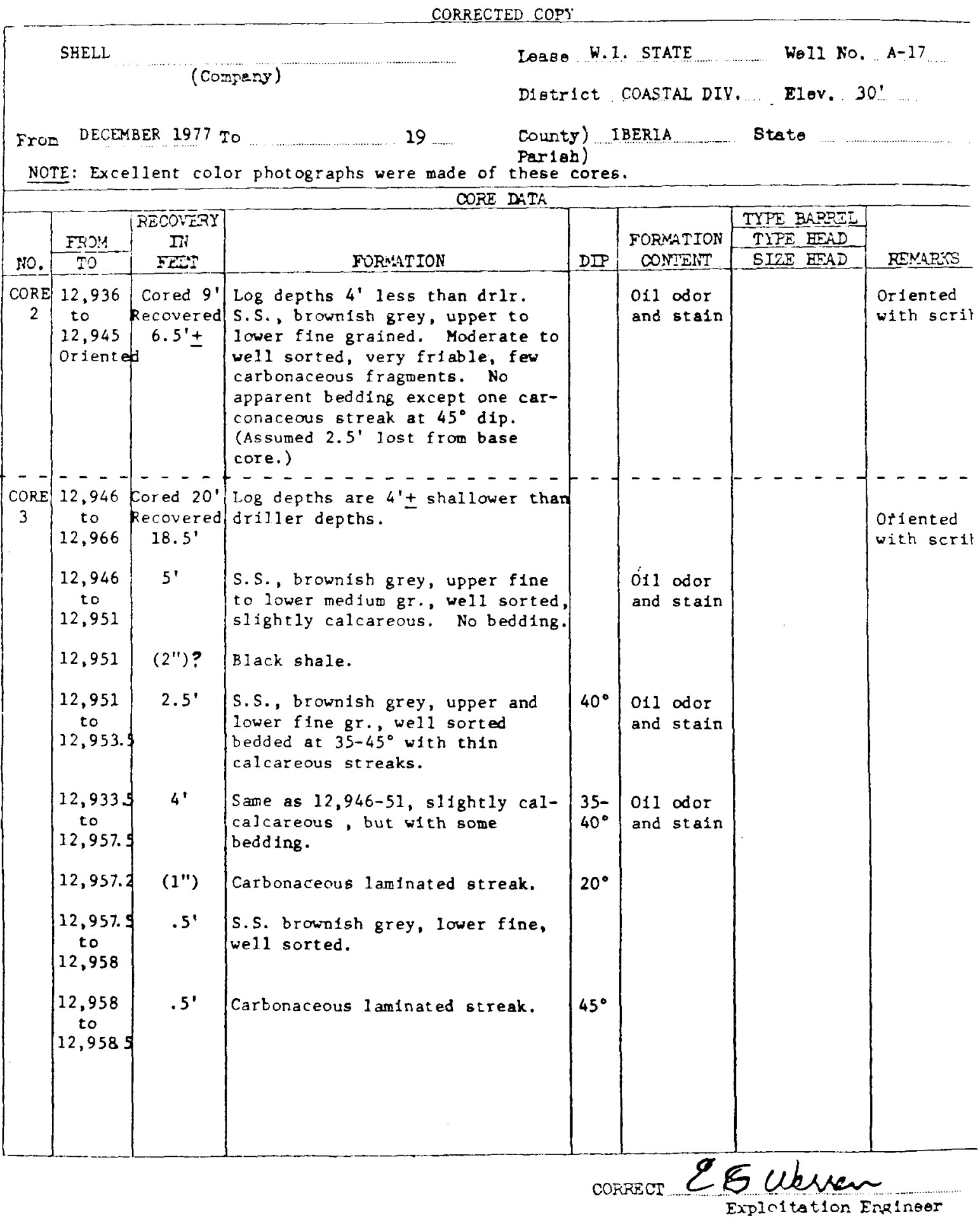


SR- $1776(10 / 20 / 42)$

Formerly TG 8

p.enes i..usa

WESKCIY CORE REPORT

CORRECTED COPY

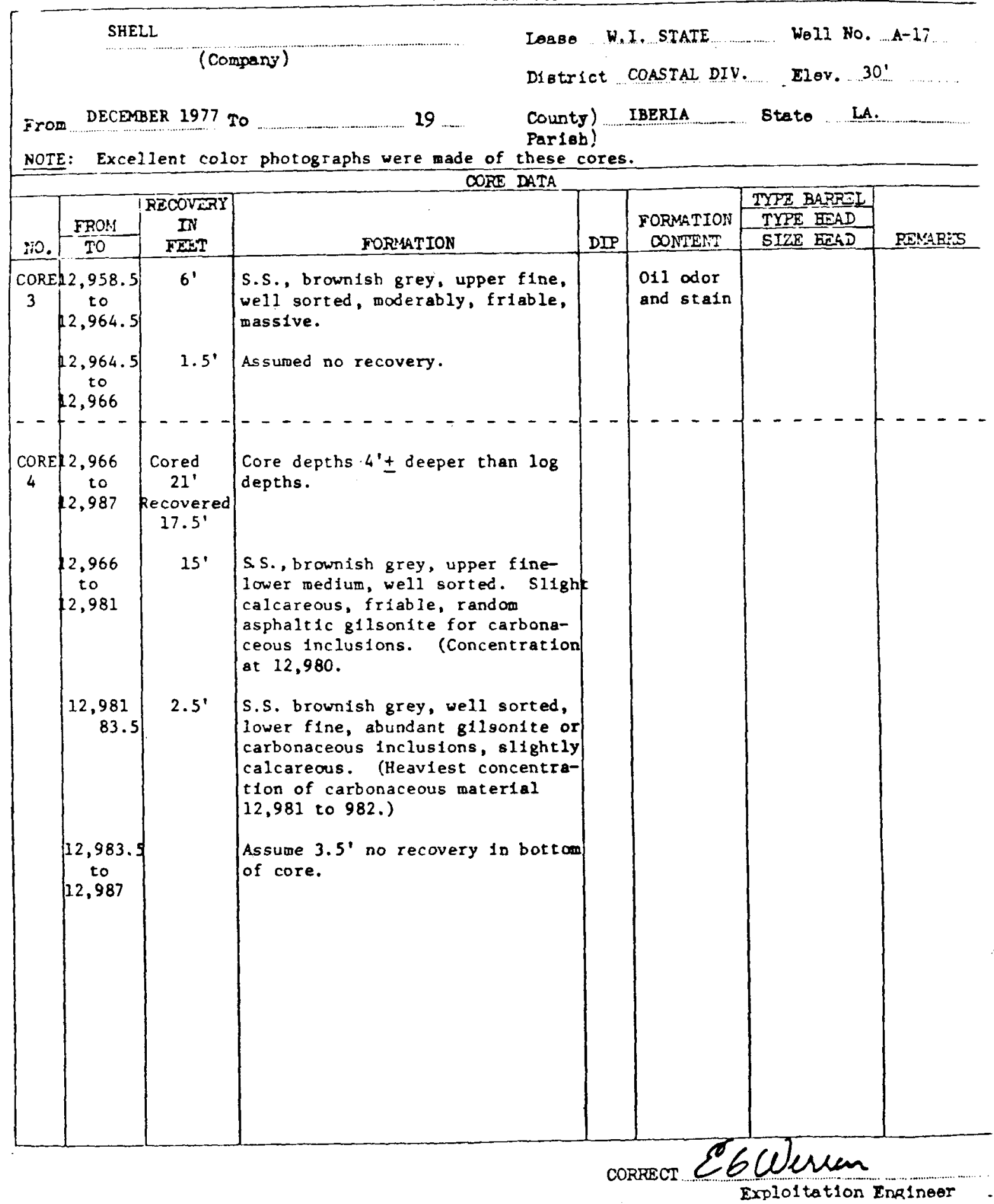

